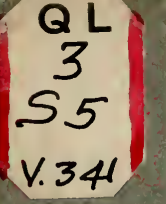

UC-NRLF

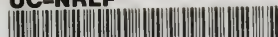

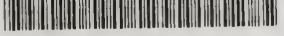

B $3 \quad 648 \quad 243$

\title{
AGRICULTURAL RESEARCH
}

AND

THE FARMER. 


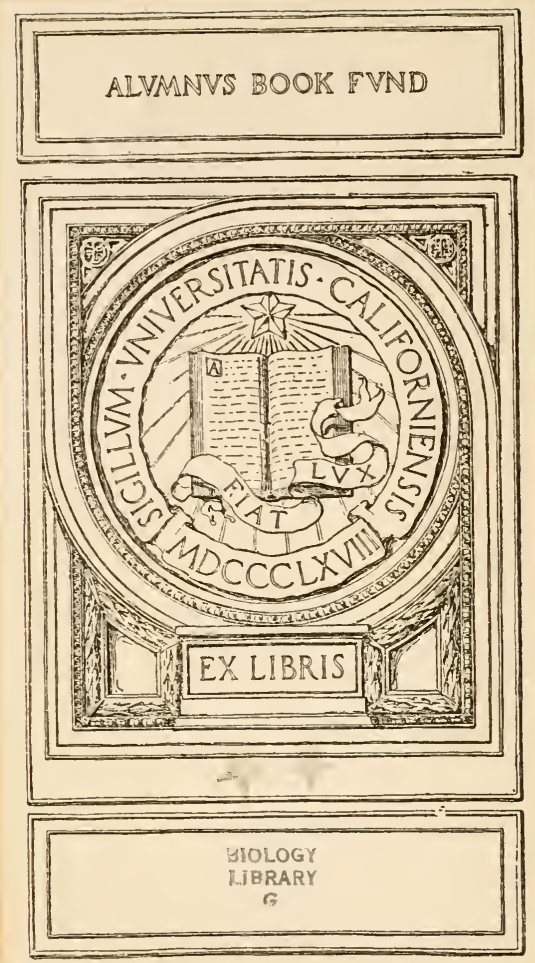






\title{
MINISTRY OF AGRICULTURE AND FISHERIES.
}

\section{AGRICULTURAL RESEARCH}

\author{
AND
}

\section{THE FARMER.}

\section{A REGORD OF REGENT AGHIEVEMENT.}

BY

V. E. WILKINS, B.Sc.

(Assistant Principal, Ministry of Agriculture and Fisheries.)

L O N D O N :

PUBLISHED BY HIS MAJESTY'S STATIONERY OFFICE.

To be purchased through any Bookseller or direetly from

H.M. STATIONERY OFFICE at the following addresses :

IMPERIAI. HOUSE, KINGSWAY, LONDON, W.C. 2, and 28, ABINGDON STREET, I,ONDON, S.W. I ;

37, Peter Street, MANCHester; 1, ST. ANDREW's Crescent, Cardiff;

or from EASON AND SON, LTDTH STREET, EDINBCRGH;

23, FORTH STREET, EDINBCRGH;

1922.

Price 2s. 6d. Net. 
lluennnuz botk figud 


\section{PREFATORY NOTE.}

British Agriculture is passing through hard times. No single panacea will cure the ills from which it is suffering, but I have the best reason to think that the leaders of the industry would agree with me in looking hopefully to the development of research as a powerful agency of restoration. I need only point to their recent action in asking and obtaining from the Government the grant of one million pounds for Agricultural Education and Research, in consideraton of the repeal of the Corn Guarantees.

There are at least three parties that are closely concerned to know what agricultural research is doing and proposing-the farmer, for whose benefit the work is primarily done; Parliament, which largely provides the cost; and the public, which pays the bill and will, I believe, ultimately receive a full return for the expenditure. But it has been urged on me that the efforts and results of agricultural research are largely unknown to these three interested parties. They are often published in scientific journals or proceedings of learned societies to which the ordinary farmer or layman does not readily turn, and they are described in technical language which conveys little or nothing to the reader without a considerable scientific training. There is a fault in the line of communication between the research worker on the one side, and the farmer and the general public on the other.

The institution of advisory officers in agriculture at the Agricultural Colleges, and other similar measures, have done something and may do more to remedy this failure of communication. But towards the end of last year I determined to try another solution of the problem, namely, the experiment of issuing a general account of agricultural research in Great Britain-not exactly a popular account, but at least one which with a little trouble an educated farmer or even townsman might understand. Mr. V. E. Wilkins, B.Sc., of the Intelligence Department of the Ministry, was chosen to collect the materials for this purpose, and to reduce them into a compact and intelligible form. I venture to think that he has done his work admirably. I hope that both the farming community and the general public will show by the practical test of buying this volume that the experiment is a success : if so, I should propose to issue a similar, though smaller, volume each year. In that hope, I commend it to the attention of all who have an interest in agriculture or in the sciences on which agriculture rests.

ARTHUR G. BOSCAWEN, Minister of Agriculture $\mathcal{E}$ Fisheries.

Whitehall Place, S.W.I. 27th February, I922. 


\section{CONTENTS.}

Prefatory Note by the Rt. Hon. Sir Arthur S. T. Griffith-Boscawen, M.P., Minister of Agriculture and Fisheries - $\quad$ - 3

Introduction

CHAPTER :-

I.-The Soil and its Effect on Plant Growth - - - + 7

II._Plant Breeding - $\quad$ - $\quad$ - $\quad$ - $\quad$ - $\quad$ - 29

III.-Plant Physiology - $\quad$ - $\quad$ - $\quad$ - $\quad$ - $\quad$ - $\quad$ - 40

IV.-Fruit Growing and Preserving - - - - - - $\quad$ - $5^{\mathbf{r}}$

V.-Plant Diseases - $\quad$ - $\quad$ - $\quad$ - $\quad$ - $\quad$ - $\quad$ - $\quad$ - $\quad$ - 69

VI.-Animai Husbandry - $\quad$ - $\quad$ - $\quad$ - $\quad$ - $\quad$ - $\quad$ - 99

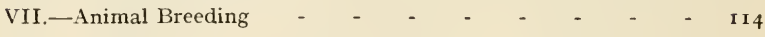

VIII.-Dairying - $\quad$ - $\quad$ - $\quad$ - $\quad$ - $\quad$ - $\quad$ - $\quad$ - $\quad$ - $\quad$ - 122

IX.-Animal Diseases $\quad$ - $\quad$ - $\quad$ - $\quad$ - $\quad$ - $\quad$ - $\quad$ - 135

X.-Farming as a Business - $\quad$ - $\quad$ - $\quad$ - $\quad$ - $\quad$ I 47

APPENDIX :-

I.-Research Institutions and Advisory Centres in England and Wales - $\quad$ - $\quad$ - $\quad$ - $\quad$ - $\quad$ - $\quad$ - $\quad$ - $\quad$ - $\quad$ - 155

II. - Titles of Papers published by Research Workers in 1920 and

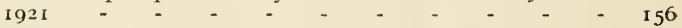
Index to Main Subjects of Research - _ _ _ - _ - $\quad$ - I66 


\section{AGRIGULTURAL RESEARGH AND THE FARMER.}

\section{INTRODUCTION.}

In the following pages an attempt has been made to describe in non-scientific language the main lines of agricultural research now in progress in this country. With two exceptions, the work is aided by funds placed by the Development Commissioners at the disposal of the Ministry of Agriculture and Fisheries. The two exceptions are the work on animal nutrition at the Rowett Research Institute, University of Aberdeen, and on animal breeding at the University of Edinburgh, in which cases the funds are administered by the Board of Agriculture for Scotland. It was felt that a description of current research in animal nutrition and breeding would be incomplete without a reference to the important investigations which are being conducted in Scotland, and through the courtesy of the Board of Agriculture for Scotland they have therefore been summarised in this publication.

A word of explanation as to the meaning of the term " research" is necessary. The word is often used by agriculturists in reference to any investigations which have as their object the improvement of existing practice. Thus experimental work in manuring, the testing of varieties, and so on, are spoken of as research. Strictly speaking, however, experimental work of this character is not research. Biological research, in the true sense of the word, aims at finding out the why and the wherefore ; it investigates principles. Later on, when such principles have been established, the scientist can use them as a basis for experimental work, and thus in due course the farmer reaps the benefit. No hard and fast line can however be drawn between research and experiment, and some of the investigations being conducted at Research Institutions are experimental in character-that is, they aim for example at finding out the results of methods of treatment selected more or less at random, rather than at establishing the principles on which scientific treatment should be based. While this type of enquiry may appeal with greater force to the farmer, it is only rendered possible if there is a sound basis of abstract research. Experimental work aims at getting practical results; research endeavours to find out fundamental principles; and the greatest need at the present time is for the 
establishment of more principles on which reasoned experiments may be based. This class of work, however, is usually highly technical; it is not easily described in popular language, and it is sometimes remote from practical application. Although many of the investigations described in this volume, however, may not be of immediate practical value to the agriculturist, it is hoped that the account will stimulate his interest in research, and show him that the scientists who are engaged in Research Institutions up and down the country are not indulging in a favourite hobby, but are working at problems of fundamental importance to agriculture, and exploring new country from which rich provision may in future years be expected. Perhaps, also, the report will serve to indicate some of the difficulties against which research workers have to contend, and the amount of time and labour which is often required to secure even a small advance in knowledge.

Under the Ministry's scheme of research, each Research Institution makes a special study of one important branch of agricultural science. A list of the Research Institutions, indicating the main problem which each is engaged in investigating, is printed as Appendix I to this Report. In addition, a considerable amount of research work is done by the technical advisers (also referred to in the Appendix) attached to University Departments of Agriculture and Agricultural Colleges. Their duties are partly advisory in character, but they are often confronted with local farming problems which require investigation, and these are dealt with so far as opportunities permit. This applies particularly to diseases of plants, and the chapter devoted to this subject is mainly a record of the results of research work recently carried out by the technical advisers in plant pathology.

It would not be possible, within the limits of a Report of this character, to deal with all the research work that is now being conducted. Moreover, some parts of it are too highly technical to be described in language which would be easily understood by a non-scientific reader. The Report, therefore, refers only to the main lines of investigation, and in some cases, perhaps, undue emphasis may have been laid on work which lends itself to popular description, although the research may not be more valuable than other work which has been described very briefly, or even omitted. 


\section{CHAPTER I.}

\section{THE SOIL AND ITS EFFECT ON PLANT GROWTH.}

It will be convenient to commence this record of the progress of agricultural research with an account of investigations that are being conducted into the constitution of the soil, and the principles underlying the feeding of crops. The institution concerned with this subject is the Rothamsted Experimental Station at Harpenden, Herts. Certain aspects of it are also being studied at other centres, and will be noted as the occasion arises.

The Rothamsted Experimental Station is famous throughout the world. It was founded nearly 80 years ago by the late Sir J. B. Lawes, and was maintained up till IgI I mainly from the income derived from an endowment fund of $£$ roo,00o given by him to the Lawes Agricultural Trust. In IgII this income was supplemented by a grant from the Development Fund, and the State grant has gradually been increased until now it is four times as large as the endowment income. The value of the research carried out at the station is generally recognised. It is not too much to say that the discoveries made at Rothamsted in the past with regard to the application of fertilisers to the soil have completely revolutionised the system of manuring-and hence farming practice-in this and other countries, and that by making it possible to restore rapidly and efficiently the food drained from the soil by the growing crops, they have been of incalculable value to the world. If the peoples of the earth are to live an existence under which the fight for food is not the dominant issue of life-if, in other words, the increase in population is to be accompanied by a corresponding increase in the amount of food obtained from the soil-then, as an essential, we must increase our knowledge of the structure and properties of the soil, and of the conditions under which we can secure still higher yields of the fruits of the earth. This, from the standpoint of mankind, is the justification for all agricultural research, or rather, the reason why such research must of necessity be prosecuted. The British farmer cannot be expected, perhaps, to view the matter from quite this broad standpoint; but for him a good and sufficient reason for the conduct of research is that ultimately it will enable him to cultivate his ground to better advantage, to secure an increased output, and hence to hold his own against foreign competitors, and obtain better financial returns for his labour. The old adage, "knowledge is power," 
applies with as much force to agriculture as to any other profession. To the farmer, experience is undoubtedly an invaluable asset, but agricultural practice, like everything else, changed with changing times, and experience is robbed of half its value unless supplemented by the knowledge which can only be given by research into the hidden mysteries of plant growth.

The purpose of the Rothamsted Experimental Station is to gain precise knowledge of soils, fertilisers, and the growing flant in health and disease. We shall refer to the work on plant diseases when we come to consider that subject in a subsequent chapter, and at present will speak only of the investigations into soils and the feeding of crops. Further, under the latter heading, a large amount of work is done on the Rothamsted farm in testing new fertilisers and comparing methods of cultivation and manurial treatment. This work is well known to the agricultural public, and as the prime purpose of the present publication is to explain the more fundamental research work that is carried on mainly in the laboratory, the valuable field experiments in progress will be dismissed with this passing reference.

The soil investigations now being conducted at Rothamsted centre round two main problems which have a vital bearing on practical agriculture. In the first place, how to provide the soil with that supply of organic matter which we know to be of such great importance; secondly, how to cultivate the soil so that it will provide the most efficient medium for the growth of crops. To solve the former problem, a knowledge of the exact constitution of the soil and of the precise part played by organic matter in the supply of food to the growing crop is the first essential; to solve the latter, we need to know what the physical properties of the soil are, how they are affected by varying conditions of climate, and what are the respective influences of weather and of soil constituents in producing that necessary preliminary to successful crop production which is known to the farmer as tilth. Bound up with this problem also is the question of implements of cultivation, for in the absence of an exact knowledge of the physical properties of the soil, the agricultural engineer cannot be supplied with the information which he requires in order to construct the ideal implements for carrying out the various processes of tillage.

\section{Life in the Soil.}

In the first place, we will consider the enquiries into what may be termed the question of organic matter, and for the sake of convenience the subject will be treated under two main headings: (I) the study of the chemistry of the soil, and of the world of life 
that exists within it; (2) the search for organic substitutes for farmyard manure. The two headings are, however, interdependent, for if the search for organic substitutes is to be successful it must be based on knowledge of the process by which plant products dug or ploughed into the soil are made available for plant food.

It has for some time been recognised that the microscopical living things known as bacteria which are found in the soil play an essential part in the feeding of a crop by attacking the nitrogen compounds supplied in the form of manure, and turning them into a soluble form in which they can be absorbed by the plant roots. More recent research has demonstrated that another group of minute organisms, known as protozoa, equally invisible to the naked eye, is present in the soil, taking an active part in the progress of events, and though noiseless and unseen, helping to determine the destiny of the crop on which the nation depends for its food and the farmer for his livelihood. In fact, the soil is no longer looked upon as an inert mass of mineral particles ; it is a great living complex, teeming with countless millions of living things each struggling for existence, and each having some influence on those complicated chemical changes on which the growth of all plants depends, and which in the course of ages have turned a stratum of bare rock into something approaching a vast chemical laboratory. And just as the adventurer, in exploiting a new country, must make himself acquainted with its wocdlands, rivers, soil and mineral wealth, no less than with the customs and manner of life of its inhabitants, so must the scientist, in endeavouring to discover principles of a more intensive cultivation of the earth than has yet been attempted, lay the foundation for his work in a precise knowledge of all that is going on in the soil. This fact has long been recognised at Rothamsted, but not until comparatively recently have the necessary facilities been available for making an adequate beginning in attacking the problem; for the living things in the soil vary in their relation towards each other day by day, and a proper understanding of the part they play in the economy of the soil can only be secured by the laborious and difficult method of making daily counts of their relative numbers over a long period of time. This has now been done. Throughout the year ending on July 5th, I92I, five trained scientific workers were engaged, Sundays as well as weekdays, in counting day by day the numbers of bacteria and of Io different kinds of protozoa contained in Rothamsted soil. The results are now being worked up, and a considerable amount of investigation is, of course, necessary, before any practical deductions can be drawn. Not only must the relations between the various 
groups be studied, but correlations must be made with such factors as temperature, soil moisture, rainfall, organic matter, etc. The continuation of the work may be summarised briefly. Each of the nineteen kinds of protozoa is being bred separately, mainly to discover reasons for the daily variations in number. Similarly, mixed colonies of protozoa and bacteria are being studied over prolonged periods. Soil samples from all parts of this and other countries are being examined to see in what way their living population differs from that found in the Rothamsted soil. The whole bacterial and protozoal population of the soil is being studied and classified.

Some idea of the work involved in the daily counting of these minute organisms may be gained by a reference to the laboratory methods employed in connection with the counting of the bacteria. Samples of soil, each Io grammes in weight, were taken daily. The soil was diluted with 250,000 times its volume of salt solution, and a known quantity of this fluid placed in dishes containing a substance which will provide suitable food for the bacteria. On the seventh day, and again on the tenth, these dishes were examined and the number of colonies of bacteria counted. From these figures, by a simple calculation, the total number of bacteria per gram of soil was estimated. Five dishes were used in this manner, and the bacterial colonies counted in each, the average of the five being taken as the number present. The counting of bacteria again on the tenth day was to ensure that slow-growing groups of bacteria would not escape being counted. This method was adopted for each of the 365 days in the year.

Here it may be useful to interpose an example of the great assistance which may be rendered by an expert in statistics in connection with research of this character. It will be understood that in dealing with such a subject as bacterial counts, everything depends on the accuracy of the method of counting adopted in the laboratory. The final working up of the results is largely a matter for the statistical expert, but his usefulness does not end here; he can also check the accuracy of the laboratory methods employed. The Rothamsted statistician his devised a formula for dealing with the mass of figures obtained in the bacteria investigation, and amongst other things this formula shows that in more than ninety per cent. of the counts made, the laboratory method was technically perfect, and that it is possible to pick out the few days in which, through some disturbance or other, the counts were made in an irregular manner and must be discarded when drawing deductions from the results. 


\section{Soil Nitrates and Bacteria.}

We may now consider some investigations which, when concluded, may have far-reaching effects on the important practical question of increasing the fertility of the soil. It is well known that nitrogen is essential to plant growth, but our knowledge of the process going on in the soil by which nitrogen is supplied to the plant in a form in which it can be absorbed by the roots is still far from complete. We know, however, that an essential and important part in the process is played by bacteria, in converting nitrogen compounds into soluble nitrates which can be absorbed by the plant roots. The investigation about to be described was undertaken during last summer in order to throw light on the relation that exists between the number of bacteria and the amount of nitrates present in the soil at any given time. Eight research workers were engaged in the enquiry, which extended over several periods, each lasting about four consecutive days and nights. Samples of soil were taken from the field at intervals of two hours, and in the laboratory the number of bacteria present was counted and the quantity of nitrates ascertained. The result showed that a close relation exists between nitrates and bacteria. The amount of nitrates and the number of bacteria both fluctuated considerably and rapidly, and the fluctuations in the two groups seemed to be connected. As the bacteria increased. in numbers, so did the nitrates in amount, and vice versâ. This gives new light upon the nature of the soil changes which control the supply. of nitrogen to the plant. There appear, however, to be two influences at work in reducing the supply of nitrates in the soil ; one limits the numbers of bacteria responsible for nitrate production, and the other influences directly the amount of nitrates available for the use of the plant. The effect of the inter-relation of these two influences is to keep down the supply of soluble nitrates. The whole question, however, needs much study, and further investigations to this end are in progress.

On another aspect of plant nutrition we are lacking in information, namely, the exact form in which nitrogen is absorbed by the plant. It is known that nitrogen compounds present in the soil, and supplied to it in the form of manure, go through a series of changes culminating in the formation of soluble nitrates, and the view generally held is that only in this form-or, in special circumstances, in the form of ammonia - can nitrogen be absorbed by the roots of the plant. This view has never been scientifically proved, and although it may be correct in the case of plants grown in pots under somewhat artificial conditions, it does not 
necessarily hold in the case of plants growing in the field. Before we can say precisely what happens however, we must have exact information regarding the chemical substances which are formed in the soil during the change from the original nitrogen conipounds to the soluble nitrates absorbed by the plant roots. The problem is a chemical one, and its solution depends largely upon the elaboration of methods of chemical analysis. Such methods are now being worked out at Rothamsted. The devising of new methods of analysis is not, however, an easy matter; for example, the methods of estimating the amounts of soil ammonia and nitrates now in use at Rothamsted were devised by a former worker after an investigation covering about two years. On the other hand, even a slight advance on existing methods of analysis is of great importance in speeding up chemical research, and also in making easier the large amount of routine work which is a feature of all chemical laboratories. The importance of discovering quicker methods of routine analysis will be realised from the fact that at Rothamsted, between I,500 and 2,000 analyses for nitrogen, phosphoric acid, and potash are made each year, and a larger number of determinations of total dry matter. The soils, manures, and crops of all the experimental plots are analysed, to ascertain the relation existing between the manuring and the composition and food value of the manured crop.

\section{Farmyard Manure and the Clover Crop.}

While research into the problems of the soil must lead to results which will be applicable to many aspects of cultivation or manurial treatment, the direction in which its value will be most appreciated is - as we have already said - that of the supply of organic matter to the soil. It has long been recognised that the presence of humus in the soil is an essential for the proper growth of crops, but it is only recently that the peculiar value of farmyard manure, as compared with artificials, has been demonstrated. In the growing of clover, for instance, farmyard manure appears to occupy a unique position as a fertiliser, and in this connection we have a problem which may have a two-fold bearing. On the one hand, we want to know how the falling-off of clover known as "sickness," which prevents a more extensive use of this valuable crop, can be prevented; on the other hand, we want to know why it is that farmyard manure exerts such a useful influence on the clover crop, for in answering this question we should doubtless throw light on the wider one of the value of dung in general. The work now in progress deals particularly with the latter aspect of the problem, and arose from a consideration of the results of experiments conducted in one of the Rotham- 
sted fields during the years I904-I9I7. The object of the experiments was to test the residual value of a number of manures, including farmyard manure, shoddy, guano, rape cake, superphosphate, bone meal and basic slag. No regular rotation was adopted, but clover was avoided. After the experiment had gone on for twelve years it was decided to make a change and to introduce clover after mangolds. It was shown that none of the manures except farmyard manure had any marked effect in increasing the clover crop. Rape cake, guano and shoddy had no effect at all, even when applied to the preceding wheat crop; superphosphate, bone meal and basic slag had a small effect but not definite. Farmyard manure, however, had a striking effect, the clover crop on these plots being approximately half as heavy again as on the remainder. Subsequent field trials have confirmed these results, and show very clearly the markedly beneficial effects of the application of farmyard manure to clover, particularly in conjunction with lime. An investigation has therefore been commenced to find out the reason.

It should be explained at this stage that leguminous plants such as clover are especially valuable to the farmer because their roots form a "breeding ground" for certain kinds of bacteria which are present in the soil and which have the power of extracting nitrogen from the air. These bacteria live and multiply in nodules on the roots of the clover plants, so that when the crop is ploughed in, it supplies the soil with a quantity of valuable nitrogen which can be used by the succeeding crop. The type of bacterium which can live on clover roots, however, is present in large numbers in the Rothamsted soil, so for the purpose of accurate experimental work it was necessary to choose another leguminous plant-the soy bean-whose roots are not acceptable to the " clover " type of bacteria, but to another type which is absent from the Rothamsted soil. By using the soy bean greater control can be exercised by adding or withholding the bacteria which will form the "nodules" on the roots of the plant.

The laboratory experiments were started in 1920 and have thus been carried on for two years. Seven series of pots growing soy beans have been taken, each series being treated differently, as follows:-(I) I lb. farmyard manure: (2) $\frac{1}{2} \mathrm{lb}$. farmyard manure; (3) liquid extract from $\frac{1}{2} \mathrm{lb}$. farmyard manure; (4) mineral salts giving the same amount of plant food as $\frac{1}{2} \mathrm{lb}$. farmyard manure ; (5) no manure ; (6) $\frac{1}{2} \mathrm{lb}$. fresh straw ; i7) $\frac{1}{2} \mathrm{lb}$. rotted straw. The experiment was carried out both in the presence of " nndule" bacteria and in their absence. For each series, information has been obtained regarding the number of nodules formed, the total dry weight of the plants, 
and the number of nodules per gram of dry weight. Briefly the results indicate that the marked benefit derived from farmyard manure is in part due to an organic constituent of the manure and not merely to the inorganic chemicals which it contains, and further that the advantage is derived from something that is contained in the straw part of the manure. What that something is, further research will, it is hoped, discover, and the results should have a valuable bearing on the question of the cultivation of leguminous crops.

\section{Artificial Farmyard Manure.}

The unique value of farmyard manure is undoubted. Some of the older agricultural chemists inclined to the view that artificial fertilisers were the chief source of fertility, and that little more need be done if sufficient amounts of these were added. It is now known that the full action of artificial manures is exerted only when there is an adequate supply of organic matter in the soil. Unfortunately, few farmers are able to obtain sufficient manure for their needs. One method of securing it is, of course, to increase the head of livestock on the farm, but this may often be impracticable. In market-gardening districts around industrial centres, which have hitherto depended largely on horsemanure for supplying organic matter to the soil, the gradual substitution of horse by motor transport is being felt acutely. Further, in many parts of the country, particularly in corngrowing districts, large quantities of straw are produced which is not only of no value to the farmer, but he is often in a difficulty as to how to dispose of it. Now straw contains all three essentials. to plant growth which are usually supplied in fertilisers, namely, nitrogen, phosphates and potash. Of itself, however, it is of little value as a fertiliser, quite apart from the difficulty of burying it in the soil. When it is decomposed by the action of animal excrements, however, the mixture, known as farmyard manure, becomes an invaluable source of fertility. The problem for the scientist to solve, therefore, was how to bring about the decomposition of straw artificially without the use of cattle, and so. provide the farmer with an adequate supply of " artificial" farmyard manure, and enable the corn-grower to use his straw in this most useful way. The subject has occupied the attention of Rothamsted for some years, and a short description of the progress of the research will enable the readers to judge for themselves whether the results so far secured have justified the considerable amount of labour and ability involved in their attainment. The account will be given in some detail, for it affords an excellent illustration of the value of pure research conducted 
without regard to its possible economic worth, and also of the way in which two scientists, working independently, may in due course come together and combine their results into a successful weapon of attack on a difficult problem.

A research worker at Rothamsted was endeavouring to find means of artificially rotting. straw. He discovered that there were certain kinds of bacteria present in straw, and in the soil, which had the power of absorbing free nitrogen from the air, and that through the agency of these organisms, wetted straw gradually became richer in nitrogen. The organisms were isolated, and an attempt was made to see if their power of using free nitrogen could not by some means be augmented, so that the fertilising value of the straw could be increased through the activity of these so-called " nitrogen-assimilating bacteria." But the attempt was not entirely successful. The bacteria could absorb nitrogen only up to a certain point, and at this stage the straw was still of little value as a direct fertiliser. Simultaneously with this work, however, research was going on in another department of the Institute, the object being to discover the organisms which are able to decompose cellulose. The Rothamsted worker was successful in discovering and isolating an organism capable of effecting cellulose decomposition. Its life history was worked out, and it was found that fixed nitrogen-i.e. nitrogen in the form of a compound-of some kind or another, was essential for its growth. Now straw contains a large proportion of cellulose, and at this stage the workers came together and pooled their results. It was seen that two different types of bacteria were involved in the decomposition, or rotting, of straw. In the preliminary stages, the " assimilating bacteria " were able to absorb free nitrogen from the air, and by that means the straw was rotted to a certain but very limited extent. The further rotting was mainly due to the cellulose-decomposing organisms, and in order that these might live and do their good work it was necessary to supply them with food in the form of a ritrogen compound. The problem of producing manure from straw thus became simplified into one of supplying the cellulose organisms with a cheap and effective source of food. Various ammonium salts were tried, and it was found that entirely satisfactory results could be obtained from the use of sulphate of ammonia, with the addition of a certain quantity of chalk, varying according to the composition of the water employed to wet the straw. A method was thereupon devised for treating fairly large quantities of straw for the formation of manure. This method may be briefly indicated. The required quantity of chalk is incorporated with the straw in building up the stack; the straw is then sprinkled 
with water in stages until it has taken up almost enough water to saturate it; and the required quantity of ammonium sulphate solution is carefully applied, so as to avoid loss of nitrogen. By this time the temperature of the stack has risen considerably. The manure can then be allowed to stand for any length of time, according to the shortness of the manure desired by the farmer, All the nitrogen is absorbed during the first three weeks, and after this the manure can be left uncovered with no risk of loss through the leaching of nitrogen by rain, etc.

Two series of field experiments with straw manure made in this manner, carried out in I920 and I92I, indicate its fertilising value. In 1920, on light soil at Woking, the straw manure gave as good a return as an equal weight of high quality farmyard manure. The season was wet, and the manures had therefore little opportunity for showing their valuable moisture-retaining properties. In I92I, however, on the heavier soil at Rothamsted, these qualities were clearly demonstrated. The plot treated with farmyard manure gave 3 tons per acre of potatoes; that treated with an equal weight of straw manure gave $2 \frac{3}{4}$ tons per acre; while other plots dressed with the weight of sulphate of ammonia required to supply an equivalent quantity of nitrogen yielded little more than a ton to the acre.

In view of the somewhat enthusiastic references that have been made to this discovery in various places, a word of caution may be advisable. The work so far has been carried out with comparatively small quantities of straw and under conditions which can be controlled by the scientist. In devising a method for use by the farmer, many practical difficulties have to be overcome, such as the supply of water, the means of conveying it to the straw and distributing it throughout the stack; the necessity of ensuring that the straw is properly saturated with water, and that the required quantity of nitrogen salts is absorbed by the straw. It is towards the solution of these practical difficulties that the work is now proceeding, and already an experimental plant capable-it is believed-of turning out 2,000 tons of straw manure per annum, and costing probably less than $£ 500$, has been designed.

An important side-issue arising out of this investigation may be briefly referred to. In making artificial straw manure, it is important that just the right quantity of ammonium sulphate solution must be incorporated with the straw. This fact led to a consideration of whether, in the ordinary process of manufacture of farmyard manure, importance should be attached to the adjustment of litter to the manure made by the animals. It was found that there is a proper pro- 
portion of straw to urine, and that if this is exceeded wastage results. If the straw is insufficient for the nitrogen in the urine, nitrogen is lost; if the straw is in excess, the manure will not make properly, and the soil derives less benefit than it should. Experiments have shown that $I$ ton of straw can be used for every roo lbs. of digestible protein fed to the animals. As a rule, however, the excretions are too concentrated, and some added water is necessary. When these proportions are maintained, satisfactory rotting of the straw proceeds rapidly, and the losses of nitrogen are at a minimum. Made under such conditions, manure at Rothamsted has rotted down to half its weight without loss of nitrogen.

\section{Green Manuring.}

A further method of increasing the all-important supply of organic matter on the farm is by the use of green manures. Attempts were made to develop this method at Rothamsted in I9I4 and I9I5, but as the only implements then available were those worked by horses it was rarely found possible to sow a catch crop, and without this, green manuring is hardly an economic possibility. The position is, however, entirely altered by the introduction of the tractor. Experiments in green manuring were started by the Royal Horticultural Society at Wisley is I9I9, and are still going on at that centre. Work on somewhat similar lines has been in progress at Woburn for several years. The experiments at Rothamsted have only recently been re-commenced, and the results from all three centres, when available for comparison, should be of the greatest use, for each centre represents a different set of soil and climatic conditions. Wisley has a dry climate and very light soil ; Woburn, with a rather moist climate, has a rather heavier but still light soil ; at Rothamsted the climate is somewhat similar to Woburn, but the soil is a loamy clay. The object of the whole series of experiments is to find out what are the best crops to grow as green manure under different conditions of soil and climate. The experiments at Wisley are on small plots, mainly for the benefit of the market gardener; at Woburn and Rothamsted, trials on a larger scale, more applicable to farming practice, are being conducted. In all three cases, however, the main lines of investigation are the same, and for the purpose of this report it will be sufficient to indicate the type of experiment in progress at Rothamsted. Leguminous and non-leguminous green crops of various kinds are sown in early autumn, immediately after harvest, and are allowed to grow on, in one case until early winter, and in the other throughout the winter. They are ploughed in, and are 
followed in both cases by spring-sown barley. The yield of the crops is determined, and throughout the experiment examinations of the soil are made in order to trace the course of the decomposition of the green crop and the production of nitrates, and also to examine the effects of the crop on the physical condition of the soil, particularly as regards its moisture content.

\section{The Growing Crop. Farm Weeds.}

We pass on to refer to some aspects of the investigations in progress in the Botanical Department of the Institute. In the first place a careful study is made year by year of the effect of various mixtures of manures on grass land, attention being paid not only to the yield of hay secured but to the botanical composition of the herbage. The field trials are the classical Park Grass Plots, which have been studied in this way since 1855 . The results are well known and appreciated, and it is unnecessary to refer to them in detail. It may be mentioned, however, that of recent years special attention has been paid to the effect of liming on the occurrence of individual species, the most striking facts emerging being that on well manured soil the application of lime results in a decided increase of the useful Foxtail grass and a decrease of the less useful grasses, Yorkshire Fog and Sweet Vernal.

The field experiments are supplemented by pot trials and by growing plants in water-culture under various conditions of treatment. This applies particularly to the case of cereals, and a noteworthy feature in connection with the root development of these plants which has recently been studied in some detail may be mentioned. By growing individual plants of barley and wheat in pots under varying manurial treatments, and carefully examining the root systems, it was found that the addition of manures resulted in a considerable increase of what are usually known as the " white roots" of the plant, the effect of the manures being somewhat different in the two cereals. These "white roots " are developed at the time the plant tillers, that is, throws out new shoots. They issue from the crown of the plant, remain unbranched for a long period, tend to grow laterally instead of downwards, and are clothed throughout their length with root hairs. As it is the root hairs-which normally only survive near the tips of the rootlets-which form the absorbing organs of the plant, the capacity of "white roots" to absorb food supply from the soil is greatly increased. An examination of the structure of " white roots" of barley showed that, compared with ordinary roots, their internal anatomy was modified to suit the needs of a rootlet that is absorbing extra large quantities of water contain- 
ing dissolved nutritive salts. By the time ear formation begins, the formation of "white roots " ceases, and those already formed become branched and eventually approximate more closely to the normal type of root. It thus appears that the formation of "white roots" takes place in order to meet the needs of the plant at a time when a sudden increase in food is essential for the production of tillers. As efficient tillering is an important factor in relation to the yield of a crop, the need of further study of the conditions which promote the growth of "white roots," and their possible encouragement by appropriate manuring, is obvious. The investigation is therefore being continued with wheat plants, and will be extended to other cereals and cultivated grasses.

In the Botanical Department also, research has been going on for some years to find out whether plant poisons applied in very small quantities act as a stimulant to plant growth. The most important results so far obtained have been with boron. Broad bean plants grown in water cultures and in pots respond by a very definite increase in growth, amounting to about ro per cent., to the addition of very small doses of boric acid, whereas a heavy dose will kill the plants. It is proposed to carry out field trials with barley and broad beans to ascertain whether the addition of small quantities of boron to the ordinary manures, would be advantageous and practicable.

Much attention has also been given during the last twelve years to the subject of farm weeds, particularly in their relation to types of soil. The results obtained up to I9I9 were incorporated in a book entitled "Weeds of Farm Land," which was published in I920. Since then special attention has been paid to the collection of information regarding the weeds growing on various types of soils. An attempt is being made to secure from all parts of the country, through the medium of public schools, training colleges, and possibly elementary schools, information regarding the weeds growing in all districts, the soils on which they grow, their relative frequency, \&c. These particulars are being tabulated so as to secure, for every important weed, information regarding its distribution and habitat, particularly with reference to the type of soil on which it grows and the crop with which it is associated. It has already been established that very few individual weeds can be regarded as indicators of definite soil types, but it seems likely that groups of weeds will afford a fairly safe index to the nature of certain soils. Information is at the same time being secured as regards local measures of eradicating and preventing weeds, so that such knowledge may be spread over a wider area. 


\section{Willows.}

A reference may conveniently be made here to investigations into willow-growing which are being conducted by the Advisory Botanist attached to the Midland Agricultural College, Kingston, Derby. This officer has for some years specialised in the subject of willow-growing, including a study of the best methods of draining, preparing and planting the land for the crop, of re-converting derelict land, of bringing into cultivation newly-formed valley estuarine and coastal land, and of the most suitable and most economic varieties for different types of soil. Research into the value of the bye-products arising from the industry has revealed the fact that we possess in this country varieties of willow containing up to 6 per cent. of salicin in the dry bark, and that tannin is present in large quantities in many varieties. In view of the value of both these substances, chiefly for medicinal purposes, the commercial possibilities of the willow crop as a source of raw material seem worth exploring. Recently an enquiry has also been made in regard to the improvement of tools and implements for treatment of the basket-willow crop. Perhaps the direction in which improvement is most needed is in connection with the peeling of willows. Up to the present this has been done by hand, but a machine has been invented, constructed and patented, capable of peeling willows at three times the rate of the hand process. Experimental work on the dyeing of willow rods in various colours, hitherto an unexplored field of enquiry but with important commercial possibilities, has met with considerable success. A willow plantation has just been laid down on the Midland College Farm, and between 40 and 50 varieties, representing the chief commercial sorts, have been planted, so that a close study may be made of their particular characters in connection with the basket-making industry.

\section{Crop Statistics.}

Before passing on to consider the investigations at Rothamsted into the physical properties of the soil, we may refer briefly to a subject which, though perhaps less interesting to the farmer than such a topic as weeds or manures, is nevertheless equally important, namely, the mathematical examination of crop records. The expert statistician is an investigator of prime importance to an institution where biological research is being conducted, for he can examine, correlate and convert into their most useful form the detailed records of results of experiments extending over periods of years. He can assist his scientific colleagues by showing them the minimum methods of treatment necessary in 
order that their experiments may furnish information which will stand the fire of criticism, and he can further, with mathematical accuracy, detect in their results any flaws or inconsistencies in the methods of experiment adopted. The Statistical Department at Rothamsted has not long been in existence, and this account of its work will therefore be mainly an indication of the general lines of investigation being followed, and of the objects which are more immediately in view. In the first place, a comprehensive study is being made of the causes of variation in the yield of crops. Every farmer knows that considerable variations are due to season and weather conditions, but nobody has yet made any attempt to analyse exactly to what extent these and other influences operate. The yield of crops is affected by a number of factors, as, for example, manuring, weather, variety, soil population, weeds, physical condition of soil (tilth), diseases, and so on. The relative importance of these factors is not known, nor is it certain that other unknown factors are not of importance. In the investigation of the subject a beginning has been made on the records of crop yields collected at Rothamsted. This is by far the longest and most complete body of material in existence, and from its study it is expected that certain general principles will emerge, in the light of which the shorter series collected at other experimental centres may be interpreted. The study of the results obtained during the past 70 years on the Broadbalk Wheat plots has shown that in most cases the weather is responsible for anything up to 75 per cent. of the variation in yield from year to year. But weather is itself a combination of many factors, and a detailed study of the effect of the various factors which contribute to weather is at present in progress, based, in the first instance, on the daily records of rainfall, which date back to February, I853. As a result of this investigation, it is expected that provisional answers will be found to such questions as the following:- How can the season, in so far as its effect upon crop yield is concerned, be deduced from weather records as taken at the present time? What is the best season from the farmer's point of view, and what are the critical periods of the year? With what accuracy can the crop be predicted from weather records alone? How does manuring affect the influence of weather upon the crop? How can a farmer make the most of a good season or mitigate the adverse effects of a bad one? How should manurial treatment suited to one type of climate be modified to suit another?

\section{The Physical Properties of the Soil.}

We turn now to consider the investigations in progress bearing on the second main problem which the Institute at Rothamsted 
keeps in view, namely, how to cultivate the soil in such a manner that it provides the most efficient medium for the growth of crops. The physical character of the soil is influenced by many conditions, such as the supply of air and moisture, temperature, the quantity and state of organic matter present, and so on. Until we know exactly what these factors are, how they are inter-related and how they are affected by influences from outside, no definite advance on existing methods of cultivation is probable, and any improvements which may be secured from time to time must be based on the purely empirical and slow method of trial and error. Moreover, the present methods of cultivation have been adopted after centuries of experience to suit conditions under which animals supply the motive power of the farm. The change to mechanical power is a fundamental one, and may not only result in a modification of our tillage methods, but may need an entire re-casting of the designs of tillage implements. Doubtless some change of this character would be introduced after prolonged experience, even in the absence of scientific knowledge of the soil. But agriculture cannot afford to be dependent on the slow and not always sure progress of empiricism. The medium in which tillage implements spend the whole of their working lives is the soil, and an intimate acquaintance with this medium should surely be the first essential for the proper study of methods of cultivation and of the design of tillage implements.

Until comparatively recently the soil was regarded as a mass of mineral particles, on the surface of which were spread thin films of moisture which together formed the water-content of the soil. Later research showed that this view was insufficient. This had been demonstrated, for example, by a somewhat complicated and ingenious experiment conducted at Rothamsted, in which an apparatus was designed in the Physical Department to measure the rate of evaporation of moisture from the soil. If the old view regarding soil texture held, evaporation should proceed at a gradual pace until all the water was driven off. Actually the rate was by no means gradual ; the moisture evaporated first very quickly and finally very slowly. Evidently, therefore, there is something in the soil which exerts a tenacious hold on moisture; this is in accordance with what is termed the " colloidal theory " of the soil, strongly supported by Rothamsted, and the results of recent research go to show that this idea regarding the structure of the soil is in its essentials correct. Briefly the view is that substances of jelly-like properties are important texture-forming constituents of soil. These substances, termed "colloids," consist mainly of particles of fine clay and of organic matter, which clothe the mineral particles and 
hold them together in somewhat the same way as flesh clothes a skeleton. If we are to be able to modify the structure of the soil, therefore, we must first learn how to modify its colloids, and an important object of the present investigations at Rothamsted is to find out precisely what the colloids are and how they can be controlled. One experiment which was recently conducted may be mentioned, as it shows the great importance of colloids in the soil. In the experiment, a careful comparison was made of the rate of evaporation of the moisture contained in soils of widely divergent type, namely, light sandy soil from Woburn and loam clay from the Rothamsted farm. The results showed that the effect of manuring in influencing the rate of evaporation was less important than the proportion of clay particles (roughly equivalent to colloids) present in the different soils. At present, investigations into the nature and properties of colloids are being continued with especial reference to their behaviour in contact with different liquids, and liquids containing varying quantities of salts.

A reference may here be inserted to research on what is known as "flocculation" in soils, which is being carried out at the University of Leeds. By flocculation is meant the gathering together of the small particles of the soil into " crumbs," thereby opening the texture of the soil and improving its tilth and ease of working. Hitherto it has been thought that the improvement in the tilth of clay soil as the result of liming was not due to the lime which was added, but to the soluble carbonate into which the lime was converted. This view has been shown to be unfounded, and the work at Leeds shows that the improved tilth is due to the direct action of the lime. The mechanism of this action has been investigated, and as a result of the work it is hoped to develop methods for the improvement of soils which are "heavy" on account of the presence of fine silt (not clay), and whose texture is not improved by liming. Such soils occur very ' ommonly on Coal Measure soils in the north of England, the Midlands, the Weald, and on the Lincolnshire warp-lands.

To return to Rothamsted. It will be understood that laboratory research into soil properties must-unless largely increased funds and staff are available-be limited to the investigation of a small number of soil types, and that the effect of varying climatic conditions can only rarely be compared. But before practical conclusions can be drawn from results obtained in the laboratory, it is essential that they should be checked against known data regarding all main types of soil under different conditions of climate. This difficulty, which is a serious one, has for some time been recognised at Rothamsted, but with the 
limited funds available it has been impossible to secure directly the physical data required relating to soils in different areas. A scheme has recently been devised which will, it is believed go far to meet the case. Through the medium of the Board of Education and the Science Masters' Association. arrangements have been made under which any school or training college which is able and willing to conduct simple soil experiments is put into communication with the Rothamsted authorities, and is supplied by them with detailed instructions. The results of the experiments give very useful information regarding the physical properties of the local soils examined in the school, and are correlated with particulars of the type of soil-as shown by mechanical analysis-and of the climatic conditions. As the experiments are carried out on the same lines in all schools cooperating, the results obtained will be comparable. The scheme is only in its initial stages, but seventeen schools have agreed to carry out experimental work on these lines, and supplied valuable information regarding the moisture contents of their local soils during the drought of 1920 .

\section{Cultivation.}

We may now consider in rather more detail the work that is in progress on the subject of what is coming to be known as the science of cultivation. The importance of this was emphasised earlier in this chapter, but it will bear repeating. At present, the cultivation of the soil is an art that has been acquired as the result of ages of experience. It has, however, no scientific foundation, in the sense of being based on scientific knowledge. The aim of a farmer in cultivating the soil by various means is to produce good tilth, but we do not know exactly what " tilth" is, and until we know this we cannot expect to secure any great improvement on present methods, nor can we proceed with any degree of assurance to adapt the design of our tillage implements to different conditions of soil and climate or to varying speeds of travel. The present position may be made clear by a comparison which, although not complete in several important respects, is sufficiently accurate for our purpose. The designer of a ship can be furnished with the scientific information he requires, and he can be tolerably certain that when the ship is launched it will do the work that he wants it to do. The designer of a plough, on the other hand, can be told at present very little about the soil in which the plough is going to work, and if his plough is in any way different from existing types he cannot tell, until he actually tests it in the field, whether it will give even approximate satisfaction. The designer of tillage implements must always be handi- 
capped until he is supplied with more precise information regarding the physical characters of various types of soil. Unfortunately the soil is of so complicated a character that some time must elapse before it can be properly understood. The directions in which the problem is being attacked at Rothamsted may, however, be briefly indicated.

In the first place an extended series of trials is in progress, the object of which is to show exactly how much work-as measured by the dynamometer-is done by a tractor in pulling various implements through the soil. The tractor will work at varying speeds and on different types of soil which have been subjected to different systems of manuring. The important physical properties of the soil, such as moisture content, humus content, etc., will be ascertained. Thus the effect of different systems of manuring, including green manuring and the ploughing in of clover residues, will be noted, and the measurements will be extended to include cultivation, cross-ploughing and such other operations as seem suitable. The results of these trials will show how the various modifications of soil type affect the draw-bar pull of the tractor, and as this draw-bar pull is reflected in consumption of fuel and in wear and tear, a small alteration in resistance will affect the cost of every operation, so that the experiments will have a direct practical bearing. Certain of the recent trials, for example, were carried out in a field part of which had been chalked nine years previously, and although the effect of chalking on crop yield had practically ceased, the chalked portion was clearly shown up by the dynamometer records, and the draw-bar pull-and consequently the fuel consumption of the tractor-was reduced by over one-tenth.

Although this practical issue is important, however, it is not the ultimate reason for the experiments. In the cultivation of soil, the main cost to the farmer is for power required to overcome the resistance to the passage of the implement which is being drawn through it. Apart from purely engineering considerations, this resistance may be broadly divided into two parts, first, the resistance offered by the soil itself-which of course varies according to composition, moisture content, humus content, etc. -and second, the resistance which is inherent in the design of the implement. Clearly, one of the first essentials for further work is to divide the total resistance into these two component parts. A good deal of information will be secured from the experiments described in the preceding paragraph, but it must be supplemented by an intensive laboratory study of certain physical properties of the soil, such as its cohesion and plasticity. The reason for this will appear from a simple illustration. A plough can be drawn 
through a light sandy soil much more easily than through a heavy clay soil, mainly because in the former case the soil particles are comparatively large and adhere loosely together, while in clay the particles are much smaller and adhere more closely. The difference is a difference in cohesion-in so far as the adherence of the particles to one another is concerned-and in plasticity, in so far as one kind of soil is "stickier" than another. When land is ploughed, the cohesion of the soil determines the ease with which the furrow slice is cut; its plasticity determines the resistance offered to the furrow slice as it slides over the mouldboard When it comes to defining in accurate scientific terms the relative cohesion or plasticity of soils, however, the question is much more complicated, for it is found that these qualities cannot be accurately forecasted from a knowledge of the type of soil, and they bear a very complex relation to the treatment to which the soil has been subjected. One of the important difficulties which the Physical Department is trying to solve at the present time is, in fact, that of arriving at some standard method of determining such properties of the soil as its cohesion and its plasticity. Bound up with this is the necessity for studying the exact causes which produce these properties, primarily the "colloids" which have already been referred to. The field of work is largely unexplored, and it is necessary, all along the way, to invent apparatus which will give the necessary information. The knowledge must, however, be gained, for until it is forthcoming no progress can be made towards the ultimate end of the physicist, which is to supply the agricultural engineer with such formulæ as will enable him to design a tillage implement in the confident anticipation that it will do the work required of it under any specified conditions of soil and climate.

\section{Soil Acidity.}

We may conclude this chapter by a brief reference to the progress of investigations into the acidity, or sourness, of soils, which is, of course, closely connected with their need for lime. Few questions are of more immediate importance to the farmer, and at the same time few are so little understood. Sometimes a soil is so obviously sour that it will not grow crops, and in such cases the cause of the trouble is easily found, and heavy liming may be safely advised as the first essential to cultivation. These are fortunately the exceptions, but there remain vast areas which appear to be in need of lime, but by no known tests can an agricultural adviser say even approximately what sort of dressing ought to be applied. When lime was plentiful and cartage not a serious consideration, a difference of a hundredweight or so per 
acre was not regarded as important, but these conditions do not prevail to-day, and we need to know exactly how sour a soil really is and what is required to put it right. An acid condition of soil indicates either an already low or else a declining supply of available lime. Lime is not only used by all growing plants, but it also acts as a great regulator of soil fertility. It may not always be advisable to lime all acid soils under all conditions, but it is very important to know whether a soil is acid, and how acid it is, in order that if lime is not used, crops may be grown which are best adapted to the conditions. Further, the degree of acidity alone is not necessarily an index to the lime requirement of a soil, which may be influenced by other factors, such as the amount of organic matter present. The present position is well illustrated by a recent report of the work of the Advisory Chemist attached to the University College of North Wales, Bangor. This officer has paid special attention to the soils of North Wales, and has made an extensive survey which is now nearing completion and should be of great value for advisory purposes. In particular he has examined the question of the lime requirements of soils in his area. He finds that he can divide the soils into three broad groups. In the first, there are those which contain comparatively large amounts of calcium carbonate, and are therefore presumably not in need of lime. Secondly, there are soils, which, although they contain little or no calcium carbonate, and give indications of lime requirement by certain recognised laboratory methods, do not show lime requirement by more modern tests. Thirdly, there are soils which show lime requirement by all tests. Generally, the calcium carbonate content of the soils is very small, and according to the older laboratory tests it would appear that liming is an urgent necessity. For various reasons liming has been much neglected in North Wales, and yet no large apparent disadvantage can be noticed.

The question of liming cannot, of course, be dealt with in the laboratory alone, and there is urgent need for an extensive series of field trials throughout the country. There is some ground for hoping that these will be arranged at no very distant date. At the same time, we want much more precise laboratory tests for lime requirement than exist at present. This need was felt, for example, by the Department of Agricultural Chemistry of the University of Leeds in the extensive investigations which they have been conducting for some years into the liming of Yorkshire soils. An endeavour was made to devise some simple laboratory test which would help to get over the difficulty, and it was found that a certain chemical solution invariably became red when mixed with the liquid extracts from soils that were known to be sour, 
but never with soils that were known to be not sour. Nearly 300 tests were made, and in all cases the results were consistent. The Department is now trying to improve the test in the hope of arriving at a method of indicating not only the presence but the amount of sourness. An attempt to discover a satisfactory test is also being made by a member of the Advisory Staff attached to the School of Agriculture, Cambridge. In this case the work originated in the discovery that certain soils in the Cambridge district which had been ignited, or burnt, did not thereby lose their acid qualities. It has hitherto been supposed that the various humic acids in the soil were driven off by ignition.

As a method of checking such laboratory tests for acidity as at present exist, and others which may from time to time be elaborated, and also in order to study the whole question of acidity in soils, an electrical apparatus has been set up at Rothamsted which is capable of measuring the acidity of a soil, not only in amount but in intensity. For a sour soil contains a mixture of acids of various strengths, and a statement of the total amount of lime required to make the soil neutral gives no clue to the "intensity" of the acid present. Two boxes of coins may be of exactly equal value, but if one contains all coppers, and the other is partly made up of silver and gold coins, the weights of the boxes are different. Similarly two soils may have exactly the same "intensity" of acidity, and similar effects on the crop, but the " quantity " of acidity, or the amount of lime required to correct it, may differ considerably. So far, the only means of ascertaining the intensity of acidity in soils is by means of the electrical apparatus referred to. It is based on a recognised method of ascertaining the intensity of acidity or alkalinity in liquids, but various modifications have been necessary to make it applicable to the examination of soils. The apparatus is now working satisfactorily, and it is hoped that the investigation will throw much needed light on the subject of acidity in soils, and possibly lead to the development of simpler methods of estimating their lime requirements. 


\section{CHAPTER II.}

\section{PLANT BREEDING.}

Perhaps in no other branch of agricultural science can the immediate value of research be shown so well as in the case of investigations into plant breeding; for it requires no power of argument to demonstrate the gain, not only to the farmer or horticulturist, but to the nation, derived from the introduction of a new or improved plant. A wheat giving a slightly increased yield, or better able to withstand the weather conditions of this country, puts money into the pockets of the farmer, and, by increasing home production and thereby lessening our dependence on the foreigner, is a national asset. In proof of this we need only mention the introduction to the British farmer of Yeoman wheat, by Prof. Biffen of Cambridge ; of Plumage Archer barley, by Mr. Beaven of Warminster; and of Blue Cone wheat, by Prof. Percival of Reading. In this chapter an account will be given of the more recent investigations at the Plant Breeding Institute at Cambridge, and reference will also be made to work that is going on at a new Plant Breeding Station that has been established at Aberystwyth, at which the main line of research lies in the direction of improving our herbage plants. As the latter Institute has not long been established, the reference to it must of necessity be confined to a description of the gradual building up of a plant breeding station, which in due course will doubtless produce results worthy of agricultural research. It is believed that such an account will be not without interest to the agricultural reader, as showing the enormous amount of detail involved in the production of improved types of plant. For this reason, too, it will be unnecessary to refer to this aspect of the subject in describing the work in progress at the Cambridge Institute.

When a Plant Breeding Institute has succeeded in producing -necessarily on a small scale-new varieties of plants which breed true and apparently contain the qualities desired, the need arises for a non-commercial organisation which shall test them on a larger scale and produce seed in sufficient quantities for distribution to farmers. For this purpose the National Institute of Agricultural Botany has recently been established at Cambridge by means of funds derived in part from subscriptions from the seed and milling trades and from private donors, and in part from the Development Fund. The Institute owns 
seed farms of about 400 acres in area, acquired by gift and purchase, and these are now being used for seed growing and variety trials. In addition, the Institute is the headquarters of the official Seed Testing Station for England and Wales, and owns and operates the Potato Testing Station at Ormskirk, Lancashire, where the official trials of potatoes for immunity from Wart Disease are conducted.

The more important breeding investigations that are being conducted at the Cambridge Plant Breeding Institute refer to wheat, oats, barley and potatoes, and we shall deal with them in that order. Then, leaving for a moment the work at Cambridge, we shall go on to describe the research in progress at the Aberystwyth Station, reverting to Cambridge in order to illustrate, by reference to some further enquiries there proceeding, the limitations under which plant breeders labour for want of further knowledge on certain points of fundamental importance.

\section{Plant Breeding Institute, Cambridge.}

Wheat.-It is well-known that in one outstanding respect, namely, in baking quality, or " strength," English varieties of wheat are distinctly inferior to much of the wheat that is imported. One of the first objects that the Cambridge Institute set out to attain therefore was the production of a type of wheat which would grow well under English conditions and produce a crop of grain sufficiently "strong " to meet the requirements of the miller. It was found that this quality of grain known as "strength" could be passed on from parent to offspring. Long extended investigations resulted in the discovery of varieties of wheat capable of producing exceedingly " strong" grain under English conditions, and by cross-breeding these with heavy-yielding English varieties, new types have been built up which are satisfactory as regards both yield and " strength." One of these varieties, "Yeoman," has now been in general cultivation for four seasons, and has rapidly made its way to the front on account of its heavy-yielding capacity. While, however, "Yeoman" has good milling qualities, and is freely bought by millers, it is not equal in " strength" to the best of the imported wheats. The Institute is therefore attempting to improve the strength of Yeoman wheat, while retaining, or even increasing, its yielding capacity. For some years all parts of the world have been searched for wheats, and the best of these types, whether from Tibet, Persia, Abyssinia or elsewhere, are being used as parents. As an indication of the importance of the work it may be mentioned that many millers now refuse to accept "soft" English wheat. The Institute has therefore 
recently decided to proceed no further with the investigation of wheats that are less "strong" than Yeoman.

At the same time, an effort is being made to produce a wheat sufficiently stiff in the straw to prevent " lodging " during rough weather. The tendency to lodge, which is unfortunately common amongst cereal crops, not only reduces the yield per acre and adds to the cost of harvesting, but prevents farmers from endeavouring to produce maximum crops by the increased use of fertilisers. The work at Cambridge has already gone far enough to show that stiffness of straw can be brought under control, and crosses that breed true have been obtained which combine the high yield of "Yeoman" with a straw sufficiently strong to resist any ordinary weather conditions. Stocks of seed of the best of those varieties are now being worked up. About half-an-acre has been sown with them during the past autumn, and the seed secured from this area in $\mathrm{I} 922$ will go to the National Institute of Agricultural Botany, so that the varieties may be tested out under farm conditions and a sufficient quantity of seed obtained for distribution to farmers.

The question of disease resistance is kept prominently in view by the Institute. Resistance against the common yellow rust was early found to be an inheritable quality, and practically all the types now under investigation are more or less immune from this disease.

A promising breeding experiment is at present in progress with the object of increasing the number of grains set per spikelet, and thus, possibly, the yield of the crop. In English varieties of wheat, although seven or eight flowers are produced on each spikelet, as a rule only about four grains are developed. Some years ago, however, a variety obtained from the Szechuan district of China was found to have the peculiarity of setting every flower that was produced, although in other respects the variety was very inferior to any ordinary English wheat. For several years efforts have been made to combine this flowersetting quality with the many spikelets characteristic of English types. Hybrids between the Chinese and English varieties have been secured, and from these it is clear that the power of setting grains may be inherited. Upwards of thirty distinct hybrids, which breed true, are at present being tested on small field plots.

It has been thought desirable to give only a brief general account of the wheat-breeding investigations, sufficient to indicate the main lines on which work is proceeding. The amount of detail involved is, however, very great. In I92I, for example, the second generation of wheat crosses amounted 
to over 80,000 plants, each one of which had to be " rubbed out " separately. From this collection it is unlikely that more than a hundred good plants will be secured, and these cannot be recognised with certainty until they have been grown on for a further period. It takes at least six years to produce sufficient seed of a new type of wheat to test it for its milling quality, and if it fails to fulfil milling requirements as a result of that test, it is scrapped. This explains why the Institute took some I4 years of continued experimental work to produce "Yeoman" wheat, and why "Yeoman" wheats cannot be turned out every year.

Oats.-The main problem which is being attacked under this head is the breeding of a winter oat. The hybridising work of seedsmen has been done almost exclusively with spring oats. In endeavouring to breed a winter oat, the Institute has used for the original parent, the old Scotch "Dun" oat, which is a hardy white winter oat and very free tillerer, but very late in ripening and producing small thin grains. This has been crossed with various parents, including Flanders Yellow and a German Tartarian oat. Two types of the eighth generation appear to possess the desired qualities, namely, winter hardiness, high tillering capacity, high yield, and early ripening. These types have been passed on to the National Institute of Agricultural Botany for testing on a field scale.

A serious difficulty with the oat crop is its tendency to lodge, and an effort is therefore being made to produce a short-strawed variety, while retaining other desirable qualities. It has been found that length of straw is a quality which can be controlled. A short-strawed oat has been bred, and an acre of this has been sown. If satisfactory, the seed from this area will be passed on to the National Institute of Agricultural Botany in 1922. A further 25 or 30 types are also under investigation in small field plots.

Barley.-The main problems under investigation are the improvement of the standing capacity of the crop and the raising of heavy-yielding varieties for feeding purposes. Previous work has resulted in the breeding of short-necked and stronger-strawed types. This is being continued, particularly in the direction of producing still stronger straw. The stronger types were bred from a parent of low malting quality, and to get rid of this defect, it has been necessary to investigate closely the manner of inheritance of all the characters concerned in strength of straw. There seems good promise that some of 
the latest types secured will combine good malting quality and high yield with very strong straw.

The ordinary six-rowed barley commonly grown for feeding purposes has two serious disadvantages. It is a bad tillerer, and has a very fragile neck, which often causes it to break off at the ear when harvested. Breeding work is in progress to remedy these defects, and also to produce a grain giving as high a percentage of nitrogen as possible. About 40 different varieties have been selected for testing on a small field-plot scale, and there is a prospect that from these it will be possible to select a variety considerably better than those commonly grown.

Potatoes.-A series of experiments is in progress with the object of raising new varieties of potatoes resistant to the serious diseases of Blight, Wart Disease and Leaf Curl, and at the same time preserving the high standard of the best commercial sorts in regard to cropping and other necessary qualities. The work was started three years ago, and certain varieties were selected as parents which were known to be highly resistant to Blight and Wart Disease. These were crossed with others possessing the necessary commercial qualities. Considerable variation appeared in the first generation amongst the 5,000 seedlings raised. From these, most stringent selections have been made each year, and particularly all seedlings suffering from Blight and Leaf Curl have been discarded. It is worthy of note that out of some 20 distinct crosses made, one family has proved itself remarkably resistant to both these diseases.

As regards Wart Disease, the immediate object in view is the obtaining of heavy cropping immune earlies and an immune variety of the Up-to-Date type. The tests for resistance to Wart Disease are being carried out at the Ormskirk Potato Testing Station. At the same time an attempt is being made to discover the exact nature of the inheritance of immunity from Wart Disease. It has already been found that immunity is not a simple inheritable factor. Two immune varieties, for example, may produce susceptible offspring.

In potato-breeding work of this type, numerous difficulties have to be overcome. In the first place there is the difficulty of securing suitable parents, for many of the favourite varieties now grown do not produce pollen, which, of course, is essential for cross fertilisation. Then there is a marked tendency for even fertilised flowers to drop off without producing seeds. If seedlings are successfully raised, there is the difficulty of saying which of them are likely to give rise to successful potato plants. 
In practice it is found that while colour and shape can be determined reliably in first-year tubers, it is only possible to give a very rough guess at early maturing and yielding capacity. There is further the difficulty of maintaining the vigour and health of the plants. It has been found to be necessary to send the seedlings to Scotland and Ireland for the production of second-year's tubers, and it is proposed to repeat this practice at frequent intervals in the life of the stock. The present position. is that about roo of the best plants have been selected from those grown in Scotland last season, and these will be again sent to Scotland for growing on for a further year. Duplicates are sent to the Ormskirk Testing Station to test for immunity from Wart Disease.

\section{Welsh Plant Breeding Station, Aberystwyth.}

Herbage Plants.-At Aberystwyth the question of producing improved strains of herbage plants is receiving special attention. The aim of the work is two-fold: firstly, to investigate the possibility of introducing new types into the country; secondly, to improve varieties already in cultivation. Under the former heading, some 20 or 30 foreign herbage plants have already been tested at the Station, and a few of these have been found deserving of further investigation. Of these the most promising are two grasses-a slender wheat grass and a species of Canary grass-and a species of clover from Australia.

The improvement of existing varieties by breeding is difficult and laborious, mainly because little work of the sort has hitherto been attempted in this country, and the grasses and other herbage plants contained in the grazing and hay pastures up. and down the country represent a motley collection of hybrids showing all possible variations. In the first instance, therefore, it was necessary to secure as many types of plants as possible, not only from cultivated and wild pastures in this country but also from abroad. A very considerable number of plants have been collected in this way and are being tested in the gardens and trial grounds attached to the Station. At the trial grounds, some 800 rod and half-rod plots are at present planted out, in addition to over 200 small garden plots. The work has already yielded interesting results. It has been found that for Welsh conditions, commercial Italian red clover is entirely unsatisfactory; that, in general, imported red clover seed is much less satisfactory than strains grown in this country; and that of " home" red clovers, two strains, viz., Cornish marl clover (from the Wadebridge district) and clover from Montgomeryshire, are particularly promising, and will be used for the purpose of. 
intensive breeding work. A further interesting fact emerging from the trials is the considerable difference that exists between commercial and indigenous (i.e., native) strains of all herbage plants, and there is a general promise of being able to secure considerably improved strains, at any rate in grazing plants, by the use of indigenous forms. The indigenous plants are generally more leafy than the commercial species, and have a much greater stooling, or tillering, capacity, thus giving longer and more continuous grazing.

In the improvement of grazing pastures, the main object to keep in view is to produce strains which will mature earlier and continue to supply food late in the season; in other words, a longer grazing season is wanted. There is usually plenty of keep in May and June, but the shortage is most felt in March and early April and again in October and November. Thus the ideal grazing pasture would include early-maturing plants giving a plentiful supply of food in March, and late-maturing plants continuing the grazing season into the late autumn. Possibly this ideal will never be obtained from a single seeds mixture, and it may prove better for the farmer to sow down his pasture fields with individual species, or limited mixtures, which will come into maximum bearing at different periods. This, however, is no more than a surmise, but it is a question under critical investigation at the Station.

For the present the Station is concentrating attention on the most important of the constituents of the ordinary seeds mixture, namely, cocksfoot, the rye grasses, tall oat grass, the fescues and red clover. For each of these species, hundreds of strains occur in nature through the continued process of cross-pollination that goes on under natural conditions. As a preliminary to breeding work, therefore, it has been necessary for the Station to collect as large a " living museum " as possible of natural strains. All possible sources, both in this country and abroad, have been drawn upon in making this collection. The number of individual plants of cocksfoot, rye grass, tall oat grass and the fescues which are being studied is nearly 5,000, and upwards of 3,000 clover plants are under investigation. Moreover, as the plants are cross-pollinated in nature, it is necessary, before critical breeding experiments can be commenced, to carry out a series of preliminary trials to find out the "habits" of the various types; to ascertain, for example, if a cross-pollinated plant can be self-pollinated; if not, how it can best be cross-pollinated; what time of the day does the plant flower, and so on. To answer such questions as these, over 300 plants were grown separately in pollen-proof cages in 
the gardens and greenhouses in I92I. A further difficulty arises in the selection of good herbage plants, for with such a large number of types it is not possible to devote more than a small plot to each in the first instance, and sometimes there is only a single plant to judge. It has, therefore, been necessary to carry out trials to ascertain whether a weekly, or a fortnightly, or a three-weekly cut of the plant best represents average grazing conditions. Testing the grazing capacity of plants is, in fact, most laborious. Each plant must be cut separately several times during the season, and the cuttings weighed; the cuttings must further be divided into stem and leaf, and each part weighed separately, for the object is to produce plants with the greatest amount of leaf and the least amount of stem. It is not surprising, therefore, to find that over 5,000 separate cuttings and weighings were made during the past growing season; and that over 800 separate plots at the trial grounds and over 500 beds in the gardens are at present being devoted to the herbage plant investigation.

As an illustration of the general method of investigation, the case of rye grasses may be quoted. The work on these plants has now gone on for two seasons. The original collection of plants was obtained from all parts of this and other countries, including Ireland, Denmark, Sweden and New Zealand. Various commercial samples of seed and plants were secured from English and Welsh seedsmen, and in addition plants from all parts of the country were rooted up, both from old pastures and wild hedgerows and commons, and re-planted at the Station. The ideal aimed at is a leafy plant with a good bulk of "top " and persistent growth. This would be a dual-purpose plant, for both grazing and hay purposes, and if it cannot be obtained, the "next best" is either a leafy and persistent plant, for grazing, or a bulky plant for hay. A further point borne in mind is that of resistance to disease. The plan of investigation will best be understood by reference to a specific case. A turf of rye-grass was dug up out of an old pasture in the summer of I9I9, and planted provisionally in the Station nursery. In the autumn it was carefully broken up into as many tillers as possible, care being taken that each tiller was actually a separate plant, and not a mixture of species. The tillers were planted out in lines at about eighteen inches apart. Their growth was studied, and it was found possible to group them into three broad types. During the autumn of I92I the best plant from each type was selected and split up again into nine tillers, each of which has been planted out separately. This year the nine plants will be treated as follows:-Four plants will be tested 
for grazing capacity, two being cut at fortnightly and two at monthly intervals; two plants will be tested for hay, being cut for first crop and aftermath; one plant will be grown on; one will be kept for botanical examination; the remaining plant will be kept for other purposes. The results will be compared with others obtained by somewhat similar methods, and as the result of the comparison it will be possible to select certain types which may be used for breeding purposes.

Oats.-In many parts of Wales and the West of England, there is much cultivated land in districts of high rainfall and altitude, and a need exists for a hardy winter oat which will mature early enough to enable the farmer to sow a forage crop after harvest. At present the varieties used locally are spring oats, which are not usually harvested until September, too late for an autumn sown forage crop. The Station is endeavouring to supply this need, and about 160 varieties of oats have been collected from all parts of the world and are being investigated in small plots. The best of these varieties, to the number of about 40, have been selected and tested for the past two years in comparison with the local sorts in plots at the trial grounds. This has involved the setting up of about 600 plots each year, varying in size from small beds to 4-rod plots. Already varieties have been discovered which are sufficiently hardy and earlymaturing, but lack the cropping powers of a really satisfactory oat, and an attempt will be made to combine by breeding, the early-maturing capacity of these varieties with a high yield.

Simultaneously with this work, an investigation is being made of the local " land " varieties, Ceirch du bach and Ceirch llwyd. These so-called varieties, which are in common use amongst Welsh farmers, are really mixtures of various strains. The Station is engaged in separating out these strains, and having selected the best, an attempt will be made to improve them by breeding. The aim is to produce varieties suited to three ranges of altitude, varying from low-lying land to land at an altitude of over $\mathrm{I}, 000$ feet.

\section{The Investigation of Principles.}

It will be understood that, although much may be accomplished by careful breeding and selection based on the knowledge that already exists regarding the science of heredity, there must come a point in almost every investigation at which the plant breeder is brought to a standstill for the want of more information regarding the fundamental principles underlying the inheritance of characters. It is not enough to know that a character is 
inherited; we want to understand how, and why. Until this knowledge is available, the plant breeder is largely working in the dark, and is about as much handicapped as a chemist would be who was obliged to mix his liquids in earthenware vessels where they could not be seen. The investigation of fundamental principles is usually termed " pure" research; its one and only object is the acquisition of knowledge. This pursuit of knowledge "for its own sake," with no obvious practical outlook, is sometimes looked upon with scepticism by the farmer, but actually it is most important, for it is the foundation of all real progress-the bricks from which the substantial building must be erected, and any half-knowledge is but a brick substitute and cannot be permanent. The main Institute engaged on the investigation of fundamental principles of plant breeding in this country is the John Innes Horticultural Institute, Merton, Surrey. This Institution is not maintained from public funds, and, moreover, an account of the investigations being conducted there would hardly be of interest to the agricultural reader. The work in many cases is remote from a practical application; but the crossing of peas by Mendel had no immediate practical bearing, and yet his results laid the foundation for most of the invaluable breeding work that has since been carried on in all parts of the world. At the John Innes Institution work is being done on a great variety of plants chosen on account of their fitness for experimental purposes rather than for their economic importance. Even weeds are thus pressed into the service. The farmer may feel that he does not want to breed weeds; but the main thing is to discover principles, and when they are discovered they may be applied to any plant, and possibly to animals.

An investigation into principles, which, however, has a more obvious practical bearing, is being conducted at the Cambridge Plant Breeding Institute, where an attempt is being made to discover the exact nature of certain inherited characters. We speak, for example, of a barley plant as being awned or awnless, and regard the awn as a definite inheritable character. But in practice it has been found possible to produce both awned and awnless plants from one variety, by sowing at different times. This danger of confusion attends work on other kinds of plant characters, and it is important that a more exact definition of each character should be arrived at. Much of the work of this type that has been done at Cambridge is so far only of academic interest, but one or two cases may be mentioned which have a more practical application. In cereal breeding the most important problem is one of yield, and this is closely associated 
with the question of tillering. It is generally supposed that prolific tillering implies high yield, and that the breeder should aim at securing the maximum formation of tillers. But this is not necessarily the case, and it is, in fact, impossible to define with precision the various factors which go to make for a high yield. An attempt is therefore being made to discover what those factors are, how they are inherited, and finally how they may be detected in a single plant or a small number of plants. The chief difficulty is that the cereal plant consists of tillers of different ages, and it has been found by chemical analysis that the tillers act with different efficiencies as factories for the manufacture of food from the soil or the air. Clearly, therefore, the aim of the plant breeder should be to secure a plant with a fair number of strong rapidly-growing tillers, rather than one with a long succession of tillers of different ages and sizes. Several oat varieties now in cultivation fail to yield well because they have numerous lateral tillers which form little grain, and do it at the expense of the strong-growing central tillers.

Another line of research that is being followed at Cambridge is the investigation of the part played by the root in the living activities of the plant. In the past, plant-breeders have generally been content to judge a plant entirely from that part of it that is above ground, and have left out of account the part in the soil, on which, in a large measure, the plant depends for its existence. It is possible that some of the failures in breeding may ultimately be found to have been due to the fact that so little attention has been paid to the influence of the root system.

At Aberystwyth also it has been found essential to investigate principles. One problem now being studied refers to the influence of cutting and methods of cultivating on the spreading of the roots of herbage plants in the soil, and the influence of this root range on the persistency of growth of the plants. The precise effect of external conditions on the growth of Red Clover and some of the chief grasses is also receiving detailed consideration. 


\section{CHAPTER III.}

\section{PLANT PHYSIOLOGY.}

Plant Physiology may be defined as the study of the life processes of plants, and how they are affected by the conditions under which the plants live. The question is one of fundamental importance. It is hardly too much to say that our lack of knowledge in this matter is the most serious limiting factor in the efforts now being made in other departments of science to devise methods of improving the health and yield of crops, and of treating the diseases to which they are subject. Perhaps a simple illustration, drawn from commercial life, will help to make this clear. We may conceive of a traveller from a foreign country landing at the port of London. He wishes to go to Newcastle, but he does not know where Newcastle is, he only knows that there are important shipbuilding works somewhere on the East Coast which he must visit for the purposes of his business. He could charter a ship and travel slowly up the East Coast, putting in at various ports on the way, until he came to the city he wishes to visit. But this would be a long task, and he happens to know that there are railway lines in the country diverging from London, and that one of them would probably lead to Newcastle. He does not know, however, which station to go to, so he might have to take a motor car and travel round from one station to another until he comes to the right one, and then he must find out what trains are running and when. This is the empirical method of finding the best way of getting to Newcastle, and with patience and perseverance the traveller would doubtless be successful in reaching the city in course of time. But if he wanted afterwards to go on from Newcastle to Manchester, or if, on returning to London, he wished to go to Birmingham, he must go through the same process of trial and error again, and in the long run the time wasted in this way would be very considerable. Fortunately for the traveller, however, there is such a thing as a Bradshaw's Railway Guide, which may be compared to the product of fundamental research, for it contains the results of a detailed investigation of the railway system of the United Kingdom. The traveller has only to consult this reference book, and he can readily see how to get from London to Liverpool, or from Devizes to Darlington, or from Cork to Killarney. Originally the book must have taken an enormous amount of 
time and labour to produce; even keeping it up-to-date must be no light task; and possibly if the traveller-being not very far-seeing-looked in at the office and saw many clerks engaged in sorting all sorts of time-tables and confirming multitudinous details relating to small out-of-the-way places, he might wonder whether all that array of facts and figures was really going to help him, and whether the clerks might not have been better employed in some other way But now he has the Guide he can see its value; in fact he could not do without it, for travelling under any other conditions would mean so much waste of time that his firm could not hope to compete with others who were more advanced in their methods.

This illustrates, in a rather imperfect way, the case for fundamental research into plant physiology; that is, into the internal workings of plants, by which they take up gases from the air, absorb water and salts from the soil, build up new material, grow, and produce flowers and fruit. The illustration may be amplified by a reference to certain problems in agriculture and horticulture which baffle us because we know so little of these matters. What constitutes the difference between a "heavy cropping" and a "light cropping" wheat? Is it a difference in the absorbing capacity of the root, or of the stem or the leaf, or is it a difference in the capacity of the plant to carry the food material in the straw to the ripening grain? If this knowledge were available, it would open up a new field for the plant breeder; he could aim direct at the differences that matter, and his labours would be shortened and more effective. Again, what makes a plant resistant to a disease? We know that a disease organism may attack one plant and not another, but we do not know why, or rather our knowledge in the matter is very limited. If we knew more, the problem of disease ccntrol, and breeding for immunity, would be robbed of much of its difficulty. Further, we know practically nothing of what it is that influences the formation of flower buds on fruit trees, and yet the success of the crop depends in the long run on this factor. At present we attempt to control the fate of buds by pruning, but our methods of pruning are " rule of thumb" methods, and must continue to be so until we know more of what is going on within the plant, which normally decides how a bud will develop. One more illustration may be given. A fruit-grower purchases a root-stock on which he will graft a scion, and if the root-stock has been properly described it will produce the kind of tree which the grower needs - a tall tree, or a dwarf, or one of medium size. But the only method by which rootstocks can be selected at present is by the long and tedious 
process of trial and error, with the possibility of failure and consequent scrapping; and before any improvement on this method can be suggested we must find out how it is that the root-stock so greatly influences the tree.*

Problems of this sort, referring to the inner processes going on in the plant, and the effect upon them of such external circumstances as temperature, humidity, amount of light, and soil conditions, are studied at the Research Institute in Plant Physiology, which is attached to the Imperial College of Science and Technology, London. In the preceding paragraphs an attempt has been made to emphasise the vital importance of fundamental physiological research, partly because an account such as this, relating to the work carried out quite recently and to investigations in progress, cannot be expected to contain much that is of direct interest to the agricultural reader. The physiologist is engaged in discovering the facts of life in the plant; it is for the applied scientist-the plant breeder, the plant " doctor" and so on-to take those facts and apply them to agricultural and horticultural practice. While, however, the following record of work done may not appear to foreshadow much immediate advance in agricultural methods, it is hoped that it may not be without interest as showing the progress of an important line of pure research, and indicating a few of the difficulties with which the research worker has to contend.

\section{Factors influencing Crop Yield.}

In the first instance we may refer to investigations which bear on the important problem of crop yield, already referred to in the second paragraph. The object of the work is to find out what are the various factors which make for yield, how they are related to one another, and how they are influenced by external conditions. For example, when we supply a crop with a certain quantity of nitrogenous manure we get an increase in the total weight. Is this because the capacity of the plants for utilising sunlight has been increased-in other words, has their "appetite" been improved-or is the benefit due to an increase in the leaf surface of the plants, thus enabling them, without increasing their "efficiency," to utilise more sunlight? To answer this question requires a detailed study of the distribution of materials in the various parts of a plant throughout its

- This problem is also referred tolon page 55 , in describing the root-stock research in progress at the East Malling Research Station. A member of the Imperial College staff is attached to the Station, in order that his investigation of the physiology of root-stock influence may be carried out in direct association with the work on classification of root-stocks. 
growth, including the variation in the relative weights of root, stem and leaf at different periods in the plant's life history, and the effect of fertilisation and flowering on this distribution. It is also necessary to study closely the increase in area of the leaf surface, which constitutes the "catchment area " for the energy derived from sunlight. The respiration of the plant at different periods in its life history must be ascertained, to find out what losses are being sustained in this way. Finally, by burning the various organs of the plants which have attained different stages of development, we can release the "energy" that has been stored up, and can thus follow the process of energy accumulation in the plant throughout its life.

The investigation is being attacked in two ways. In the first place, barley plants growing in the field and in pots at Rothamsted are being studied. In the case of the pot plants, the dampness of the soil is regulated and kept as constant as possible. Records are kept of temperature and light intensity, and samples of the soil are taken at regular intervals for partial analysis. The gradual increase in leaf area is ascertained by making frequent tracings of each leaf of each plant, and finding the areas with a planimeter. The dry weights of various parts of the plants, such as stem, leaf and root, are ascertained at regular intervals; part of the dry matter is analysed chemically and part burnt. Most of the operations have to be done on a number of similar plants, so that the amount of work involved is very great. From the data collected during I92I, a chart has been constructed showing how a plant grows under certain standard conditions. Later it will be possible to compare this with the manner of growth under different conditions, and thus to ascertain exactly the extent to which the efficiency of the plant is altered by changed conditions. By " efficiency" is meant the proportion of the sun's energy that the plant is able to use; this, after all, is the phenomenon on which all living matter depends for its existence. It is important that we should know whether the efficiency of plants growing under different conditions-e.g., light and shade-varies greatly; whether manuring has any effect in increasing the efficiency of the plant; whether the difference between a light cropper and heavy cropper is a difference in efficiency.

The other method by which the problem is being attacked is with cucumbers growing under strictly controlled conditions. The cucumber has been chosen partly because it will tolerate great changes in conditions of light, temperature, etc., and partly because it is an important glasshouse crop, grown under condi- 
tions which can be easily controlled by the grower. The cucumbers are grown in pots in an experimental glasshouse so constructed that it is possible to control, and to keep constant, the conditions of humidity, light intensity, and temperature. In the series of experiments carried out from IgI9 to I92I the humidity and light intensity have been kept constant throughout, while the temperature has been varied for each experiment. The light is supplied by means of powerful electric lamps overhanging the pots. The first experiment was conducted at a temperature of $95^{\circ} \mathrm{F}$, and it was found that the plants grew less and less rapidly, and stopped growing after a fortnight. This was curious, for in commercial practice the temperature of cucumber houses often reaches $120^{\circ} \mathrm{F}$. It was important to find out why the falling off in growth had taken place. There were three alternatives; either the temperature was too high, or the light intensity was too low, or the effect of continuous light was bad. Subsequent experimients were therefore carried out at increasingly low temperatures, and as the temperature was lowered the growth improved. Already a temperature of $75^{\circ} \mathrm{F}$. has been reached, and the rate of growth has not yet reached its maximum. Thus there is clearly some factor detrimental to growth which increases with the temperature of the house. Exactly what that factor is, further experiments now in progress will doubtless discover.

In another set of experiments, the effect of varying light intensity was studied, and it was found that the greater the light the greater the growth. If this is confirmed by further work under varying conditions it should have an important practical application, inasmuch as it will show that cucumber growers should aim at a high degree of light intensity, especially during the winter months. An inference of this kind had already been drawn from the results of a test made at Cheshunt in a new greenhouse of a cucumber grower in that district. The rate of growth of the cucumber plants in their early stages was more than doubled in the new houses compared with the old; after six weeks the plants in the new houses were about a fortnight ahead of the others. The explanation probably was that the new house, instead of facing north and south like the old, faced east and west, with a steep roof sloping to the-south, so that the rays of evening or winter sunlight struck the roof almost at right angles and reached the plants instead of being mainly reflected as in the case of the old houses. The study of the effects of light intensity at the Institute is now being extended to test whether continued light has any beneficial effect. The results of this work may be also, of course, of practical importance. 
In general it may be said that any physiological work of this character is likely to yield results of direct value to the glasshouse grower, who is able to control the conditions of cultivation of his crops to an extent that is impossible to the farmer.

\section{Resistance to Disease.}

We may now refer to some very important research work, the object of which is to throw light on the complicated question of immunity from disease. It is well known that most disease fungi and bacteria show a preference for certain plants, which they will attack and injure, while other types of plants in the neighbourhood remain free from infection. It is also known that in the case of certain diseases, such as yellow rust of wheat and wart disease of potatoes, it has been found possible to breed varieties of the plant which are immune from the disease. One of the most important benefits that the plant breeder can confer upon the farmer or horticulturist is to produce for him a variety of plant which will resist attack from a disease that causes serious losses. Already much has been done in this direction by purely empirical methods; but unfortunately it often happens that an immune variety is not so good in other respects as a susceptible, and that it is found difficult to combine immunity with other desirable qualities súch as high yield or first-rate flavour. This was so, for example, in the case of wart disease of potatoes, where until recently the immune varieties which were produced as the result of prolonged experimental work were not equal in cropping power to the susceptible sorts. If the plant breeder could be told exactly what it is that makes one variety resistant to disease, he would be in a much better position to reproduce that quality than he is at present. Now, in a sense, he is working in the dark; he must consider the plant as a whole, and find out, by infection experiments, whether or not it is liable to attack. With more definite knowledge of the nature of immunity he would be able to confine his attention to the particular factors causing immunity, and his sphere of usefulness would be greatly increased.

In its essence the problem of fungoid disease is a physiological one; it is concerned solely with the life processes of the fungus and of the "host" plant on which the fungus becomes established. It is also extremely complex. The infection of a particular plant by a particular fungus follows upon a long series of physiological actions on the part of the fungus, and simultaneous actions or reactions on the part of the plant. The question is further complicated by the fact that the method of attack is not the same in all cases. Sometimes the fungus enters 
through a wound in the plant, and can feed directly upon the plant juices; at other times the fungus enters through the outer "skin" of the plant, and the resistance offered by this skin must be overcome before the fungus is able to gain access to the food material contained in the plant tissues. Even if this resistance is broken down, the fungus may be unable to live on the juices of some plants, and cannot cause an outbreak of disease. It is not surprising therefore that the work which has been going on at the Imperial College for the past few years has as yet only touched the fringe, as it were, of this difficult problem. On the other hand, most valuable preliminary results have been obtained, and there is good ground for expecting that further research will be successful in providing definite information which will be useful not only to the plant breeder, but also in suggesting new methods of controlling fungoid diseases.

It would be out of place in this publication to refer to the details of the methods that have been employed in tracing the various stages in the penetration of the host plant by the minute fungus parasite. The work is very difficult, and involves the use of electrical apparatus as well as a considerable knowledge of organic chemistry. It is necessary to study the action of the fungus on numerous plants, some of which may for various reasons be very unsatisfactory material for experimental work. Further, the behaviour of different species of fungi may vary, so it has been necessary to examine several species, although for the accumulation of comparative data the work must perforce be done on one species only, and in this connection the fungus Botrytis cinerea has been used. The experiments up-to-date have established certain facts which are in a high degree important. It has been found that in many case the "spores" (roughly equivalent to seeds) - which are of course the normal agents of infection-germinate in the moisture coating the outside of the plant, but are unable to pierce the outer skin (or epidermis) unless they are sufficiently vigorous, and that the feeding necessary to supply this vigour does not come solely from something within the "spores," but is exuded from the plant. Thus we already see one reason why some plants are attacked and others not. In the one case, the plant can exude through its skin-perspire, so to speak-chemical substances which form a food supply for the fungus spores, and enable them to develop the degree of strength necessary for piercing the skin and entering the tissues of the plant. In other cases such chemical substances are not exuded, or it may even happen that substances are exuded that are actually injurious to the fungus, so that it is prevented from germinating and penetrating the skin. 
This does not, however, complete the story. The fungus may be successful in penetrating the skin of the plant, but its difficulties have then only begun. It has to break down the plant tissues, and secure a supply of food for its growth and reproduction. To do this it must manufacture a chemical solvent known as an enzyme. By means of this enzyme it can break through the network of partitions underlying the skin of the plant, which form, so to speak, the skeleton in which the "flesh" of the plant-the protoplasm-is suspended. Thus we have another reason why some plants are attacked and others not. In the former case, the fungus is able to manufacture the enzyme which breaks down the internal framework of the plant; in the latter case, it cannot, and so it makes no progress.

Assuming, however, that the fungus spore has satisfactorily germinated, has penetrated the skin, and by manufacturing an appropriate enzyme has gained access to the plant juices, it may still be unable to continue, for unless it can live on those juices it must perish. This constitutes a third reason for immunity; a plant is safe from serious infection if its juices are unpalatable to the fungus. It is this part of the problem which is under investigation at the moment. What is it that makes certain plant juices so distasteful to a fungus that it will die rather than partake of them? Why, for example, does Botrytis parasitica thrive on the onion and die on the apple; and why does Monilia cinerea flourish on the apple and refuse to live on the onion? The examination of this and similar problems is still only in an early stage, but it has been shown that, in addition to cases where the fungus will not begin its growth at all in a particular plant-juice, there are other cases where it will begin to grow quite well, but sooner or later poisons itself by its own waste-products. A good deal more remains to be learnt, but when all the phenomena of this life and death struggle -as vital for the farmer as for the fungus-have been investigated and explained, we shall have a complete history of the physiology of fungus attack, of an importance which can hardly be over-rated.

\section{Electrical Treatment of Crops.}

Some years ago a Swedish Professor who was on a visit to the Arctic circle was struck by the rapid summer growth of plants in those regions during the Arctic summer, and began to wonder why. It could hardly be due to excess of sunlight, because the sun is always low, and its rays strike the ground at an oblique angle. He was led to the view that the electrical conditions were abnormal near the poles, and that the plants 
receive a much larger electric current from the atmosphere than they get in more central regions. This view seems to have been unfounded, but it initiated the experiments which have since been conducted in various countries into the effect of electrical discharge on the growth of crops. In the earlier experiments carried out in this country the amount of electrical discharge was not measured, and the value of the results obtained was much lessened in consequence. In the experiments begun at the Imperial College in rgr6, special attention was paid to the question of measurement. In IgI8 a Committee was set up by the Ministry of Agriculture and Fisheries to investigate the whole subject thoroughly, and, as a consequence, the Imperial College has become mainly responsible to this Committee for directing the investigations. The initial research into the effects of electrical discharge on the plant is done at the College. Pot experiments with maize, barley and wheat are carried out at the Rothamsted Experimental Station. Field experiments with clover, hay, barley and winter wheat are conducted at Rothamsted, with oats at Lincluden, Dumfries, and with oats and clover hay at the Harper Adams Agricultural College, Newport, Salop.

The laboratory work at the Imperial College is an object of fascinating interest to the visitor. Young seedlings are grown in an enclosed chamber so cleverly insulated that its temperature is kept constant throughout the day. The growing tip of the seedling is subjected to a downward electrical current, kept constant by means of the most sensitive galvanometer that can be obtained. The growth of the tip is traced by means of a microscope, and readings are taken at ten-minute intervals throughout the day. The object of the investigation being conducted at the moment is to find the ideal current to apply. The maximum current-beyond which growth is adversely affected-has already been ascertained, and at present the current being used in the field experiments is about I milliamp. per acre, which is about I00,000 times as strong as that supplied normally by the atmosphere. It still remains to be discovered, however, whether a smaller current may not be equally efficient or even better.

An analysis of the results obtained in the field since I9I5 shows that with spring-sown cereals an increase of 22 per cent. in the yield, or 7 bushels per acre, has been obtained as the result of electrification. In four experiments with clover-hay, a mean increase of 20 per cent., or $3 \frac{1}{2}$ cwts. per acre, has been secured. This evidence of the beneficial effect of electrical discharge has been confirmed by the numerous pot culture experiments that have been conducted. On the other hand, 
more work remains to be done before a decision can be reached as the economic value of electrical discharge. The effect of the discharge on crops other than clover-hay and spring-sown cereals. is not definitely known, and no experience has been gained of the actual working of field installation in practical farming. Further, the period in the life of the plant when the current may be most economically applied, and the strength of current which should be used at different stages of its growth, are not yet known with precision. As regards the field experiments, the most recent development has been in the direction of testing the effect of higher wires. Hitherto the wires have been 7 feet high, and supported by numerous poles, which in practice would interfere with farming operations. In the new experiments. the wires will be $r 8$ feet high and there will be fewer poles. The difficulty in the case of field experiments is that one particular set of conditions must be kept constant throughout several seasons before a result can be relied upon, and every change in the conditions must be tested for the same length of time. Thus a set of experiments lasting through several seasons is required for each strength of current, each crop, and every change in the daily period during which the current is applied. On the other hand, there is no doubt that electrical discharge will increase plant growth, and it is hoped that it will be found possible to continue the patient experimental work that has. been going on for some years, for it seems certain that sooner or later electricity must play an important part on the farm in increasing crop production.

In the foregoing account, we have been unable to do more than refer to the main lines of research in progress at the Imperial College of Science. A number of subsidiary investigations are being conducted, but these, although important enough in their bearing on other research, are too remote from farming operations, to be detailed here. One branch of work may, however, be referred to briefly, although it is not aided from the funds of the Ministry of Agriculture and Fisheries. The Food Investigation Board of the Department of Scientific and Industrial Research have provided the means for a study of the physiological aspect of cold storage. Estimations are being made of the changes that go on in the fruit throughout the whole period of storage of different varieties of apples and pears stored under ordinary conditions and at low temperatures. These estimations. are being made in an attempt to discover the cause of the "mealiness" which develops in apples and pears stored too. long. Storing at low temperature delays the onset of the 
" mealiness," but it comes sooner or later, and the fruit is spoiled. The experiments have already proceeded far enough to indicate what are in all probability the causes of the trouble, and when this has been established it will be possible to say more definitely what is the most suitable temperature for storage, and perhaps to discover other and more economical methods of storage than that of low temperature. 


\section{CHAPTER IV.}

\section{FRUIT-GROWING AND PRESERVING.}

The main institute for research in fruit-growing in this country is the Agricultural and Horticultural Research Station at Long Ashton, attached to the University of Bristol. A second research station has been established at East Malling in Kent. Investigations into methods of fruit preserving and vegetable drying are conducted partly at the Long Ashton Institute, and partly at a station set up for this purpose at Campden, Gloucestershire. The latter station was established to continue the experimental work carried out directly by the Ministry of Agriculture and Fisheries during the War; arrangements have recently been made under which the station has been taken over by the University of Bristol so that its work may be supervised by the Long Ashton Institute and co-related with the investigations there being conducted. The present chapter will give an account of the main lines of investigation at all three centres, and inasmuch as work of this character must normally be continued for several years before results are obtained, it will be necessary to refer to the work of previous. seasons in describing experiments now in progress.

\section{Root-Stocks.}

It will be convenient to commence with some account of the investigations of root-stocks and their influence upon thetree. These have been carried out partly at Long Ashton and partly at East Malling. At the former station the study of various aspects of the root-stock question has been in progress. since its establishment in 1904, the questions receiving most attention at the outset being the possible influence of the rootstock on the quality of the fruit borne by the tree, and the vegetable propagation (i.e., propagation by layers) and comparative trials of certain selected types of "free" apple stocks. When some eight years later the East Malling station was started and a programme of work was considered, it was decided that the time had arrived for a more exhaustive investigation on root-stocks than had previously been possible at Long Ashton alone. It was recognised that the root-stock question was of fundamental importance to fruit growers, who at that time either regarded the subject with indifference or, in the case of 
the more progressive growers, had to be content with material often far from uniform and about which very little in the shape of precise knowledge was available. Instances of fruit plantations suffering from the use of unsuitable and mixed stocks were then and are still all too commonly to be found. Hence it was clearly worth while to devote considerable time, labour and land to an investigation of the whole question.

As a beginning a study of apple stocks was arranged jointly between the two Institutes, I.ong Ashton undertaking the classification of the so-called "free" and "crab" types and East Malling the "Paradise" types. As the work proceeded it became obvious that the popular conception of apple stocks was entirely misleading. In the popular mind apple stocks were of three types: (I) Paradise or dwarfing stocks with fibrous and surface roots. These were raised by layers, and were suitable only for bush and garden-trained trees. (2) Free or strong growing stocks raised from seedlings of various sorts, mere chance crosses, suitable for standard trees and weak-growing varieties. (3) Crab stocks raised either from pips or suckers of the "True Wild Crab," supposed to be especially hardy and suited to the same purposes as the free stocks. Both the free and crab stocks were reckoned to be deeper and coarser rooted than the Paradise. For the investigations at Long Ashton and East Malling, many thousands of stocks have been obtained from nurserymen and others in this country and from other parts of the world, and have been closely studied and classified. Briefly, the work on Paradise stocks shows that there are eight or nine types of so-called Paradise in fairly general use in this country, that the strong and weak types are frequently badly intermixed, and that the names are interchangeable and inaccurate. The types range in vigour from the true Broadleaved English Paradise, strong and vigorous enough for orchard standards in many soils, to the true French Paradise, which forces Bramley's Seedling in the second year from the graft into copious fruiting. It was found that even stronger types than the Broad-leaved were in use on the Continent, and these appear to be as vigorous and well-anchored as any so-called " crab." Similarly in the case of free and crab stocks, there is no marked distinction between these two trade divisions in root character, but they include a range of root systems and vigour. similar to that obtaining in the case of Paradise stocks, but with even more extreme variety.

Now whereas Paradise stocks are raised vegetatively, and any particular member of the series can be reproduced by that method again and again, free stocks are normally raised from 
seed, and hence show an infinite variety and inequality, while true crabs, which are the chance progeny of wildings, show as great a variation as free stocks. Although vegetative propagation is a little more laborious and expensive than propagation from seed, it is probably amply repaid by the certainty of producing stocks true to type. From that point of view this method is much to be preferred, provided a range of stocks capable of vegetative propagation can be secured suitable for all the needs of the fruit grower, and no deterioration occurs as the result of such propagation continuously repeated. This is the main problem which the East Malling station has set itself to solve, and already with considerable success. From the vast array of Paradise stocks collected and examined at the station it has been possible to make a classification into four main groups $(a)$ very dwarfing, $(b)$ semi-dwarfing, $(c)$ vigorous and $(d)$ very vigorous, which between them will, it is believed, fulfill all the requirements of the apple-grower. It has been shown that by " working " a single variety upon representatives of these four groups, not only is it possible through root influence practically to secure trees with double the vigour of others of the same variety as demonstrated by wood growth, but also to produce a remarkable change in the relation between wood growth and blossoming. A single variety worked upon the very dwarfing group has averaged one fruit bud to each 2 inches of new wood growth, whilst at the other extreme the same variety averaged one fruit bud to each $\mathrm{I} 6$ inches. The classification has, of course, been based mainly on the experience gained under the Malling conditions of soil and climate, and must be tried under other conditions before it can be put forth as of general application. Duplicate trials have therefore been planted out in Kent, Surrey and Sussex on five different types of soil, and stocks have also been supplied to county experimental stations, Agricultural Colleges, etc., in all parts of the country, so that a thorough and exhaustive test of the results obtained at East Malling is in progress.

While East Malling has been arriving at these conclusions, viâ the Paradise stock route, Long Ashton in turn has reached substantially the same point from the free and crab stock direction, and it has been found that for general purposes free and crab stocks can be graded into similar classes to those already indicated for the Paradise forms. This grading is, however, based mainly on a consideration of root growth, and until further investigation has thrown more light on the inter-relations between the root and branch systems of a tree, it would be premature to suggest that on the basis of such classi- 
fication it will be possible to raise trees of any desired degree of vigour. In the case of seedling stocks future practice will turn upon this point. If drastic or " selection " grading of the stocks according to the nature of the root system is sufficient for the production of trees of uniform standard, the more expensive method of stock production from layers may not be required for the stronger types. For the more dwarfing types it will still be wanted, because the percentage of seedling stocks of this nature is too small to meet requirements. If, on the other hand, "selected" seedling stocks of the stronger types prove too variable in respect of the trees produced, vegetative propagation of suitable individuals will be needed to ensure uniformity, in so far as it is possible for the root system to accomplish it. There will be no difficulty over the propagation of free or crab stocks by the layering method, for it has already been proved that many of them can be multiplied in that way, and in that sense they rank with the Paradise forms.

From the foregoing it is obvious that the old classification of apple stocks into Paradise, free and crab is meaningless and misleading as an indication of vigour and root character, and that, so far as methods of propagation are concerned, "frees" and " crabs " can be multiplied vegetatively in precisely the same manner as "Paradise." Confusion would in future be avoided if the terms "free" and "Paradise" were dropped, and the stocks designated according to grades of strength and method of production, "layered " or "seedling," as the case might be. There is something to be said for the retention of the term "crab," as indicating an origin, ultimate or direct, from " crab" apples; but even in that case the distinction is of doubtful value, since existing " crab " apples are wildings of hybrid character, and several of the cider varieties from the seed of which free stocks are raised are substantially of the same order.

The above record of research into root-stocks has been confined to apples. Similar work is also being done at East Malling in the case of stocks for other kinds of fruit, although the investigations have not proceeded far enough to enable such definite conclusions to be drawn. So far the larger share of attention, next to apples, has been devoted to stone fruit, and it has been shown that in the case of plums some eight or nine types of stock, comprising at least three species of plum, are being used almost indiscriminately to-day for bush or standard fruits. There are, for instance, at least four distinct types of " mussel " plum stock, varying considerably in vigour and differing in ease of 
propagation. All these plum stocks have been classified and selected, and the first considerable trial plantation was planted out about two years ago.

While the main interest in the work at East Malling, from the point of view of practical results, has naturally centred round the enquiry into root-stocks, other fundamental problems affecting fruit-growing are not being neglected. Such questions as root influence with regard to effect upon disease, the functions of different types of roots, comparison of budded with grafted trees, effect of depth and method of planting and treatment of soil on roots, methods of vegetative propagation, and so on, are being studied simultaneously or in connection with the stock classification work. Further, important work in connection with the breeding and trial of new varieties of hops, with special reference to aroma, resin content, fruitfulness, extension of season and resistance to disease,* has been in progress since I9I7 under the direction of the Advisory Mycologist attached to Wye College, and some promising new varieties have been secured. Under an arrangement made with the Imperial College of Science, a physiologist is attached to the station, and his researches are at present largely concentrated on finding out exactly how it is that the root-stock has so much influence on the tree, with a view to establishing guiding principles for the best possible selection of stocks.

\section{The Root.}

During the progress of research in fruit culture it has become increasingly evident that the well-being of a tree is influenced primarily by the behaviour of its root-system. If it is to lead a healthy existence and produce profitable crops, its roots must be able to function satisfactorily and be kept throughout life under the best conditions. Relatively little is known on the subject of root-action, and the Long Ashton Institute has therefore set itself to find out the conditions that promote healthy root-growth. Since fruit trees invariably have to be transplanted from the nursery quarters where they are raised into their permanent position in the orchard or fruit plantation, the enquiry was begun by an examination of root behaviour following transplantation, combined with which was a series of experiments to test the effect of various methods of root treatment at the time of planting. The re-establishment of the root-system after planting is, of course, a critical factor in the life history of the tree, and it may well be that the future fate 
of the tree is largely determined by the manner and rate of its recovery after the shift.

Apple trees worked on the Broad-leaved English Paradise stock have been selected for this investigation. A plantation of such trees, one to three years old from the graft, was established in I920, the trees being grouped into permanent and temporary sets. The temporary trees are to provide material for direct observation of root growth. There are I50 of these in all, which it is proposed to lift and examine at the rate of 30 a year. The planting of the trees has been so arranged that the different annual stages in the development of the root-system can be followed in detail without disturbing the permanent trees. The latter, of which there are I5O also, are to serve to indicate the nature of the correlation between the growth of the root and that of the branch system of the tree. Shootgrowth in relation to root-growth will thus be followed stage by stage. Concurrently with these trials in open ground, two somewhat similar trials were conducted with smaller numbers of trees in pots, one group being planted in sand and the other grown in water.

As the experiment has not yet concluded its second year, the main results so far obtained are limited, of course, to the question of the effect of treatment of the root-system at the time of planting. It should be explained that it is a generally recognised maxim amongst fruit-growers that when a tree is transplanted great care should be exercised to ensure that its root-system - which is the source of food supply from the soil to the tree-is damaged as little as possible, and that the fibrous roots are preserved. Clearly this is a point of practical importance, for the existing belief implies a great expenditure of time and labour in lifting, packing and planting trees. The results of the Long Ashton experiments show conclusively that in the case of trees worked on freely-rooting types of apple stocks, such a measure of care in the treatment of the root is unnecessary, at any rate under conditions approximating to those at Long Ashton; for the existing root-system will play practically no part in the further growth of the transplanted tree, which will develop a new root-system independent of the old. In the experiments, the root-stocks, before being transplanted, were treated in various ways. With some, great care was exercised, according to established custom, in retaining as much fibre as possible; in others, all fine fibrous roots were removed; in others, all fine fibres and also all the coarser lateral roots were removed, leaving only the central stump. The results showed that in all cases of the trees grown in the Long Ashton soil, 
whatever the original root treatment adopted, a complete new root-system was formed in the "collar" region of the tree, just below the surface of the soil. In sand (with excellent conditions of aeration) all parts of the root-system gave rise to an abundance of new roots; and in water culture (with bad conditions of aeration), while the same thing happened at the outset, the trees rapidly became unhealthy, new root formation ceased, and death in many cases resulted before the end of the summer. While these results must at present only be considered as applying to trees worked on root-stocks which produce fibrous roots freely, it appears obvious that aeration is one of the primary factors in influencing the production of new and healthy roots, and that, given aeration, a root-system of the type indicated which has been severely handled before replanting will not adversely affect the further growth of the tree, provided the "collar" region is not damaged. Before planting fruit trees, therefore, a grower should make sure that his land is well drained and well cultivated. The better the tilth, the better the aeration of the soil from above, and the more healthy are the trees likely to be.

In a further investigation an attempt was made to trace the course of development of the root-system of a plant throughout the growing season. Two series of experiments were carried out, but a description of the method employed would involve the introduction of technical terms which might be confusing, and we will, therefore, refer only to the results obtained. It was found that there are certain periods during the season which are marked by a distinct speeding up of root-growth, and that these periods appear to be closely related to the amount and distribution of organic food reserves within the tree. The beginning of the growing season is marked by a vigorous root development, which seems to coincide in point of time with the circulation of the reserve food material which was stored in the tree as the result of the previous season's growth. When these reserves are exhausted-the plant then being dependent in respect of new growth on organic food manufactured in the leaves-the shoot portion, being nearest to the source of food (the leaves) apparently gets the first call on supplies, and the tendency is therefore for shoot-growth at that period of the season, namely, at midsummer, to outstrip root-growth. This state of affairs is soon followed by a period when the roots are Fresumably unable to supply sufficient sap for the manufacture of material for the maintenance of such a vigorous shoot-growth; at any rate the latter is slowed down, and root formation again sets in, seemingly because food reserves have again had a chance to accumulate and circulate to the root. 
These results have so far been obtained for one season only, and need confirmation. Further trials on the same lines will be carried out this year, and, if possible, they will be supplemented by actual analysis of different parts of the trees. Recent American work has shown the close connection between the food reserves in the tree and fruit bud formation, and it is evident that investigations in these directions will lead to knowledge on which can be based methods of manuring, pruning, and other cultural forms of practice founded on sound scientific principles.

The results just recorded appear to have significance in connection with the peculiar complaint of fruit trees known as "leaf scorch," now being investigated at Long Ashton. This affects orchards largely on certain soils, where for reasons hitherto unexplained the leaves develop a brown dried margin which gradually extends until the whole leaf may die. This occurs normally in early summer. In bad cases the tree may be practically defoliated, thus seriously affecting the food supply for the following year's crop, and the general health of the tree. The disease is not caused by an insect or fungus pest, but may be associated with an extreme of the "unstable" midsummer condition referred to in the preceding paragraph. It is found that many "scorching" soils have one feature in commonthat in the drier period of the season the water supply tends to be relatively deficient as compared with non-scorching soils. Further, the root systems of trees on "scorching" soils are usually of a distinctly inferior character, in that the roots are not well developed and there is a relatively small amount of fibrous root. Thus in summer, when transpiration is most active, the tendency will be for the water supply to the leaf to be seriously reduced, a condition which seems to favour the initial stages of "scorching." We have seen that it is about this time that root development begins to slow down in relation to shoot development. In the second half of the summer, in " scorched "trees, there is a new leaf development; this corresponds to the time when-as shown in the experiments-root development has again become active. Thus the results obtained in the experiments seem to be strikingly co-ordinated with the observed facts regarding "leaf scorch." (Experiments on "leaf scorch" are also referred to on page 63.)

\section{Treatment of the Tree.}

So far this record of the work of the Stations has taken account only of those questions directly concerned with root action, and the underlying suggestion that the vigour of growth 
of the tree is due in part to the nature of the root-stock and in part to the influence of various conditions on root-growth will probably have been apparent. That the size of the tree is determined to a large degree by the root is evident, but it must not be assumed that the growth of the tree is regulated solely by the nature of its root system. Reciprocal action between the parts of the tree above and below ground is always in progress, and the root itself is just as dependent for growth on material supplied by the stem and branch system as the latter is on the root for the crude food materials absorbed from the soil. It is thus possible to produce a dwarf form of tree on a strong type of rootstock by various methods of control of the stem portion of the tree. As an extreme example, the practice of " ringing," to which reference will be made in due course, may be quoted. A less drastic method, capable nevertheless of producing quite pronounced results, has come under observation at Long Ashton during the course of investigations on the influence of intermediate stocks. As is well-known, the use of the intermediate stock is frequently necessary in the case of pears grown on the quince root-stock, and in the case of apples, although normally the required variety is grafted direct on the root-stock, occasions arise-particularly in connection with orchard renovation-when the graft is made on an intermediate stock. The earliest series of experiments, commenced in I904, while not showing any clear evidence that the intermediate stock affected the quality (flavour, size, keeping powers, etc.) of the fruit, except possibly as regards size, have demonstrated that the stronger intermediate stocks give rise, as a rule, to distinctly more vigorous trees than the weaker. To confirm this result a second investigation was commenced in I9I4. The results suggest that the intermediate stock exercises a dwarfing effect on the growth of a tree if a stronger variety is worked on it, but a stronger intermediate stock does not increase the growth of a weaker variety. So many complicating factors occur in experiments of this nature, however, that confirmatory evidence from further trials must be forthcoming before these conclusions can be considered established.

The work on "ringing" has been done at the Long Ashton Institute. It was realised that fruit-growers were under a great disadvantage in having no means of preventing a tree from making excessive wood growth, other than by omitting to prune or by withholding manure. Neither method is satisfactory; the first results in the flowers developing high up in the tree, and under some conditions the formation of extensive bare branches, while the second starves the tree. It is possible, by careful root pruning, to prevent excessive wood growth and throw the tree 
into flower, but this method is too expensive to be practised on a large scale. For the last four years, therefore, the Institute has been investigating the practice of " ringing," which consists in removing a narrow ring of bark from the main stem of the tree. Under this treatment the growth of all the shoots of the tree above the ring is checked; consequently many buds that would otherwise have formed twiggy shoots make short spurs crowned with flower buds. Another result from "ringing," to which attention does not hither to appear to have been paid, is observed below the ring, where buds which would otherwise remain dormant are stimulated into growth. This observation has led to the development of a method by which dormant buds in any position on the tree may be forced into growth. It is well known that many varieties are in the habit of producing considerable stretches of bare wood, which may now be remedied by making a knifeedge " ring " around the shoot immediately above the dormant area. These results are of direct practical importance, and enable the fruit-grower to increase in a simple and inexpensive manner the number of fruit buds on trees which have hitherto been deficient in that respect. The practical aspect of the investigation is now approaching completion, but many suggestive points have been raised during its course, and they appear sufficiently promising to justify its continuance and extension.

Experimental work on pruning is in progress both at Long Ashton and East Malling. At the former Institute, the possibilities of summer pruning have been explored, and particular attention has been given to the Lorette system of pruning advocated on the Continent. The experience of the past five years has shown that considerable modifications are necessary to enable growers under English conditions to secure maximum results with least expenditure. It has now been possible, as the result of the investigations on various factors influencing fruit bud formation, to formulate a scheme of treatment designed to replace the somewhat indefinite methods of pruning hitherto practised, and promising to give the grower a very great measure of control over the crop-producing capacity of his trees.

At East Malling the work is confined to endeavouring to improve established methods of winter pruning through a detailed study of the habits of growth of different varieties, and has reached a sufficiently advanced stage to be referred to in more detail. The experiment had its origin in a visit paid to the Station by a number of Kent fruit-growers about six years ago. They found that the methods of pruning adopted in various districts differed widely, and wished the Station to conduct comparative trials. A 3-acre plantation of trees of I5 commercial varieties, 
which had been planted as "maidens" and cut hard for about two years after planting, was chosen for the experiment, and the growers recommended (on the basis of their existing practice) three different types of pruning, leaving one row of trees uncontrolled. Without going into details regarding the methods of pruning employed, it may be said that three essential facts have emerged from the results of the trial up to date.

The first and most important is the absolute necessity of adapting methods of winter pruning to the natural habit of the variety. Differences in varietal habit are so great that no rule of thumb method is equally applicable to all varieties, and although certain groupings of varieties according to habit of growth and fruiting have been indicated and are being worked out in greater detail, it is scarcely too much to say that no two varieties can satisfactorily be treated alike. If, for instance, two well-known commercial varieties, Worcester Pearmain and Newton Wonder, are taken, it is found that the method of pruning adopted must have regard to the ready formation of natural spurs on the Newton Wonder and the almost exclusive tip bearing (when young) of the Worcester Pearmain.

Secondly, the problem of pruning a temporary tree designed for quick cropping should be approached from a different standpoint from that of the long-lived permanent tree. In very many cases growers have pruned these temporary trees far too drastically.

In the third place it has been found that profuse blossoming does not necessarily lead to fruit in proportion. Pruning may actually reduce blossoming, but at the same time improve the setting of the blossom; so much so, that under conditions at East Malling, the pruned Newton Wonders, though producing far less blossom than the unpruned, have actually over a series. of four years, produced more fruit of considerably better quality. The work is considered so promising as to justify an extension to demonstrate the best methods of winter pruning for each variety and purpose.

As in most descriptions of research work, a bare narrative of results gives no clue to the amount of labour and care involved in obtaining them. The Malling pruning trial affords a good illustration of this point. The experiment has lasted for six years, and during the last three an enormous number of records have been taken, including, for every tree, the number and weight of fruit (including dropped fruit); the number and weight of scabbed fruit, if any; the number of fruit found in 2,3 and 4 in a bunch; the number of blossoms; the kind of blossom (spurs, terminal or axillary); the height and spread of tree; girth of 
trunk; and the weight of prunings. To the ordinary reader some of these points may appear to be hardly of sufficient importance to justify such a large expenditure of labour, but the scientist knows only too well that if his results are to be of general application and unquestioned utility, all avenues of information must be explored, and every loophole for error must as far as possible be closed.

\section{Manuring.}

Having now arrived at methods which can give the grower control of flower formation, which may be regarded as the first step on the road to crop production, it remains to be learnt what is the maximum crop which a tree is capable of carrying, and how flower formation can be translated into crop production. This leads naturally on to questions affecting the nutrition of the tree, among which those concerned with manurial treatment occupy a prominent place. In this country it is a recognised practice of all our prominent fruit-growers to apply heavy dressings of fertilisers on their plantations, and large sums of money are spent annually in this way. It is not surprising therefore to find that the advice of the technical horticulturist is often sought on the subject of the manuring of fruit crops, and in giving advice the latter is in a much less fortunate position than the agriculturist, inasmuch as the results obtained in previous experiments on the manuring of fruit crops have beeen very inconclusive and in many cases entirely contradictory. Most of the experiments on this subject have been carried out in America, where climatic conditions, methods of cultivation, etc., are admittedly very different from those obtaining in this country, and it is doubtful whether the results secured would in any case be applicable to the conditions existing here.

At Long Ashton, it has long been felt that the need for definite information on the effects of the various constituents of manures on fruit trees, bushes, etc. is very great, and experiments have been commenced recently to study these effects. The preliminary work is being carried out with pot cultures of trees, bushes, and plants in order that the conditions of experiment may be more strictly controlled, and the observations made in greater detail than is possible under field conditions. The object of the series of experiments now in progress is to ascertain the effects of omitting the various chemical constituents of a complete plant food from the diets of apple trees and strawberry plants grown under the conditions described above. In order to accomplish this end, batches of apple trees and strawberry plants have been 'divided into several series, one series of each being fed with a 
complete nutrient solution, other series being fed with nutrient solutions from which one of the following has been omitted, viz., nitrogen, potash, phosphoric acid, calcium, magnesium; whilst one series of each receive rain-water only.

As the experiments have been in progress over one season only, it is undesirable to refer in detail to the interesting results that have been obtained, which require confirmation before definite conclusions can be drawn. As regards the apple trees it may be said, briefly, that detailed observations have been made regarding the character of the leaves in the several series, the time of fall of the leaves, the length of total shoot-growth made during the season, the appearance of the barks of the trees, and the development of the root systems. The question of liability to leaf " scorch" has received special attention. It was shown in the case of the apple trees grown in sand that leaf " scorch" developed when the trees were fed with a complete food solution. "Scorch" did not develop under similar treatment when soil was used in place of sand. Further, the amount of leaf " scorch" was greatly increased when potash was omitted from the nutrient solution and slightly increased when magnesium was omitted. The omission of phosphoric acid and calcium tended to mitigate " scorch." No leaf " scorch" was developed on any tree in this experiment when fed with a nutrient solution from which nitrogen was omitted or when treated with water only. Further experiments carried out on broad beans indicated that bright sunlight favours the development of leaf " scorch."

At East Malling field manurial trials with Black Currants, true to name, have been in progress for seven years. The primary object was to test the effect of quantities of dung alone, and dung with the addition of artificial potash and phosphates, upon the setting and weight of fruit. Very definite results have shown that under these soil conditions comparatively generous dressings of dung annually have nearly quadrupled the crop as compared with the untreated plot. The additions of potash and phosphates have yielded quite negative results. These experiments are now in course of repetition with another variety and upon more extensive lines, the main object being to test the value, compared with dung, of various other organic and largely nitrogenous manures.

\section{Fruit Breeding.}

Simultaneously with the research going on in various directions. to find out the best method of dealing with varieties of fruit already in existence, an effort is being made to raise new varieties of the different kinds of hardy fruits, which will possess the 
necessary commercial qualities and will provide the grower with suitable sorts to cover the whole season. At present he has a wide choice, but relatively few varieties possess the combination of characters entitling them to rank as first-rate commercial sorts, and these only provide supplies for a portion of the season. Apart from the general points, such as heavy cropping power, good flavour, etc., which apply to all fruits, specific qualities are aimed at in particular kinds. In apples, pears and plums, for example, late-blossoming varieties, which run less risk of injury from late frosts, are desired. In apples, particularly, the grower wants varieties that will fill up the gaps at present existing in the seasonal output, especially late-keeping sorts. The Station is endeavouring to combine the cropping qualities of some of the more prolific cider apples with the flavour of market varieties. Resistance to disease is kept in view, e.g., canker in apples, silver leaf in plums, scab in pears, mildew in gooseberries, \&c. As regards soft fruits, varieties which will preserve and bottle well are needed, and there is ample room for late and early kinds, which would extend the present very short season.

Breeding work, especially with such fruits as apples, is necessarily slow in yielding results; but a number of apple trees which have been raised as the results of crosses made in the earlier years of the work are now bearing crops, and some information regarding the inheritance of chemical characters of the fruit has been obtained. When dealing with soft fruits more rapid progress is possible, and promising seedlings of strawberries, raspberries and black currants have already been selected and are being propagated for further trial on a larger scale. Breeding work with tomatoes is also yielding encouraging results more quickly. Although particular attention is being paid to the selection of good varieties of fruit obtained as the result of crossing, yet at the same time as many observations as possible are being made with the object of tracing the inheritance of various characters. Information so gained should be of considerable value in the future when endeavouring to attain desired combinations of qualities by crossing.

While this account of the research work on fruit culture has been devoted primarily to the investigations on tree fruits, it should be stated that the problems arising in connection with the culture of soft fruits are not being neglected by the Institutes. For the most part the subjects being dealt with have chiefly to do with manuring and pest control, and are hardly advanced enough to require detailed notice ; but at Long Ashton an investigation of considerable possibilities dealing with the fertility of strawberry plants calls for passing mention. A few years ago 
it was demonstrated there that plants of the Royal Sovereign variety obtained from different districts varied to a very marked extent in cropping power. A repetition of the trials gave very similar results, and it appears, therefore, that a strawberry runner at the time of planting in its permanent position possesses within itself a definite tendency towards high or low cropping capacity. Whether it is a case of a definite "strain " of the variety, or whether cropping power can be affected by treatment of the runner itself prior to planting, or of the mother plant, are questions of which a solution is now being sought.

\section{Cider and Perry.}

A feature of the work at Long Ashton is the investigation of problems connected with cider and perry making, for which purpose, indeed, the Institute was originally primarily established. Cider and perry are the expressed and fermented juices of apples and pears respectively, and of the two, cider is, of course, much the more widely used. With the exception of a few large firms and a certan number of small makers, the manufacture of cider is in the hands of farmers. Whereas some farmers turn out very good cider, this is far from being the rule, and a much too large proportion of cider apples are turned into a sour and, for the normal palate, unpleasant drink, which can only be enjoyed by those who have been accustomed to it from childhood. Probably at least 75,000 acres are devoted to the culture of cider and perry fruit in the West of England, and there is thus plenty of room for an Institution like Long Ashton, which makes it part of its business to investigate methods of growing cider apples and of their manufacture into cider, so as to be in a position to help the farmer to make the most satisfactory use of his crop.

The chief features of the work may be condensed into a few sentences. Systematic trials of varieties of apples and pears grown in the farm orchards of the West of England, which after preliminary examination appear to possess vintage value, are made regularly, and these trials are supplemented by others in which continental varieties of vintage repute are tested as opportunity arises. The most promising of these are then selected for propagation in the nursery at the Station, and the trees thus raised are ultimately distributed through the county councils associated with the Institute to form trial orchards under different conditions of soil and situation. In this way information is being obtained as to the kinds of cider and perry fruit which are most suitable to grow for vintage purposes, and as to the effect of soil and other local conditions on the quality of the fruit and the growth of the trees. The methods of making 
cider and perry, of controlling fermentation, and of blending have been closely studied, with the result that, so far as seasonal influence permits, it is now possible to produce with reasonable regularity and uniformity any standard type of cider and perry desired. The various disorders to which these beverages are liable have been investigated, and in most cases methods of prevention have been discovered.

\section{Fruit and Vegetable Preservation and Storage.}

We may now consider what is being done to ensure that the final product of the fruit-grower is used to the best advantage; and here the problems with which a Research Institute is faced relate mainly to the storing of the fruit, so that it may be put on the market-either in its fresh form or as jam or other preserve -when there is no glut and consequent reduction in price. At present the grower is at the mercy of the market, and continually runs the risk of a sudden fall in prices, which may make all the difference between profit and loss on the year's labours. A few years' patient research in the laboratory-the expenditure of a few hundred pounds in salaries and apparatus-would surely be amply justified if as the result the grower could withhold his fruit from a glutted market, and send it out later on when prices would bring him a profit instead of a loss. The problemhow to prevent an apple from rotting-is less simple than it ajpears. The foundation of future work must be laid in an accurate knowledge of the chemistry of the apple, and of the gradual changes that take place within the fruit during the ripening period. Unfortunately our knowledge on this subject at present is very meagre, and limits not only the investigation of methods of storage but research into apple diseases, cidermaking processes, \&c. It is beyond the scope of this book to record the abstruse chemical examination of the apple now in progress at the Long Ashton Institute, but a few remarks may not be: out of place as showing the stage which the work has reached in one direction. Broadly speaking, the changes occurring in the fruit during ripening, and leading up to the rotting of the fruit, are very marked in the case of the group of jelly-forming compounds known as pectins. The unripe fruit contains a pectin compound in an insoluble form; during ripening it is converted by stages into pectin which is soluble. This change is an important feature of the ripening process, and it is necessary to hinder or delay the conversion of the insoluble pectin compound into the soluble pectin in order to delay ripening, and therefore rotting. Clearly, therefore, one object of research is to discover accurate methods of finding out the stage to which this con- 
version of insoluble pectin compound into soluble pectin has reached. Two such methods have been recently worked out, and there is good promise that they may be found to answer all requirements of the chemist, and thus facilitate considerably the investigations into methods of storage. The pectin content of the apple is, however, influenced by a number of factors, and an intensive study of them is necessary in order to find out the best conditions for the preservation of the fruit in cold storage or by other methods. It may here be stated that under an arrangement with the Department of Scientific and Industrial Research a cold store has been installed at the Institute, and in that are being conducted experiments on methods of storage of fruit at low temperatures. This subject of cold storage is also being dealt with at the Imperial College of Science, London, and the work there is briefly mentioned in the chapter on Plant Physiology.

Investigations into methods of fruit and vegetable preservation are conducted at the Experimental Station at Campden; but research at this centre has only lately become possible through the establishment of a small laboratory at the Station within the past year. The main problems which have been undertaken within this short period have dealt with the commonest type of preservation, i.e., jam-making. In this connection, special attention has been paid to certain points which are of paramount importance in the making of a good and economic preserve, namely, the minimum sugar content required, the obtaining of a "set" or gel, and the retention of flavour and colour. It is not generally known that there are three essential features necessary in order to obtain a good preserve with sufficient "set" to overcome an often noticed " runny" conditionusually very difficult to counteract in certain varieties of fruits; or alternatively, to prevent crystallisation of the sugar at the surface of, and sometimes right through, the jam. These three essentials are pectin, acid, and sugar, in the correct proportions. Most fruits contain some of each, but by no means always in the proportions essential to a successful result. Data are gradually being built up at Campden which should throw considerable light on this hitherto little-known subject.

In regard to the retention of flavour, much work has yet to be done, but it may be mentioned that the flavours contained in the different fruits are extremely volatile, especially under the application of heat. The necessity therefore arises for the improvement of means whereby this volatile flavour can be prevented from escaping in the large proportion usual under ordinary conditions of preserving, and this point is under investigation. The question 
of colour retention has been studied in some detail. It has been discovered that preserves heated above a certain degree rapidly change colour. In the case of the majority of green fruits, this change is to brown. Investigation into methods of prevention have already yielded satisfactory results, and data will shortly be available in this direction.

Preliminary investigations have also been carried out in reference to crystallised fruits; the bottling of fruits-the uses of syrups in this connection; and the prevention of fermentation and putrefaction.

Another side to the Station's work is that of education. It is the chief centre from which information on the most improved methods of the preserving of fruit and vegetables is obtainable. Courses of instruction are given to meet the needs of the general public, and also those of Domestic Science Teachers; the latterwho come from all parts of the country-attend a special Course provided for them each year. This special Course is the only one of its kind available in this country.

The above is a brief account of the main results of recent research work at the three Institutions concerned, but it is not complete, for it omits the important investigations into fruit tree pests which have been carried out at Long Ashton and East Malling. For the sake of uniformity, however, these have been reserved for consideration in the next chapter, which is devoted to the subject of plant diseases. 


\section{CHAPTER V.}

\section{PLANT DISEASES.}

The importance of extended and continuous research into the numerous pests which annually take such heavy toll of the farmer and gardener needs no emphasis. This chapter will therefore be confined to a brief account of the steps that are being taken to deal with the problem, and in the first place an outline of the general scheme in operation in the country may be given. An Institute for Research into Plant Diseases has been established at Rothamsted, its primary purpose being to study fundamental principles which affect more or less the whole realm of plant disease investigation. In addition, it may study groups of pests, such as the Aphids, which attack most crops to a greater or less degree. Normally, however, research into specific pests-which are often especially prevalent in certain well-defined areas-devolves upon the Plant Disease Advisers attached to Agricultural Colleges and University Departments of Agriculture. These Advisers, in the course of their work amongst farmers and gardeners in their areas, are brought into direct contact with the diseases causing most damage, and in so far as the limited time at their disposal permits they investigate the diseases and attempt to devise methods of prevention and cure. The Research Institute and the Advisers work in conjunction with the staff of the Ministry's Pathological Laboratory, which forms a " clearing house " for all questions relating to insect and fungus pests. These three units, with the addition from the administrative point of view of the Ministry's Horticulture Inspectorate, form the Plant Disease Service of the country. Pests affecting glasshouse crops, such as cucumbers and tomatoes, are investigated at the Cheshunt Experimental and Research Station (Nursery and Market Garden Industries' Development Society, Ltd.). This Station is situated in a district containing approxi. mately $I, 000$ acres of glasshouses, and its research work on the cultivation and manuring of tomatoes and cucumbers, and the pests to which they are subject, is, we believe, much appreciated by the growers in the locality, and its influence is extending elsewhere. Finally, where a disease is causing widespread damage and its investigation is a matter of time and expense beyond the scope of an Adviser, a grant of money may be made to enable a specialist at some other centre to prosecute the necessary research. 
In practice the scheme is not quite so clear-cut as might be inferred from the above outline. The Research Institute has only been recently established, and fundamental problems such as fungicides, insecticides, sulphur washes, \&c., have been attacked at several. centres. Further, owing partly to the scarcity of plant pathologists and partly to shortage of funds, the scheme towards which the Ministry is working, under which Advisers in both insect and fungus pests would be stationed at each of the provincial Agricultural Colleges, is at present only partly in operation. In due course there is no doubt that men with the requisite agricultural and scientific qualifications for competent plant-disease investigation will be available, and it is to be hoped that funds will be forthcoming to enable the scheme to be completed, for insect and fungus pests cause such serious damage, and often spread so quickly from district to district, that no scheme of control can be said to be efficient which does not provide for a network of research workers spread over the country.

\section{Diseases caused by Fungi or Bacteria. \\ Rothamsted Experimental Station.}

Fungi and Alga in the Soil.-An important investigation in progress at this Institute consists in an intensive study of the microscopic fungi and algæ present in the soil. The soil teems with living organisms, and our knowledge of it will not be complete until we have accurate information regarding these organisms - what they are, what is their relation one to another, what is their effect upon the soil and upon plants growing in the soil, how they are affected by the cultivation of the soil, and the application of manures, and so on. This has already been noticed in the discussion of the enquiry into the microorganisms, bacteria and protozoa, present in the soil, described in the first chapter (see page 9). In addition to bacteria and protozoa the soil contains numerous species of fungi and algæ, and many higher forms of life such as insects and earthworms. The last-named group is being studied by the Entomological Department and will be referred to later. The fungi and algæ -with which this section of the chapter is concerned-are studied in the Mycological Department.

The first stage in the work consists in taking soil samples at varying depths from fields which have been subjected to known manurial treatment. The minute algæ and fungi which exist in enormous numbers in the soil are then separated out and grown in suitable food solutions, so that each type may be 
studied separately. Great difficulty is experienced in isolating some of the types and growing them on for further study, and laboratory methods to overcome this trouble are being devised. It is also difficult to estimate accurately the relative prevalence ot the various types, and here again methods are being worked out. One important aspect which is kept prominently in view is the part which algæ and fungi respectively play in connection with the accumulation of nitrogen in the soil. The question of disease is also of the greatest importance. So far as is at present known, no green soil algæ cause disease, and probably some of the types are very useful in the soil. Many soil fungi, however, are known to cause destructive diseases, and an attempt is being made to find out which types are harmful and which are helpful, and what are the conditions under which the former can operate. This will lead up to methods of encouraging those which are helpful and eliminating the harmful.

Possibility of Change in Fungi and Bacteria.-A second line of investigation arose out of a study of one of the commonest and most destructive fungi, Botrytis cinerea, in which it was found in one instance that instead of the reproductive bodies being of the usual black colour, part of them were black and part white. This is the only known instance of white reproductive bodies having been produced by this fungus, and it opens up a considerable field for enquiry; for if fungi have the power, so to speak, of changing their colour, their capacity of attacking plants may also be changed. In other words, a fungus which is now able to attack, say, the potato, and cause a disease, might become changed in nature so that it could attack not only the potato but certain other plants. The change observed in Botrytis may prove to be an entirely isolated case, but the question is in urgent need of further enquiry. Certain destructive species of bacteria and fungi are therefore being grown and studied; in each case, some colonies are kept under constant conditions and others are subjected to continually changing conditions, so that every opportunity is offered to the fungi or bacteria to alter their character. If any such alteration takes place, its nature will be studied, to see whether it extends to the power of the organism to attack its normal host plant, or gives to it the power of producing disease in crop plants previously immune. Just how far its powers may thus be modified is an important question.

The Basis of Spraying.-Another investigation deals with the fundamental nature of spraying. At present a farmer or fruitgrower often sprays in order to kill fungi; but no one knows exactly how or why the fungi are killed, and until this information 
is available our knowledge of spraying must necessarily be empirical and little real progress can be made. The work naturally takes time, but the twelve months so far devoted to it have thrown much light on the fundamental nature of the disinfection process. The object is to find out exactly what happens when the poisonous substance actually meets the fungus spore; what are the effects of varying external conditions; what strength of solution is required under particular conditions; how many spores are killed and in what time, \&c. The fungus so far used has been Botrytis, and the work is now being extended to include killing by heat as well as by poisonous re-agents.

Wart Disease of Potatoes. - This disease is so widespread and disastrous that a special grant for its investigation has been made by the Ministry to the Rothamsted Institute. The question is being attacked in various ways at several centres; at Rothamsted, prevention by means of soil sterilisation is the main subject of study. The necessary field and glasshouse trials are being carried out at the Potato Testing Station at Ormskirk and at Rothamsted. A wide range of poisons and other sterilising agents are being tested, to find out their effect upon the wart disease fungus in the soil, the object in view being to discover some economical treatment which will kill the fungus without adversely affecting the soil. In this connection it is important to have rapid laboratory methods for examining the soil and finding whether or not the fungus has been killed. The present methods are being improved upon, thus speeding up the work ronsiderably. Experiments are in progress to see how far the progress of the disease is affected by such factors as the age or size of seed, time of planting, conditions of the weather and soil, manurial treatment, and so on. The question of a possible "alternative host" on which the fungus may spend part of its life history is also being examined, for the fungus has been found on tomatoes and woody and black nightshade. A further very important aspect which is being actively studied concerns the nature of immunity from and susceptibility to the disease, and the differences in quality, \&c., which exist between immune and susceptible varieties.

The above indicates briefly certain of the main lines of work on fungi and algae in progress at the Institute The question of insect pests is dealt with by another Department of the In stitute, and before dealing with it we will refer to the investigations into fungus diseases which are taking place at other centres. 


\section{University College of North Wales, Bangor.}

Finger and Toe in Swedes.-This disease is widespread and serious throughout North Wales. Carnarvonshire, the hill districts of Denbighshire, and the portion of Anglesey bordering the Menai Straits, suffer so heavily that in some localities swedes are being omitted from the rotation. The extent of the loss is shown by the fact that in many cases farmers cannot rely upon lifting more than 4-ro loads of roots per acre. Application of lime is usually impracticable, owing both to the initial cost of the lime and the expense and difficulty of transport. Experiments were therefore commenced with a view to testing the relative susceptibility of different varieties of swedes to finger and toe, to find out whether any particular variety has special powers of resistance to the disease. As a result, a Danish variety has been found which possesses powers of resistance to a marked extent. On the assumption that complete loss of crop can be indicated by the figure 20 , the intensity of attack in this variety varies on the different plots from 2.4 to $4^{\circ} 9$, as compared with a British variety usually considered to be resistant to this disease, which showed an intensity of attack varying from $5^{\cdot} 8$ to $9^{\circ} 2$ on the same plots. This Danish swede also shows considerable resistance to the swede "Mildew," a troublesome disease in dry seasons. The cropping power appears to leave little to be desired. The crops from six varieties have been clamped separately in order to compare the keeping qualities, and, in addition, the feeding quality of each will be determined by chemical analyses. The field work has been supplemented by laboratory investigations into certain aspects of the life history of the organism which causes finger and toe.

Bacterial Rots of Swedes and Turnips.-Very considerable losses have been caused in the wetter parts of North Wales by the rotting of roots in the field-in some cases 80 per cent. of the crop has been destroyed. These "rots" have been the subject of investigation for some time, and have been found to be due to both fungi and bacteria. At least two different species of bacteria are responsible; one reduces the swede or turnip to a rotting mass within a fortnight from the beginning of the attack, whereas the other attacks only the centre of the root, leaving the rind and foliage healthy. The bacteria have been isolated and have been found capable of reproducing the diseases on roots in the laboratory. Investigations are being continued as to the effects of time of sowing, soil conditions, and manurial treatment upon the incidence of these root diseases. 
Rust Diseases of Oats.-During the past two years research has been carried out on two rust diseases of oats-Crown Rust and Black Stem Rust. The former was at least partially responsible for a much reduced yield in the oat crop of North Wales in 1920, and the latter attacks the oats every year in one locality in Anglesey, sometimes causing a practically complete loss of the crop. The research has so far been productive of results in three directions. In the first place, varieties of oats resistant to these two diseases have been discovered. The method of early spring infection of Crown Rust has been shown to be due in all probability to overwintering of the summer stage of the disease, whereas the evidence so far obtained is against the likelihood of overwintering in the case of Black Stem Rust. Finally, the research has shown that many grasses are affected by these two rust fungi, and that infected grasses may induce the diseases in oats and vice versâ.

\section{Agricultural and Horticultural Research Station, Long Ashton, Bristol.}

Sulphur as a Fungicide.-The value of sulphur and related substances such as lime-sulphur and liver of sulphur for the control of many fungoid diseases is well recognised, but the manner of their action is not understood. It is of peculiar interest, because it is effective not only at the places where the material is in immediate contact but at some distance away also. It is this latter feature which offers important possibilities of practical utilisation provided that it can be suitably controlled. These points have been under investigation for the past three years and much new and significant information has been gained. The action at a distance has been very definitely established and its mechanism is now explained. It has been proved that the poisonous action of sulphur is very selective towards different fungi, some, including mildews, generally being very sensitive and easily killed; others, e.g., the apple and pear scab fungi only moderately affected; others again, e.g., the apple canker fungus, grow freely in its presence. Minute amounts of sulphur in the atmosphere are sufficient to render growth of the more sensitive forms impossible. The further progress of the work depends in many ways upon the possibility of detection and estimation of these traces, a chemical problem of considerable difficulty on which attention is being concentrated.

Canker of Apple Trees.--This is one of the most serious pests of the fruit-grower, especially in the West of England. Until recently it has been regarded as exclusively a " wound " parasite, 
that is, the fungus was supposed to enter the tree only through wounds. Work on the pest was started some years ago, to find out exactly how the fungus infects the tree. In the first place the fungus was isolated and artificial infections were carried out. Infection under natural conditions was then studied, in the hope of being able to devise means of preventing such infection. It has been found that the most important means of entrance for the parasite is not through mechanical injuries, but through the "leaf scars" which are left on the stem after the leaves fall. Immediately after the fall of the leaves a period of very active infection may take place in the autumn, especially as regards certain varieties of apple, and another period of active infection may occur in the spring just before the buds burst. The microscopic details of such infection have been worked out, and it appears that the fungus enters the stem through small cracks that appear in the leaf scar tissue. The results therefore point to spraying as a method of preventing canker, and spraying experiments are in progress to ascertain whether this method is effective. Copper sprays have been used, since the canker fungus is not sensitive to sulphur. The first year's experiments carried out in 1920 were somewhat promising, but in I92I the dry season prevented much canker from appearing, even on the control branches, so that significant results have unfortunately not been obtained. Another method by which the fungus enters the tree is through scars formed by the "scab" fungus, Venturia incequalis.

It has also been shown that a further means of infection is through the galls caused by Woolly Aphis, thus confirming ali opinion generally held by growers that the two diseases have an association. The importance of combating attacks of Aphis is therefore two-fold. In this case it has been found that infection takes place in the autumn of the year in which the Aphis appears, and not-as supposed-in the succeeding year.

Bark Canker of Apple Trees.-A disease of apple trees discovered at Long Ashton during I920 and not hitherto reported in this country is under investigation. It has also recently been found doing considerable damage in a nursery in Somerset. It was noticed first in America in $\mathrm{rgr} 8$, where it was given the name of Bark Canker. The causal organism appears to be a fungus called Myxosporium corticolum. It is possible that this disease is fairly widespread, as owing to the somewhat similar appearance of the scars to those of the canker fungus it might easily be mistaken for the latter. 
"Die Back" of Plum Trees.-The die back of plums is a serious disease which has also received some attention. Bacterialike bodies have been found in immense numbers in the diseased tissue adjacent to the healthy region, and it may prove that they play an important part in the production of the disease, either directly or in association with a fungus which is also frequently present.

"Bud Rot" of Apple Trees.-Work is also in progress regarding a disease of apple buds caused by a fungus of the genus Fusarium, which is very destructive on certain varieties in some districts. The trouble is not apparent until bud-bursting time in the spring, and it has been generally supposed that infection occurred about that time. It is now suspected that infection takes place at a much earlier period, and accordingly spraying experiments during the winter season have been initiated for the control of this disease.

"Shot-Hole Disease" of Peach and Other Stone Fruit Trees.A shot-hole leaf disease of peaches has during recent years been prevalent and caused much damage to foliage. This has been examined in some detail and found to be caused by Clasterosporium carpophilum, a fungus hitherto unrecorded in this country. Infection experiments have shown that this organism readily produces similar leaf disease in other forms of stone fruits, such as plums and cherries, and it is probable that it is relatively common throughout the country. Control measures are under investigation. Sulphur fungicides appear to be ineffective.

Wilt of Michaelmas Daisies.-An obscure disease of Michaelmas Daisies causing wilting and death of the shoots and serious loss to raisers of these plants has been proved to be due to a parasitic fungus which infects the woody parts of the stem. The propagation from healthy stock has been found to be of first importance in the control of this disease.

\section{School of Botany, Cambridge.}

Silver Leaf Disease. - The ravages of this disease are so serious and widespread that a special grant has for the last few years been made by the Ministry to the Cambridge School of Botany to defray the cost of an investigation of the subject. The disease is caused by a fungus, Stereum purpureum, which enters the tree through wounds, lives in the stems, and by some secretive action affects the living substances of the branch so that the inner part of the leaves gets partially detached from the epidermis, or "skin," thus causing an interference with the 
normal reflection of light from the leaf and giving the latter a silvered appearance. Once inside the tree, the fungus spreads upwards and downwards, chiefly in the wood, and sooner or later the branches begin to die off. In the majority of cases the fungus spreads extensively, often causing the death of the tree; and fruit bodies of the fungus arising on the dead branches are a potent source of infection to healthy trees in the immediate vicinity. By careful and prolonged experimental work it has been proved that if the fungus is prevented from fruiting within a plantation the spread of the disease is greatly reduced. As a result of the work the Silver Leaf Order was recently introduced by the Ministry of Agriculture and Fisheries under the Destructive Insects and Pests Acts. Under this Order, fruit-growers must take adequate measures to prevent the fungus from fruiting in their plantations; for example, all dead wood, on which the fungus can fruit, must be cut away and destroyed. Fruitgrowers have welcomed the Order and are prepared to co-operate to the utmost extent required.

During the past year considerable attention has been paid to silver leaf disease in apples and peaches, in both of which it is becoming increasingly serious. In these fruit trees the disease has been found to be due to the same fungus as in plums, and to take the same course. The varieties of apples commonly affected are Early Victoria, Lord Grosvenor, Lord Suffield and Newton Wonder. In an apple plantation of about six acres near Wisbech more than I,000 trees were found to be silvered in all stages of attack, the epidemic being due to large branches within 2 feet of the ground having recently been cut carelessly to facilitate cultivation and the wounds not protected, thus affording opportunity for the fungus to enter. The disease is prevalent on peach trees in glasshouses on the south coast. Work has been commenced at Cambridge and East Malling on the susceptibility to silver-leaf of the various stocks used for plums, and of the relative susceptibility of common varieties worked on different stocks. Experiments are also in progress at East Malling to test the effect of working stocks at different levels, also the effect of alternative methods of stooling and budding with a view to reducing the possibility of infection during these operations. A good deal of preliminary work has been done in attempting to cure the disease by injecting some substance which will kill the fungus without injuring the tree At the same time laboratory experiments are in progress to test the effect of these substances on the fungus grown artificially. Some experiments have also been made as to the possibility of curing light attacks by ring-barking. Research is also in 
progress to determine the period of the year during which the danger of infection is greatest, the nature of the wounds most susceptible to invasion by the fungus, and the best substances for protecting exposed wounded surfaces.

\section{University of Leeds.}

Dry Spraying for the Destruction of Charlock-Experiments with dry sprays of some powdered chemical substances were carried out during IgI9 and I920 by the Advisory Botanist and his staff, with a view to ascertaining whether an efficient and cheap dry spray could be recommended for districts where the question of water supply presents a difficulty. The substances selected for the test were nitrolim, sulphate of iron, and sulphate of copper (bluestone). The spraying was done in the summer of both years, when charlock was in full flower in the fields selected for the experiment. The results indicate that provided an efficient machine is used for the purpose, the destruction of charlock by dry spraying is cheap and effective, and should recommend itself to many farmers, particularly to those who live in the more waterless districts of the country, where the wet method has aiways been heavily handicapped. It is important, however, that a suitable day should be chosen for the operation. The weather should be fairly settled, and there should be a heavy dew and no wind at the time of application.

Common Scab in Potatoes.--Experiments have been conducted to test the effect of liming the soil in relation to this disease. Previous work at Leeds had been successful in definitely proving the fungus origin of the disease, and in isolating the organism responsible. These organisms are probably present in large numbers in the soil, where they play a beneficial rôle in the initial stages of the decomposition of organic matter, and appear to show a special preference for herbaceous plant residues, such as leaves. The organisms apparently attack the potato tubers only when the supply of their natural food in the soil becomes exhausted; thus common scab may be prevented by introducing into the soil a sufficient quantity of green-plant matter, such as grass or green manure, which presumably acts as a preferential food for the scab-producing organisms, thus protecting the potatoes from attack. Liming experiments carried out during the last six years on a field scale showed definitely that liming the soil induces Scab, but that the effect can be neutralised by 
green manuring. Experiments in I92I indicated that a similar though less effective result is obtained by the use of old hay and spent hops.

A Bacterial Disease of Rhubarb.-Research has recently been carried out into a disease which causes serious losses to growers of early rhubarb. This is a considerable industry in the north of England, round the industrial centres. The rhubarb is grown in fields for three or four years, and is then taken up and placed in forcing sheds in the autumn, providing a supply of early rhubarb from the following December to March, which is sent to the main English markets and to the Continent. Of late years serious losses have been caused by a disease which causes the crown of the rhubarb to break away from the roots, thus spoiling the latter for further growth. The disease is extremely infectious and is responsible for losses amounting to many thousands of pounds yearly. Research into the nature of the disease was commenced about two years ago, and it was found to be caused by a bacillus. The bacillus belongs to a group of organisms found in sewage, and the widespread nature of the disease is very probably due to the fact that night soil and sewage have been largely used for manure by the rhubarb growers. Field trials have been carried out and various antiseptics applied to the soil, with the result that it was found possible to reduce the disease by 75 per cent. by the use, for example, of bleaching powder or ammonia. A further series of antiseptics is being tried this year in the hope of discovering one which shall be cheap, easily applied and still more effective.

\section{East Malling Research Station, Kent.}

Test of Fungicides on Apple Trees.-A series of experiments for the control of scab and other fungi on apple trees was begun in the spring of IgI9 and continued through I920 and I92I, the object being to test the comparative value of various fungicides, their fungicidal power, and the extent of the injury they cause to the foliage and fruit of certain varieties of apples. A number of fungicides were tested:-Lime sulphur, alone, and in mixture with other materials; "Bordeaux-mixture" of two different formulæ; and ammonium polysulphide with soft soap. Comparisons were obtained of the value of lime-sulphur and Bordeaux; lime sulphur alone and in mixture with lead-arsenate and saponin; lime-sulphur and ammonium polysulphide; and the two Bordeaux formulæ. The work was done with the advice and assistance of the Advisory Mycologist at Wye College. On account of various limitations in the experiment, the results 
can only be taken as indications, and as a basis for the work which is still in progress, but they may be briefly referred to here. It was found that apple scab on fruit and leaves has been reduced by every fungicide tested; that scab infection of the wood is also greatly reduced by summer spraying, thus reducing the sources of re-infection in the following summer; and that the effectiveness of the fungicides tested in the control of scab varies considerably. Bordeaux mixture was found to be the most effective, the two formulæ used giving practically identical results; next in effectiveness came lime-sulphur, which appeared however to reduce the crop; ammonium polysulphide with soap was the least effective against scab, but the trees of the two varieties sprayed with it bore more than double the crop of similar trees sprayed with lime-sulphur. Ammonium polysulphide with soap was found to be the most effective against apple mildew, and Bordeaux the least. Summer spraying with the fungicides reduced attacks of brown-rot, thus improving the keeping qualities of the fruit; it also considerably reduced bud infections of canker. Finally, it was found that the size of the fruit was usually increased by the spraying, and further that the effects of spraying are cumulative, spraying done in I9I9 having affected the trees and fruit in I920, regardless of the treatment in 1920 .

University of Manchester.

Mosaic and Leaf Curl or Leaf-roll Diseases of Potatoes.-These two diseases are undoubtedly present in serious proportions throughout Great Britain. It is not uncommon for some potato varieties to be infected with Mosaic to the extent of from 50 per cent. to Ioo per cent., while in the case of Leaf-roll, although the percentage of infection may not be so high, the effect upon the plants is more serious, since the yield and size of the tubers may suffer a reduction of as much as 75 per cent. In both cases the tubers carry infection. Although it is now known that both diseases are infectious and that the active principle or virus is carried by insects from plant to plant, the actual cause of the trouble is still obscure, and all the efforts so far made to isolate an organism from the affected tissues have failed. Research was therefore commenced in the spring of I920 to ascertain, if possible, the exact cause of both diseases, the method and course of infection, the relative susceptibility of various varieties of potato, and the part played by insects, especially aphids, in spreading the diseases. The experimental work, both in the laboratory and field, has been of a particularly 
intricate character, and although the work has not gone far enough to yield any definite results, valuable records have been obtained which will be of use in the further experiments now in progress.

\section{South Eastern Agricultural College, Wye.}

Lime-sulphur Wash.-The extended use of lime-sulphur wash in this country as a preventive against the ravages of fungus diseases, chiefly American gooseberry mildew, and to a less extent apple scab, is largely due to the investigations of the Advisory Mycologist attached to Wye College. The strengths known as the " summer strength" and " half summer strength" were determined as the result of spraying experiments extending over several seasons. The provision on the English market of brands of concentrated lime-sulphur washes of a I'30 specific gravity was due to the representations made by the College to commercial firms to standardise the concentrated wash on a specific gravity basis. During the work on lime-sulphur-which is still proceeding- -a new and useful fungicide, ammonium polysulphide, was discovered which is equal in fungicidal value to lime sulphur, and superior in that it does not leave a visible deposit on the sprayed part, thus making it possible to protect from mildew gooseberries which are approaching ripeness. More recently, attention has been given to the discovery of some substance for use with lime-sulphur as a "spreader." Soap cannot be used for chemical reasons. Two substances, viz., saponin and calcium caseinate, were ultimately found to be satisfactory, and are now being used with good results. The chemical researches are at present being directed to another matter of great practical importance, on which the farmer has long awaited exact information, viz., the effect of mixing an arsenical wash (an insecticide) with lime-sulphur. The outcome of last season's experiments has shown that arsenic itself is a powerful fungicide against " powdery mildews."

Control of Bunt in Wheat.-Since I9r9, plots of wheat grown from seed heavily infected with "Bunt" (Tilletia tritici) have been cultivated on the College farm for the purpose of investigating the effect of "pickling" the seed wheat before sowing. An inquiry was first made into the effect of the usual method of sprinkling the seed wheat with a solution of "Bluestone" (copper sulphate). It was found that this method when used on certain varieties of wheat such as "Red Standard," severely injures the germination of the wheat, in one case reducing the percentage of germination from 98 per cent. to 60 per cent., 
besides greatly retarding germination. It is thus probable that many cases of a "poor plant" in wheat have arisen from "pickling" the seed with too strong a solution of copper sulphate. Repeated tests with formalin of varying strengths were then made, and the fact established that sprinkling seed wheat with formalin ( I tablespoonful or $\frac{1}{2} \mathrm{oz}$. (fluid) to I gallon water) using 2 gallons to the sack (4 bushels), and then covering over the wetted heap for four hours with sacks moistened with formalin of the same strength, is a complete prevention of smut while not appreciably affecting the germination of the wheat.

Diseases of Hops.-Since I9r7, the question of the immunity of certain forms of the hop-plant to " mould" (Spharotheca Humuli)-a disease which in many seasons threatens the prosperity of the hop-grower-has been made the subject of an extended research. Whilst no commercial variety of hop at present cultivated has been found to be immune, the horticultural variety, the "Golden Hop," as well as certain seedlings raised from the "wild hop" in Italy, have been proved to be either immune from, or extremely resistant to, this disease. The possibility of obtaining a commercial variety of hop immune from "mould" is therefore in sight. New seedling varieties of hops, immune to " mould," and others immune to the false nettlehead disease, raised at Wye, are being tested at the East Malling Research Station in Kent, where also other valuable commercial characters, e.g., yield and brewing value (percentage of resins) are being investigated.

The Brown Rot Diseases of Fruit Trees.-These diseases which are responsible for heavy losses annually to plums, cherries, pears, and apples, have been under continuous investigation by the Assistant Mycologist for over six years, and the work is still in progress. The most recent work is along the following lines :-

(I) A "Shoot-Wilt" disease of plum trees has been investigated during the last two years. It has been found that the fungus, which proves to be identical with the one common on the fruit (Monilia cinerea), infects the short leafy shoots through the leaves and invades the twigs to form cankers.

(2) A special fruiting form of the fungus, found on old mummified plums which had been placed on the ground, has been shown to be a stage in the life-history of Monilia cinerea referred to above. Though the "Monilia" form, so frequent on the mummified plums while they are still on the tree, is in this country the more serious source of infection, the fact that "mummies" lying on the ground 
may under favourable conditions, produce another form of fruiting of the fungus is of some practical interest.

(3) A " Blossom-Wilt" of pear trees, apparently caused by a Brown Rot fungus, is under investigation.

\section{Glasshouse Pests.}

Experimental and Research Station, Cheshunt, Herts.

"Damping off" of tomato seedlings and "Foot Rot" of young plants.-In a bad year this disease is estimated to cause a loss of between $£ 6,000$ and $£ 8,000$ in the Lea Valley district. Coming as it does at the beginning of the season, it is a considerable source of anxiety to growers. In the seed-boxes, the young seedlings are attacked at the base, and the rapid collapse of the stem tissues causes the seedlings to fall over. Sometimes the young plants are attacked in the same way after "potting up " or even "planting out "; in this case the disease is known as "foot rot." The disease was investigated at the Station, and it was shown that the parasitic organisms concerned were distributed in the pots and boxes, soil and water. It was found that the sterilisation of soil, boxes and pots by baking, steaming, and a 2 per cent. solution of formaldehyde, and the use of a clean water supply, proved a sure way of prevention. Growers, however, also desired some means of checking the progress of the disease should it actually appear during the growing season. A fungicidal soil compound was therefore devised, and this mixture, which is known as the Cheshunt Compound, has proved of great value. Copper sulphate $(2 \mathrm{oz}$.) and powdered ammonium carbonate (II oz.) are intimately mixed, stored for at least 24 hours, and I oz. of the mixture dissolved in 2 gallons of water. This solution may be watered on to growing plants without injuring them in the least, and will at the same time destroy the "damping off" organisms. It has been widely used with satisfactory results. One tomato-grower, for example, had replanted two houses four times and lost practically all his plants each time. After applying the above solution to the soil both before and after planting, he lost only four plants out of 2,000 .

"Sleepy Disease" of Tomato.-This is caused by a fungus Verticillium albo-atrum. The disease leads to extensive losses each year (roughly $£ 20,000$ in the Lea Valley per year), especially during cold seasons. Laboratory and glasshouse experiments have shown that above an average day and night temperature of $77^{\circ} \mathrm{F}$. the diseased plants recovered. The physiology of the 
disease was carefully studied and the following action is recommended when the disease appears:-(a) Shade houses with light shading of water white-wash; $(b)$ Raise temperature of the houses by closing ventilators and suitably increasing the boiler heat, until the average day and night temperature is above $77^{\circ} \mathrm{F}$.; (c) Earth-up base of plants to encourage new root production; (d) Reduce watering to an absolute minimum, but give an over-head damping when wilting is severe. By adopting these measures growers have been enabled to carry their crops right through the year instead of losing them in May as they otherwise would have done. In one case 68 per cent. of the plants on a nursery were showing symptoms of "Sleepy Disease" before these methods were adopted, but a fortnight after only Io per cent. remained wilted.

Arum Soft Rot.-This is a disease of the arum lily, caused by the parasite Bacillus aroidece. It is extremely dangerous when it gains foothold in a district, and in the past no cure was known. The method of treatment was to destroy all diseased corms and start afresh, with a consequent considerable financial loss. After investigation, the following method of control has been devised at the'Station and has sofar proved satisfactory:After drying off the plants, all rootlets are removed from the diseased corms, which are then thoroughly scrubbed and all soft places cut out. After a final washing they are placed in a 2 per cent. solution of Formaldehyde for four hours, care being taken to keep as much of the foliage out of the solution as possible. They are next removed from the solution and potted up in clean virgin soil or sterilised soil. Fresh clean rootlets are quickly formed and healthy plants result.

This treatment has been the means of saving for one grower the whole of his arum stock, which he valued at $£ 3,000$.

\section{Diseases Caused By Insects.}

\section{Rothamsted Experimental Station.}

Insects and Allied Organisms in the Soil.-As has previously been stated, the soil contains numerous organisms, about many of which we know little or nothing. Information is particularly lacking in regard to the higher forms of soil life, such as insects, mites, millepedes, centipedes and earthworms. Research has therefore been commenced on the soil of the Broadbalk wheat field at Rothamsted, and the results so far obtained clearly show that in this arable land the greater proportion of these 
forms of life are distributed in the top three inches of soil, and thus within easy reach of the plough. . The layers between 3 and 5 inches contain small numbers, and below 5 inches the numbers rapidly decrease until at a depth of 9 inches the numbers are negligible. A census of the soil population has been taken, and shows that the numbers per acre present in the soil down to a depth of 9 inches is dependent on whether or not the land has been dressed with farmyard manure, the manured plot containing three times as many organisms of this type as the unmanured plot. The vast majority of the animals are non-injurious. In the arable land studied the chief injurious insects are wireworms, leather-jackets and the larvæ of the swift moth. These are present in almost equal numbers in the manured and unmanured plots, showing that the continued use of farmyard manure does not materially affect the numbers of these injurious animals. Another definitely injurious group is the millepedes, which are frequent pests of potatoes, roots, \&c., and in this case the manured plot contained more than double the numbers present in the unmanured. The numbers of earthworms present in the soil was found to be many times more numerous than had previously been supposed.

The work is now being extended to another of the Rothamsted experimental fields, which is divided into a large number of plots manured in different ways. It will thus be found whether different manurial dressings or methods of cultivation have any marked effect on the higher forms of animal life present in the soil, particularly in regard to the pests harmful to crops.

The soil at Rothamsted is a loamy clay, and it does not follow that the distribution of insect life will be the same on other types of soil. The same methods of investigation are now being carried out by other Institutions, representatives of which have visited Rothamsted to discuss the subject, and it is hoped that comparative information will thereby be obtained for soils of a different character.

Plant Lice or Green Fly (Aphididx).-Aphids, as is wellknown, are amongst the worst enemies of the farmer and fruitgrower. With few exceptions all plants are susceptible to attack by one or another of these pests. Hitherto the methods of repression have been limited to the application of sprays, but this is expensive, for the spraying needs to be carried out at frequent intervals owing to the extraordinarily rapid multiplication of the aphids, complicated by migrations from other plants on which they can live. There is urgent need for a thorough study of the various members of the aphid family, to find out 
their life histories and habits and the conditions under which they flourish; for until we know this we cannot say what are the best means of repression. Spraying, although the best available remedy, cannot be regarded as really effective. The first essential, however, is a correct knowledge of the Aphid group, and in order to get this, each important species within the group must be critically examined. We need to know if any good will come from eradicating the alternate hosts - that is, plants, other than the injured crop, on which the aphids spend a portion of their lives-and whether the enormous reproductive power of the aphid is due to seasonal or plant conditions or to something inherent in the insect which must be accepted and cannot be modified. We need to obtain an index of the susceptibility of different varieties of each plant to aphid attack, to see whether it is possible by selection and breeding to produce aphid-resistant varieties. We want to know whether cultural or manurial conditions will affect the susceptibility of the plant to attack. And as a preliminary to all such enquiries, it is essential to obtain a complete knowledge of the life-history of each species, and to find the most vulnerable stage at which to attack it.

An investigation having these objects is now in progress at Rothamsted, the first species selected for detailed study being the Common Bean Aphis (Aphis rumicis, Linn). The results so far obtained show clearly that this aphis, which utilises many alternate hosts, is not able to reproduce itself with the same facility on all of them. For example, dwarf French beans are only slightly infested. The aphis has two types of host, winter (perennials) and summer (annuals). The range of hosts is so wide that it is of no use attempting to eradicate them; the most that can be done is not to grow the hosts most favoured by the insect in close proximity to one another. Sugar beet, for instance, suffers severely from this aphis on the continent, and if it is to be widely grown in this country it should not be grown in close proximity to field beans, or to corn fields containing abundant poppies, which is another favoured host. It has also been found that different varieties of beans exhibit a wide range of susceptibility to aphids. One variety, Vicia narborensis, is only slightly susceptible, and an attempt will be made to cross this with a highly susceptible variety, to ascertain whether resistance is an inheritable character.

Chemotropism: A method of trapping Insects.-One of the great controlling factors in the lives of insects is their sense of smell. By it, for instance, they find their food; the male seeks out the female; the female discovers suitable places for depositing 
her eggs. A thorough investigation of the responses made by insects to volatile chemical substances is likely, therefore, to yield important results, possibly in the direction of leading to methods of controlling such pests as the pear midge and the apple blossom weevil, which have hitherto resisted all attempts to control their ravages. The method is, of course, widely used in some directions, as, for example, in hospitals, for the control of house flies; in America, by the use of poisoned sprays to attract certain pests; in Australia, as a method of controlling fly pests of sheep. The subject is now being investigated at Rothamsted, the work up to the present being largely the testing of a number of volatile substances with a view to determining their attractive properties. These substances do not necessarily occur in the immediate environment of the insect, for it is known that certain insects are attracted towards chemical substances that are neither associated with the smell of the food nor occur in their immediate neighbourhood. A large number of substances have been tested and it has been found that:-(I) beer, cane molasses, - and mixtures of these substances, are very attractive; (2) alcohols are not markedly attractive, with the exception of normal propyl-alcohol; (3) acids, mineral and organic, are not markedly attractive; (4) alcohols mixed with certain acids are highly attractive. The work is being continued.

\section{Agricultural and Horticultural Research Station, Long Ashton, Bristol.}

"Big Bud" and Reversion of Black Currants.- "Big Bud" of black currants has been known for at least 70 years; "Reversion " for at least 20. The two diseases are prevalent wherever black currants are grown, and cause especially serious losses in the Eastern counties. Bad cases of "reversion" will reduce the crop to $5 \mathrm{cwt}$. per acre or less, as compared with an average crop of about a ton. A noticeable feature of the diseases is the frequency with which one accompanies the other. In the case of " big bud," the damage is caused by a mite which enters the growing point of the shoot, where it rapidly multiplies causing swelling of the bud scales and destruction of the flower embryo. In "reversion," the leaves are longer in proportion to their breadth; the leaf margins are more coarsely serrated; the leaf veins decrease in number; there is an extensive growth of lateral buds resulting in a crowded instead of an open form of bush; and the fruit falls off before it attains full size. Work on "reversion" has been in progress at Long Ashton for six years. An important initial difficulty arose from the fact that there 
were no means of identifying bushes which were in the early stages of "reversion," so it was impossible to carry out definite experimental work or to advise growers which bushes to " rogue." After observations extending over three seasons a method of identification, depending on the character of the leaf, was discovered, and definite experimental work was thus made possible.* As a result growers are now in a position to recognise the early stages of the disease and can in consequence rogue both plantations and cutting beds. It has been shown already that this method, if rigorously employed, is sufficient to keep down the disease to a minimum, and to secure paying crops. The recognition of early stages also enables the grower to avoid propagating from diseased stock, a course of action which invariably reproduces diseased specimens. So far the results in the field appear to indicate that the presence of mite in a black currant shoot causes a change of leaf type from the normal to the reverted, thus apparently confirming an opinion that exists among growers that the two diseases are closely associated. If this view is confirmed, the problem of control resolves itself into the securing of clean stocks and the prevention of mite infection. An objection to the view is that certain varieties, such as Seabrook's Black, which in some districts are resistant to " big bud," are yet decidedly susceptible to reversion. In these cases, however, it has been found that the variety is not immune from attack by the mite, but that for certain reasons, the normal swelling of attacked buds does not occur. Work is in progress to obtain further information regarding the association of " big bud " with " reversion." In the meantime experiments are being carried out for the control of mite attack, and so far the most promising method employed has been the application of sulphur sprays.

Apple Blossom Weevil.-This pest has been very serious in apple-growing centres during the past four years. Eighty per cent. blossom damage has been common. During the past eighteen months the life-history has been investigated and the work has shown the following important results:-(a) That the weevil continues to feed on the leaves during the summer and does not remain without food as previously supposed. Nevertheless laboratory trials have shown that lead arsenate is ineffective for killing them at this stage. (b) That in the early spring the

* It should be mentioned that as the result of work carried out on this disease simultaneously at the East Malling Research Station it was found that "reverting" could be usually identified during the flowering season by means of the colour of the blossom and other characters 
hibernating weevils leave their winter quarters and feed on the swelling buds, after which they again seek cover prior to egglaying, which takes places about a fortnight later. At their first appearance they are practically insensible to jarring, but are easily shaken off when egg laying. (c) That very many, if not all, seek their winter quarters in the bark crevices of apples, plums and other trees, and that in this position it is possible to kill them by a cheap spray.

Insecticidal Washes.-The work done during the past nine years may be grouped under three heads (I) cover washes, (2) The importance of wetting power, (3) combined insecticides. Experiments on cover washes, of which the main ingredient was whiting or lime, have shown that lime is the more satisfactory, and further that with the exception of glue, every addition of another body, including salt as commonly advocated, impaired the good qualities of the mixture. The method of slaking lime was shown to have the greatest bearing on the resulting adhesiveness of the wash and that, contrary to general opinion, a cold lime wash was superior to hot. The best conditions for slaking have been determined, as well as the range of time during which lime spraying is effective and safe. The way in which lime spraying controls certain insects has been shown to be due, not to any direct chemical action, but simply to the mechanical cover.

Eight years ago, the importance of the wetting power of summer washes was pointed out, and since that time work has been done on various well-known accessory wetting substances such as casein, gelatine, saponin soap and paraffin oil emulsions, which has shown that the first three are almost valueless for the purposes of wetting insects. The usefulness of soap was of course well known, but the possibilities of paraffin oil emulsions were much less so. Investigation showed that a very high degree of wetting power could be obtained by suitable combinations of oil and soap. The reason of the injurious action found to follow the use of some formulæ has been shown to be due to a too high proportion of paraffin to soap, and all the possible economic mixtures, their wetting powers and liability to injury, have been tabulated. This work led to the use of a 2 per cent. emulsion which, combined with nicotine, has proved of the greatest use as a summer treatment for Woolly Aphis. It wets with great ease, has a strong killing action, and is non-injurious to green foliage. This mixture has a dual action in that it is effective both on sucking insects and on many biting ones, such as caterpillars in their young stages. It thus forms an 
example of a combined insecticide, a subject which has received considerable attention during the last four years. It is a subject of the utmost importance to the fruit-grower, who for economic reasons must limit the number of his applications. The same end would be attained if insect eggs could be killed or prevented from hatching, but hitherto this has not appeared very likely. Recently American work has shown that lime sulphur applied at a certain time has marked egg killing powers, and similar trials are in progress at Long Ashton. The work of testing such washes is, however, necessarily slow, and though the position looks promising, no clearly marked results have yet been obtained.

\section{School of Agriculture, Cambridge.}

Wheat Bulb Fly.-From time to time numerous complaints have been made of serious damage to wheat by this pest in various parts of the country, particularly in the eastern counties of England and parts of Scotland. The worst attacks follow a bare fallow or bastard fallow, and bad attacks also occur after crops of potatoes, rape, swedes, turnips and mangels, especially where the soil is bare during the summer, as would obtain with poor crops of roots or where potatoes are lifted early or the tops die off early in the season. One of the largest farmers in the Fen counties reported that in 1920 , owing to the pest, hundreds of acres of wheat had been destroyed in that area, and the land re-ploughed and sown with barley, and hundreds of acres bore only half crops. The life history of the fly was not known, so preventive methods had not been discovered. The question has been investigated at Cambridge, and the life history appears to be as follows:- The flies hatch out in June or July, and lay their eggs in bare soil, about one-eighth of an inch below the surface, in July, August and September. Most of these eggs hatch out early in the following spring, as they are usually found in the wheat plants in March and April. The larva on hatching from the egg makes its way to the middle of a wheat shoot, where it feeds at the base of the shoot, which it kills. Several plants may be attacked in succession. When fully fed the larvæ make their way into the soil, where they pupate about $I \frac{1}{2}$ to 2 inches below the surface. Pupation usually takes place in May.

The discovery of the life history of the fly makes it possible to conduct experiments into methods of prevention. The problem suggested is, how can the flies be prevented from laying their eggs in soil where wheat is to be sown. In this connection the 
flies' choice of bare soil for egg-laying offers a possible line of attack.

Frit Fly in Winter Wheat.-It has been shown that bad attacks of Frit Fly occur on winter wheat following leys containing either rye grass or Italian rye grass. Experiments extending over three years and carried out on the University Farm have shown that this is due to the fact that the autumn brood of flies lay their eggs on the grass, and that the larvæ feed on the shoots, and after the grass is ploughed in they eventually migrate to the young wheat plants. The field experiments were supplemented by pot experiments in the laboratory. One result of the work has been that the Farm Manager has decided that it is no longer profitable to grow wheat after rye grass, unless the latter is ploughed in before harvest.

\section{University of Leeds.}

Garden Chafer.-(Phyllopertha horticola).-As a result of some trials on a Yorkshire farm it is believed that much improvement has been effected in a grass field which owing to the White Grub attack had for several years been losing condition. Some good was done by dressing the field in Spring with agricultural salt; but the best results were obtained by adopting the plan, which has frequently been recommended, of destroying the parent beetles. Advantage.was taken of the beetles' habit of swarming on young bracken to collect them by means of a scoop-and-box apparatus devised for the purpose, the work of destroying them being much facilitated by their being largely confined to the injured field and its immediate vicinity. When the field was inspected in November, I92I, it presented a healthy appearance, and the tenant expressed himself as well satisfied that the treatment had been effective.

Wireworm Experiments.-In I9I9 and I 920 experiments were carried out in a field infested with wireworm to test the effect of a dressing of Io cwts. of crude naphthalene per acre in reducing wireworm attack. The dressing was applied on October 22nd, I9r9, and barley was sown in April, I920. The growing period of I 920 was favourable, so that is is somewhat risky to draw conclusions from the experiment, but from the results obtained it appears that a heavy crossing of crude naphthalene if applied in autumn will reduce in the course of the following winter the number of wireworms in an infested field, and that, when wireworm attack is feared, it is well in the case of corn crops to increase the rate of sowing. 


\section{University of Manchester.}

Carrot Fly.-In many parts of Lancashire and Cheshire, although the soil is quite suitable for carrots, it is almost impossible to grow this crop owing to the ravages of the carrot fly. The fly appears in Spring and attacks the carrots in the seedling stage, causing in many cases the total loss of the crop. An investigation of the disease was commenced at the University in 1920 , the first object being to discover the life history and habits of the fly, in order to find the most vulnerable point for attack. It was found that the fly does not lay her eggs on the plant but in the soil, and that in about a week the larvæ emerge and penetrate through the soil to the root of the plant, entering at the growing point. They feed on the tissues of the plant, causing wilting and yellowing and ultimately killing it. The larvæ then leave the carrot and pupate in the soil close to the root. After about a month in the chrysalis stage the flies emerge in August, and start laying eggs in a week or ro days. The larvæ which hatch out from these eggs remain in the soil through the winter in the pupal stage and the flies from them emerge in the following April.

In the case of this pest, therefore, the object to be aimed at is either to prevent the fly from laying her eggs, or, if they are laid, to ensure that the maggots which hatch out do not reach the plant. Many chemicals have been tried in this connection, with varying degrees of success. In 1920 good results were obtained on an allotment scale with green tar oil and precipitated chalk in the proportion of I part oil to 99 parts chalk. The experiments were repeated on a larger scale and with fresh chemicals in I92I, but the dry season prevented the fly from appearing. It may be added that another partial method of prevention arises from a knowledge of the life history of the pest. If the carrots are sown late, the first generation of flies is avoided. This may be a useful means of reducing risk of attack in cases where the time of marketing the crop is not a vital factor.

Onion Fly.-An investigation on somewhat similar lines to the above has recently been carried out in connection with the Onion Fly, which is another very serious pest in Lancashire and Cheshire, practically preventing the growing of onions in that area. In this case the problem of control is more difficult, for it has been found, in the first place, that the fly lays her eggs on the seedling plant and not on the ground, and therefore the deterrent effect of chemicals spread on the soil is likely to be less, and in the second place, that instead of two generations 
during the season there are three, each of which overlaps the one following, so that a continuous supply of flies is forthcoming. Methods of prevention by the use of chemicals are being explored, but so far the results are not so hopeful as in the case of the carrot fly. On the other hand, it has been found that hard varieties of onions, such as White Lisbon and Blood Red, are much less frequently attacked by the fly, if they can be got safely past the seedling stage. Experiments in this direction have therefore been instituted.

\section{Armstrong College, Nerecastle-on-Tyne.}

Wireworm Experiments.-In I92I a series of experiments was carried out on a 20 -acre field in Cumberland which in 1920 grew a crop of swedes which was almost completely destroyed by wireworms. The results have a bearing on methods of reducing the losses incurred from this serious pest of the farmer. The field was sown with "Captain" oats on April Irth, under excellent conditions of soil and tilth, and the trial plots were laid out to test the effects of rate of sowing and of manurial treatment. It was found that on a good soil containing wireworms, extra seeding alone is sufficient to produce a uniform crop; that the addition of sulphate of ammonia with extra seeding is likely to prove beneficial on poor soils badly infested with wireworms; that cross-sowing at the ordinary seed rate is advantageous on good growing soil. Extra seeding might be useful on poor soil; but with extra seeding together with sulphate of ammonia on good soil there is a danger of producing too rank a growth of plant, with the result that the crop would be easily " laid." It was further noticed that no migration of wireworms to the headlands took place in the particular field under experiment while it remained fallow.

Black Fly on Beans.-Spraying experiments were carried out in I92I on a 5 -acre field of beans which were badly infected with black fly (Aphis rumicis). Different strengths of solutions of Quassia chips and of paraffin with soft soap in water were tested. Briefly, the results showed that spraying should be done at the first signs of fly attack, and that a spray consisting of $3 \mathrm{oz}$. soft soap, $4 \mathrm{oz}$. Quassia chips to each gallon of water is very effective in its immediate results. It is important to check the spread of the attack from the patches on which the Black Fly is first observed.

South Eastern Agricultural College, Wye.

Woolly Aphis.-A discovery of some importance has recently been made with regard to this serious apple pest. Research 
workers in America have found that the Aphis spends part of its life in trees other than the apple. The Advisory Entomologist at Wye therefore made a thorough investigation of the complicated life-history of the pest in this country, and as a result it is established that the aphis spends part of its lifehistory on the elm during the winter in its sexual stage. Winged forms are produced on the elm in the early summer, and migrate to the neighbouring apple trees, so that it may be of little use adopting the accustomed expedient of winter spraying the trees with caustic soap to prevent the attack.

Insecticidal Washes.-During the past four or five years numerous types of washes have been investigated at Wye. The best was found to be nicotine, at the rate of $\mathrm{I} \mathrm{oz}$. to ro gallons of water, plus I lb. of soap. This, however, is an expensive wash, so tests have recently been made with nicotine sulphate, to see whether this substance, which is less than half the price of nicotine, possessed similar insecticidal properties. It was found that a wash made up of I oz. nicotine sulphate and I oz. of soft soap to Io gallons of water is just as effective as the nicotine wash, and the effect is more lasting. The nicotine sulphate wash was found to be particularly helpful in getting rid of the Apple Case-bearer (Colleophora nigricella). This pest causes severe damage to apples and plums; it cannot be destroyed by the usual method of summer spraying with arsenic, and trials made during the winter of I920-2I with various winter washes proved completely ineffectual. On the other hand, the nicotine sulphate spray was attended with marked success, nine-tenths of the caterpillars being destroyed at one centre.

A Simple Cure for Ground Pests.-The Advisory Entomologist has found during the last two years that fowls are extremely valuable as a means of keeping down pests. This refers especially to the Cutworms, a pernicious pest that attacks corn, roots, potatoes and cabbage. In Canada a method of trapping and killing cutworms with a mixture of Paris green (or lead arsenate) and bran has been found successful and is widely adopted. This method is certainly effective in destroying the cutworms, but in this country it may also poison fowls and partridges, and its use therefore is limited. Fowls or geese, however, will clear the ground of cutworms, and since this method was advocated by Wye it has been adopted by farmers in Kent. The Pear Midge is another enemy against which poultry-keeping proves a useful weapon. The fiy in this case lays her eggs in the unopened pear blossom, and the larvæ which hatch out are completely hidden until they descend to the ground Spraying is therefore 
of no use against the pest, and so far no effective soil insecticide has been discovered. Fowls, however, relish the larvae, over 400 having been counted in one young chicken. In numerous instances the pest has been controlled by this means.

Red Spider.--Investigations have also been carried out in regard to destruction of Red spider. Wheat flour at ro $\mathrm{lb}$. to roo gallons of water has proved quite effectual for those species which can be treated with sprays, such as Hop and Fruit Red Spiders.

\section{Glasshouse Pests.}

Experimental and Research Station, Cheshunt, Herts.

Glasshouse Tomato Moth (Hadena oleracea).-The larvæ of this moth cause extensive damage to glasshouse plants and fruit. In a recent year the damage in the Lea Valley alonewas estimated at $t 30,000$, quite apart from the heavy cost of picking off the larvæ by hand. In some cases the whole staff of a nursery has been occupied on this work, to the neglect of other duties, in order to keep the pest within bounds. The life history and habits of the moth formed the subject of a thorough investigation by the Entomologist attached to the Station, with a view to finding out methods of control. As a result, the following method of control was elaborated :-

(I) Spraying with Arsenate of Lead.

$6 \mathrm{lb}$. Arsenate of Lead paste.

Ioo gallons of water.

$2 \mathrm{oz}$. Saponin (to be added to water before the paste).

Spray the plants just before planting out and again a month before first fruit is to be picked.

(2) Trapping of Moths.

This reduces the infestation when spraying is no longer possible. Traps consist of $2 \mathrm{lb}$. fruit jars, each containing about $3 \mathrm{oz}$. of the following mixture :-thick brown treacle, one part; ale, two parts; sodium fluoride, one per cent. Six jars are used to each $200 \mathrm{ft}$. house.

(3) Destruction of Chrysalids.

(a) Baskets and canes dipped in boiling water.

(b) Houses drenched with boiling water.

As the result of the adoption of this treatment in the Lea Valley the loss from caterpillar is now practically nil. 
White Fly.-(Asterochiton vaporariorum).-This is one of the worst pests of greenhouses. Breeding freely on a variety of plants outside, the adult insect constantly gains access to the houses, in which it is able to pass the winter. Considerable financial loss is caused to tomatoes, beans and potatoes grown under glass. If infection takes place when the plants are young, and no treatment is resorted to, frequently more than half the crop is lost. As the result of an extensive investigation at the Cheshunt Station, it has been demonstrated that successful control measures are attained through fumigation with hydrocyanic acid gas, which is generated with the following chemicals: sodium cyanide, I Oz.; sulphuric acid (specific gravity $I \cdot 8$ ) $I_{\frac{1}{2}}$ fluid ounces; water, 3 fluid ounces. For houses in good repair, or in blocks, $\frac{1}{5} \mathrm{Oz}$. sodium cyanide is required for every $\mathbf{I}, 000$ cubic feet. To prevent damage to the foliage, water must be withheld from the tomato plant before fumigation, and the jars for generating the gas should be placed at equal distances from one another, a maximum of $\mathrm{I}$ oz. sodium cyanide being used in each jar for houses 20 feet wide, and $\frac{1}{4} \mathrm{oz}$. for those $\mathrm{r}_{4}$ feet wide. Fumigation must begin at dusk, and the ventilators be opened again at dawn; the temperatue should not exceed $60^{\circ} \mathrm{F}$. during the operation. As the eggs of the fly are not killed by the gas, a second fumigation is necessary from I $_{4}$ to 25 days after the first according to temperature.

\section{East Anglian Institute of Agriculture, Chelmsford.}

Eelworm in Tomatoes.-Experiments to control this glasshouse pest have been in progress for several years. As a preliminary, it was necessary to test numerous chemicals and proprietary articles, and it was found that the most effective was sodium cyanide applied in heavy doses to the affected soil. The more recent glasshouse experiments have been undertaken to discover the minimum dressing of cyanide, and it has been found that if applied at the rate of ro cwt. per acre per I foot depth, this will clear the soil of eelworms without adversely affecting the tomato plants. The tomato grower in whose glasshouses the experiments have been carried out has become enthusiastic of the method. $\mathrm{He}$ estimates that a moderate attack of eelworm disease would reduce a crop by 25 per cent. Assuming a low average price of $6 \mathrm{~d}$. per lb. for the tomatoes throughout the season, this loss would be equivalent to at least $£ 600$ per acre. The cost of treatment with sodium cyanide, even at present high prices, would not be more than $£$ roo per acre. 


\section{Insecticides and Fungicides AND the Chemistry of Plant Diseases.}

\section{Rothamsted Experimental Station.}

A series of investigations in progress at the Soil Research Institute at Rothamsted may properly be referred to in this chapter. The work consists mainly in a study of the fundamental nature of insecticides and fungicides. Our present knowledge on this subject is largely empirical, depending on the results of trials of various chemicals, \&c., and until we know more of the chemical principles involved and the reasons for the effects observed, further progress cannot be very rapid.

There is urgent need for work on insecticides, not only to relieve the present scarcity of nicotine, but also, if possible, to discover an insecticide which, while being poisonous to caterpillars, would not be injurious to larger animals. Various plant products are being investigated from this standpoint, in collaboration with the Ministry's Pathological Laboratory. Tuba Root (Derris elliptica), an Eastern plant, has been closely examined in this connection and holds great promise. The root has been dealt with by intricate chemical analysis, and found to contain products highly poisonous to insects, and particularly to caterpillars. Different consignments of the root, however, vary greatly in their efficiency. A simple chemical method has been devised for ascertaining the relative efficiency of different consignments, thus making grading and blending possible. The poisons contained in the plant have been extracted in a pure state and shown to be at least as poisonous, weight for weight, as nicotine, to caterpillars, but not so poisonous to aphids. Various methods of extraction are being studied to devise means of securing the poisonous compounds in a concentrated form.

Another important field of work is the search for an effective soil insecticide. A study of the poisonous effects of various products to wireworms revealed the fact that some of the most commonly used insecticides and partial soil sterilisers are ineffective in certain soils. Thus, naphthalene, which is widely used as a soil insecticide either in a pure state or in the form of a proprietary article, and-in conjunction with other materialsas a partial steriliser, may be decomposed by soil bacteria before its poisonous action reaches the wireworms, and the latter are able to move away from the sphere of influence and so escape death. This is the case with such disinfectants as carbolic acid (phenol, cresol), naphthalene and toluene. In collaboration with the Bacteriological Department of the Institute, some of the soil bacteria which are responsible for this decomposition have been 
isolated in pure culture and are now being studied, particularly as regards the rate at which they are able to attack antiseptics in liquid and soil under control conditions. This is clearly an important factor in connection with the application of volatile antiseptics, such as naphthalene, to the soil. In glasshouses, for example, soils are apt to become infested with harmful organisms through intensive cultivation under semi-tropical conditions, and applications of the disinfectant (cresol) are only partially effective on account of its rapid disappearance. The work has so far indicated a method by which this rapid disappearance may be prevented, and this method is being further investigated. It may be mentioned that an examination of nearly a hundred samples of soils from different districts has shown that the organisms which are able to decompose disinfectants are widespread.

A large number of chemical products have been tested for their poisonous effect on soil insects and pests, and it has been found that definite and important relations exist between the chemical constitution and physical properties of the materials studied and their poisonous action. The work is being continued. In connection with this investigation it has been shown that chloropicrin, for example, is most highly poisonous to wireworms and eelworms. Owing to its disagreeable and poisonous nature, however, great care is necessary in its use, and its utility is probably limited to glasshouse work.

Preliminary investigations have also been commenced on fungicides. It is further proposed to study the chemical side of the question of the immunity of plants from disease, which may lead to results useful to the plant breeder. In this connection special attention is being paid to wart disease of potatoes. 
CHAPTER VI.

\section{ANIMAL HUSBANDRY.}

Although this country has achieved fame for the excellence of its cattle and sheep and the rapidity with which they are fattened, and has come to be regarded as the most important "stud farm " of the world, it cannot be said that our methods of feeding are economical, or that our present output of meat is entirely satisfactory. When allowance is made for imported feeding stuffs it may be estimated that the cultivated land (arable and grass) of the United Kingdom produces about 800,000 tons of beef and mutton per annum; further, that some I7,000,000 acres of pastures and meadows are used for this purpose, so that the output of beef and mutton from these principal sources of supply is considerably less than I cwt. per acre per annum. Moreover, imported feeding stuffs are costly; in I9I9 the imports amounted to nearly $£ 60,000,000$. There is thus ample room for improvement in methods of feeding and management, not only in order to secure a greater yield of meat, but also to reduce the present heavy expenditure on feeding stuffs imported into the country. Research into this subject is carried out in England at the Animal Nutrition Institute attached to the University of Cambridge. In Scotland such problems are dealt with at the Rowett Research Institute attached to the University of Aberdeen with the aid of funds provided by the Board of Agriculture for Scotland, through whose courtesy we are able to include an account of the work in this chapter.

\section{Protein.}

The investigation of problems concerning nutricion has resulted in discoveries of far-reaching importance during the last 20 or 30 years, and it is clear that our knowledge of the science of nutrition is far from complete. For example, at the present time a farmer buys a feeding stuff largely on an analysis which divides the constituents of the food into groups of substances-albuminoids (i.e., protein), fats, \&c., according to certain chemical reactions. A knowledge of the percentage of each of these groups present is valuable as a rough basis of comparison between it and other food stuffs; but the method takes no account of certain vital facts regarding foods which nutritional research has brought to light. From the point of view of the farmer, the most important of these discoveries concerns the nitrogenous part of the 
food, or, as it is usually called, the protein. This is the most necessary and at the same time the most expensive constituent of all feeding stuffs. Until a few years ago protein was regarded as a definite unit, which was used directly by the animal in restoring the waste of tissue which goes on continually in the body, and in providing material for growth. But it is now recognised that the animal cannot make use of protein as such; the protein has first to be split up by the digestive ferments into nitrogenous substances known as amino-acids. This discovery would not be so important if all proteins contained the same amino-acids in the same proportion; but actually the proteins in the various feeding stuffs vary considerably in their amino-acid content, and some idea of the complexity of the whole question may be gained from the fact that at least I 8 amino-acids have already been found to be present, in varying proportions, in the proteins of ordinary feeding stuffs.

Perhaps the importance of the subject to the stock feeder will be better realised if a rough indication is given of the changes that go on inside the body of the animal. The animal has to produce, say, muscle, which consists of proteins containing certain amino-acids combined in a definite and constant proportion. As raw material for the manufacture of this protein, the animal is supplied by the farmer with feeding stuffs containing various other proteins, and each of these proteins contains its own mixture of amino-acids in a definite proportion. The first thing the animal does is to dissolve these various proteins in its digestive juices, and separate out all their amino-acids, so that from these amino-acids it can build up the new proteins of which its muscle is composed. But the new proteins must contain certain amino-acids in definite proportions, and any amino-acids which are left over, being of nouse to the animal for flesh formation, are converted into urea or uric acid and excreted in the urine. The aim of the stock feeder, therefore, must be to provide his animal with feeding stuffs in such a proportion that their proteins supply amino-acids in the proportion required for flesh formation, for only by so doing can feeding be carried out without a considerable loss of the most expensive ingredient, protein. In other words, in compiling rations regard should be had not so much to the protein content of the various food stuffs, as to their aminoacid content, and it is this that the research worker is now engaged in finding out. The chief difficulty in making an attempt to adjust the amino-acid supply of the food to the amino-acid requirements of the growing tissues of the animal is that the composition of the proteins of both the tissues and the food are not fully known. At the Rowett Institute work on the compositon of flesh 
is being carried out, and at Cambridge work on the composition of certain foods.

The analysis of protein by present methods is, however, tedious and laborious, and recent work has been directed to discovering simpler and shorter methods that will give more accurate results than those hitherto employed. The success of the work may be shown by the fact that when the work began at Cambridge a few years ago, the most up-to-date analytical methods could only identify and separate about half of the amino-acids present in the chief protein of milk, namely, casein. By improved methods, the Cambridge workers have been able to account for nearly 97 per cent. of the protein of milk, the increase consisting partly of an amino-acid not previously found in casein. The work is being continued with some promise that before long the whole of the protein will be accounted for, when it will be possible to state precisely what is the amino-acid constitution of the protein of milk. While special attention has been given to milk, in view of its great importance in connection with both human and animal nutrition, other feeding stuffs are being dealt with so far as facilities are available. Palm kernel cake, for example, is at present being investigated from the protein point of view. But the work is long and laborious, and considerable time must elapse before practical data become available. The thorough investigation of the protein in a single feeding stuff by the most up-to-date methods may quite well occupy the time of an expert agricultural chemist for a year.

In the feeding of animals, the proportion of protein in the food is of great importance, not only on account of the fact that foods rich in protein are generally the most expensive, but also because a deficiency in protein stunts growth, while an excess is not only wasteful but may be harmful to the animal. Work done at the Rowett Institute indicates that the protein requirement of an animal has been over-estimated, and that a better utilisation of the food can be obtained with less protein than the amount usually fed. By experiments involving the analyses of urine and fæces it has been found that it is possible to ascertain whether protein is being fed wastefully by a simple method of estimating the amount of a substance-creatine-which undersuch conditions is voided by the animal in excessive quantities. By an extension of this work it seems that it will be possible to determine with a degree of accuracy the most economical amounts of protein to feed.

Another direction in which improvements in analytical methods have paved the way for further progress in nutritional research may be referred to. It is clear that before our methods 
of feeding can be perfected, it is necessary to know with certainty all the various stages by which food for the animal is built up in the plant, and, a stage further on, broken down again in the body of the animal to be rebuilt in the form of flesh or of milk. In practice, this knowledge must be based upon a detailed study of the composition of plant and animal fluids and juices, such as urine, blood, \&c., at various stages throughout the life of the animal or plant. In the mangold, for example, the proportionate amounts of the nitrogenous constituents of the root vary according to the length of time the root has been stored, a certain amount of nitrogen in a form unavailable to the animal bzing converted, during storage, into an available form; thus the feeding value of the roots improves as the storage period increases. It is clear, however, that before the whole " story" of the process -from soil-water to plant juices and from plant juices to meat and milk - can be written, a vast amount of chemical analytical work must be done, and that the rate of progress will depend largely on the perfection of the methods adopted in the laboratory. It is therefore satisfactory to be able to record the discovery in the Cambridge laboratory of new simple and accurate methods for the estimation of various organic constituents of plant and animal juices. By the application of these methods it is now possible to speed up the investigation of such processes as putrefaction and fermentation, the rotting of manure, the quality of meat and fish, the making of silage, the feeding value of agricultural products in relation to maturity and conditions of storage, \&c. Already a good deal of work has been done on the question of putrefaction and fermentation, in collaboration with an eminent bacteriologist on the staff of the Medical School of the University.

\section{Digestibility of Feeding Stuffs.}

Another important question which closely affects the stock feeder is the digestibility of the feeding stuffs supplied to his stock. So far as the animal is concerned, it is not so much the composition of the food which it eats that matters, as the proportion which it can digest. An Animal Nutrition Research Institute, therefore, must endeavour to provide the farmer with accurate information regarding the digestibility of feeding stuffs. At Cambridge much attention has been given recently to the question of the digestibility of silage, and a brief outline of the method employed may not be out of place. Little or no attention had hitherto been given to this matter, although it is of obvious interest to determine how the digestibilities of the ingredients of silage compare with those of the green crop from which it has been made, for without 
this knowledge it is not possible to settle the question of the relative economy of hay and silage production. In the experiments the comparative digestibilities of green oats and tares, oat and tare hay, and oat and tare silage are being investigated. The trial is carried out in duplicate with sheep, two wethers being used for the purpose. The period of trial is three weeks, but the final figures are based on the results obtained in the last fortnight, during which the conditions of experiment are considered to be stable. The sheep are kept during the experiment in specially designed feeding stalls, and harnessed with an equipment consisting essentially of a rubbered canvas sheet fixed by suitable means to the hindquarters of the sheep. The solid excreta fall down a funnel-shaped shoot attached to the cage into a receptacle below. The urine drains through the perforated floor and is caught in a bottle. The sheep are weighed at the beginning and end of each period, and full analyses made of the feeding stuffs supplied and of the dung and urine. From these data, and knowing the weight of the foods, the proportion actually digested can be ascertained by subtracting from the known constituents of the food consumed, the known constituents voided in the dung.

\section{Feeding Value of Oat Straw.}

At this point we may leave for a moment the work in progress at Aberdeen and Cambridge, and refer briefly to an investigation of the feeding value of oat straw which is being carried out by the Advisory Chemist at Armstrong College, Newcastle-on-Tyne. This enquiry arose from a consideration of the fact that oat straw apparently varies very much in quality, inasmuch as farmers in many districts feed cattle during the winter almost entirely on roots and straw, whereas in other districts this system of feeding is not satisfactory. An exhaustive chemical examination of swedes obtained from various districts showed that roots grown in districts which made little success in feeding roots and straw were just as good as those from districts where this system of feeding was successful. The difference, therefore, apparently lay in the straw. The straw investigation has now proceeded for some eighteen months, and the considerable initial difficulties in connection with the analytical methods have been overcome. The preliminary work has shown that the chief variations in composition are due to the sugar and albuminoid contents of the straw, and principally to the sugar. The important cause of variation is the district where the crop is grown, straws from northern counties having a total sugar content about three times as great as those obtained from other districts. Further, oat straw from the western side of the northern counties is much 
richer in albuminoids than straw from the eastern side. So far, therefore, the investigation has shown the west side of the northern division to produce straw of from 50 to 70 per cent. better feeding value so far as the flesh formers are concerned. Further, as soon as a straw crop is cut, loss of sugar appears to begin, and the sugar can only be saved if the crop loses its moisture at a fairly rapid rate, any delay in drying being accompanied by a deterioration in feeding value. Delay in drying may be caused by wet weather, moist atmosphere, or stacking in a damp condition. In the northern counties early cutting showed an advantage of about I per cent. total sugar, but there is good reason to suppose that the advantage of early cutting does not depend on obtaining unripe straw but on obtaining straw harvested under good conditions.

\section{Feeding Experiments.}

Some account may also be given of recent pig feeding experiments conducted by the Advisory Chemist attached to the University of Leeds. The more important refer to the use of fish meal or dried blood as food for pigs. Three pens of pigs abont three months old, selected so as to be as uniform as possible in every respect, were used. One pen received a ration of mixed cereal meals, a second the same mixture in which a portion of the cereal meals was replaced by fish meal, which thus formed about one-seventh of the total ration. The third pen had a portion of the meal replaced by green food in the form of kale. The pen receiving fish meal went ahead more rapidly than either of the others, although at the end of about eight weeks this difference in rates of live weight increase gradually disappeared. On transposing the rations of pens $I$ and II, it was found that pen II, now receiving fish meal, began to go ahead and showed decidedly the beneficial effect of fish meal. In each experimental period it was found that the cost of one pound of live weight increase was about threepence less where fish meal was fed than where it was not fed. Finally one pen was kept on a ration containing fish meal right up to the time of slaughtering, and a cooking test gave no indication of any taint in the taste of the pork, and furthermore the butcher reported the carcases as quite satisfactory. This more rapid live weight increase is not specific to the use of fish meal itself, but rather to the fact that, by its introduction into the ration, a fairly high proportion of albuninoids was being fed. That this is the case was shown by a repetition of the experiment in the following year, in which similar results were obtained by using dried blood as a source of 
albuminoids instead of fish meal. In each year the pen of pigs receiving green food came out as well as the pen receiving only mixed cereal meals, and the pigs were in excellent condition throughout.

An experiment has also been conducted to compare the values of green food and undecorticated cotton cake for feeding to dairy cows at grass. The results of this experiment were somewhat inconclusive in the summer of 1920 when there was plenty of grass, but it was clear from the results obtained in the summer of I92I, when there was a scarcity of grass, that cotton cake could be substituted by an equivalent amount of vetches $\left(5 \frac{1}{2} \mathrm{lb}\right.$. of vetches for I lb. of cake) without any detrimental effect on the yield or quality of the milk.

\section{Energy Requirements: The Calorimeter.}

Reverting to the work in progress at Cambridge, we may now refer to an attempt to deal with another important question for the stock feeder, namely, what is known as the " energy requirement " of different classes of livestock under varying conditions. All work done by an animal, whether in digesting food, or forming flesh, or trotting, or pulling a cart, can be expressed in terms of energy, and the food which an animal requires can be determined in the first instance by its energy requirement. It is comparatively easy to determine how much energy a particular weight of a given food will supply, and if we knew precisely the total amount of energy needed by an animal for a certain class of work, it would be possible to say beforehand just how it should be fed most economically and efficiently. In experimental practice, energy is measured in terms of heat. In the case of the animal, this heat is produced by chemical changes taking place within the body of the animal, and the amount of chemical change can be calculated from the heat evolution, which can in turn be measured by means of an instrument known as a calorimeter. After a considerable period of experimental work, an apparatus for this purpose, large enough to take a bullock and cheap enough to be within the reach of any scientific institution, has been constructed at Cambridge, and from preliminary trials there is reason to hope that the apparatus will be found sufficiently accurate for all practical purposes and will lead to the accumulation of extremely important data regarding the feeding of stock. A brief description of the apparatus may be interesting. The calorimeter consists of a cylindrical galvanised iron tank, 9 feet 6 inches long and 5 feet 6 inches in diameter, round the outside of which is soldered a spiral of lead pipe through which a constant stream 
of water flows. The whole tank is surrounded by 12 inches of granulated cork to prevent as far as possible loss of heat to the surrounding air-with the exception of the door, which is insulated with felt. The water which flows through the spiral pipe enters at a temperature which is kept constant by an electric thermostat. If there is an animal in the calorimeter, the circulating water picks up the heat given off by the animal and is thereby warmed. The differences in temperature between the outflowing and inflowing water, expressed in Centigrade degrees, multiplied by the number of litres flowing round the calorimeter in, say, one minute, gives the amount of heat (in calories) extracted during that minute. To this must be added corrections for heat carried out or in by the ventilating air, the latent heat in the water vapour given off by the animal, and leakage of heat through the walls of the calorimeter. The sum of these gives the heat given out by the animal per minute.

The calorimeter-which has only recently been completedis being used for some preliminary experiments on the nutrition of the pig. When this work is completed it is proposed to begin an investigation of the net nutritive value of various feeding stuffs, to ascertain how much of the value of various foods is lost in the processes of digestion and utilisation.

It is not contended that the Cambridge calorimeter will give absolutely accurate records. To secure them, a very much more expensive apparatus would be required. Existing calorimeters in America and elsewhere give extremely accurate results, but they cost some thousands of pounds to erect and require an expert staff of half-a-dozen or more attendants to conduct an experiment. Funds for research are much more readily forthcoming in America, however, than in this country, and the Cambridge apparatus - which could be duplicated for less than $£ 500$ and is easily worked by one person-represents a commendable attempt to do the best that is possible under existing financial conditions in England, and will, it is confidently believed, prove a very valuable means of adding to our present store of information regarding animal nutrition.

A still cheaper apparatus has been devised by the Aberdeen Institute. This apparatus is a modification of tl. Haldane Douglas method already employed in connection with nutrition experiments on the human subject, and can be mad at a cost of about $\AA_{25}$. The consumption of oxygen and the oduction of carbon dioxide and methane by an animal can be determined, and from these data it is possible to calculate the production of energy by an animal under different conditions, and also to get an indication of the use made of the constituents of the food 
when digested and absorbed. From the results of some preliminary experiments which have been done on the goat it looks as if this method can be used in dealing with those problems of nutrition which can only be solved by means of calorimetric determination.

\section{Vitamins.}

Another large and important field of nutritional research of which only the fringe can so far be said to have been explored is that relating to the minute " accessory food substances" or vitamins, which are known to play such an enormously important part in the health of man and beast. One of the most important discoveries of recent years has been that there are these unknown and previously unsuspected constituents of food which are necessary for the health of all animals and for the growth of young animals. If these unknown substances are absent, conditions of malnutrition arise in the full-grown animal, and the young animal either ceases to grow or grows at a much lower rate than it would do if the substances were present. Many feeding stuffs, and especially the artificial foods, such as cakes, meals, \&c., are deficient in these substances, and when these are fed alone the animal grows slowly and with lack of vigour. Work on this subject is being carried out both at Aberdeen and at Cambridge,* and while at this stage in a new line of investigaton it would be unwise to dogmatise, it may be said that the results show that many cases of slow growth, digestive troubles and other obscure conditions of malnutrition may be due to a monotonous diet deficient in vitamins, and further that the number, size and vigour of the young at birth is to some extent influenced by the vitamin content of the food of the mother. It is obvious that this may prove to be a most profitable line of research and that results of great economic value may be obtained.

Some recent pig-feeding experiments at Cambridge are interesting in their bearing on this point. It is well-known that ryefed pork is regarded with particular favour on the Continent, but the practice is not adopted in this country, and the experiments were instituted to determine, if possible, why rye-feeding is not usually successful here. Put very briefly, the Cambridge work showed that with young pigs rye was entirely unsatisfactory when fed alone, but when supplemented by only a small handful of grass per day it proved as wholesome as any other food. It appears, therefore, that rye is deficient in a certain vitamin which

* Vitamin experiments have also been carried out at the National Institute for Research in Dairying at Reading, and are referred to in the chapter on Dairying (see page r33). 
can be supplied by adding a very small quantity of green food to the ration. The trials were preceded by some preliminary experiments with rats from which it was discovered that these animals thrive on barley meal, but die if fed on rye meal alone. The experiments were therefore repeated with pigs. The rye-fed pigs ate their moss litter in order to get the vitamins necessary to keep them alive. The pigs were then put on wooden floors, and so isolated from any vitamin-containing material. They were fed with rye-meal and palm kernel cake, neither of which contains vitamins, and vitamins were supplied by means of a trace of linseed and a very small quantity of green stuff. On these rations the pigs made such progress that at six months old (i.e,. in July, I92I) they won a prize in the bacon pig competition at the Cambridgeshire show.

A large-scale feeding experiment which is valuable not only for its practical bearing on the causes of a prevalent disease of pigs but also for the light that it throws on a certain aspect of vitamin research, has recently been concluded at the Aberdeen Institute. The experiment was spread over a period of $\mathrm{I} 8$ months, and upwards of Ioo pigs, varying from 7 weeks to 6 months old, were employed. Primarily the trials were intended to determine the causes and methods of prevention of a nutritional disease which is very prevalent in the case of pigs kept in confinement. The most obvious symptoms are loss of appetite, lethargy, stiff stilted gait affecting the hind quarters, and later loss of power of the legs. In severe cases, deformities of the long bones and fractures of the ribs occur. In certain districts it has been estimated that about 50 per cent. of the animals born in the Autumn or in the early part of the breeding season suffer from this disease in one form or another, and it affects not only flesh production at the time, but the health of the animal afterwards. The disease is generally known as " rickets," but it is not certain whether it is identical with the true rickets affecting children. Interesting as the Aberdeen experiments are, they can only be summarised very briefly here. There were two series of experiments, the first of which dealt with the part played by vitamins in connection with the disease, and while these showed that a deficiency in vitamins was certainly not the chief factor in producing the disease, it was ascertained that the rate of growth, and thus the production of pork for a given amount of food, was dependent upon whether on not certain of these vitamins were present. From the point of view of prevention of the disease, however, the most useful results were obtained from the second series of experiments, which dealt with the question of the influence of mineral matter in the food. The foods com- 
monly fed to pigs, such as grains, wheat offals, bye-products from margarine factories, \&c., are all deficient in bases, such as lime, and contain an excess of acids. It was found that when the mineral matter of the food was adjusted to the requirements of the animal by the addition of certain salts the disease did not occur; but when these food stuffs were fed in the natural condition without any adjustment of mineral matter, the disease invariably occurred under all conditions. These results confirm and explain the experience of pig breeders, who are troubled with the disease particularly in cases where pigs have to be fed in styes, and have no yard or garden in which they can roam. If the pig is able to root up and consume earth, he is probably able to supply himself with sufficient mineral matter, such as lime, to ward off the disease. If he cannot do this, he is likely to develop the disease unless his ration contains some quantity of the required mineral matter.

\section{Reproduction.}

We may now consider some valuable work which is being done at Cambridge on the subject of the physiology of reproduction, particularly with reference to the milk supply of the cow. It is a frequent cause of complaint amongst dairy farmers that they are unable to get young heifers in season in the months of December and January, to come in for the subsequent autumn and winter's milk supply. If a heifer cannot be put to the bull till the spring she will be too late for the following winter's milk supply, so that a cow calving in April or May is worth less than one calving in the late autumn. Further, an examination of the milk records of several societies in different parts of the country, especially in the west of England, shows that cows ealving in November and December are yielding more milk per annum than those calving from April to July. Sterility, too, is extremely high in cows; probably upwards of $15 \%$ of cows in any season are sterile for a whole season, and in a much larger percentage there is an apparently sterile condition for more or less prolonged periods. Unfortunately, these sterile periods usually occur about December or January, that is, at precisely the time when it is most important that a cow should be put to the bull. The experimental work at Cambridge has therefore largely taken the form of a close study of the periods of "heat " in young heifers, and for some time past observations have been made at two-hour intervals throughout the day and night, The main practical facts that have emerged are that thi: period of "heat" varies considerably with different animils and 
according to the time of year; that in winter it may be so short (lasting only a few hours) as to be frequently overlooked in practice; but that there are certain indications by which it is possible for a farmer to ascertain approximately when a condition of "heat" will arise, and by turning out the heifer with the bull at that period he can practically ensure service.

In these "heat" investigations, the observations on the living animals are supplemented by and linked up with a detailed laboratory study of their breeding organs after death. Everything possible is found out from close observation for some weeks before the animals are killed, and afterwards such organs as the ovaries, uterus, vagina, mammary glands, \&c., are preserved and studied in detail. During the past year eleven animals have been dealt with in this way, four of them being pregnant. In order to detect with absolute accuracy the occurrence of the " heat " period, a bull is used which has been operated upon in such a way that he can serve the cows but cannot make them pregnant. When pregnancy is desired recourse is had to another bull. The work has lately been extended to cover a comparative study of the development of the milk glands during pregnancy, for there is some reason for assuming that the milk yield of an animal varies with the size of the milk tissue in the udder. Four pregnant animals are being kept for the purpose of this investigation and will be killed and examined at various stages of pregnancy. Supplementary material is being obtained from slaughterhouses. The aim of the investigation is to ascertain what are the primary factors concerned in controlling the formation of milk in the milk glands of the cow. Already a considerable amount of work has been done with rabbits, and certain definite conclusions drawn, which it is desired to confirm or otherwise in the case of the cow.

Another significant fact emerging from the work of this character recently carried out has been the large wastage of what may be called reproductive activity which occurs in the animals examined. A study of the breeding organs of numerous sows, rabbits and sheep has shown that the actual litter is very much smaller than the number of eggs originally fertilised. In rabbits, out of an average of 20 eggs shed, only 12 developed normally and gave rise to young animals; 4 or 5 degenerated, and the remainder were missing. It is quite clear that abortion was not due to bacteria, because the uterus in all cases was perfectly clean and aseptic. Moreover, the condition was not found in wild rabbits, so it seems that domestication has been responsible for some derangement of the animal's internal functions, resulting in a failure to give birth to the proper number of young. This 
condition may be partly due to feeding, and arrangements have been made for a large scale feeding experiment with sows to test the effect of feeding upon size of litter, and to find out not only how far feeding may be effectual in increasing the size of a litter, but how far it is desirable to go in this direction; in other words, what is the best size of litter to be aimed at, and how, by feeding, can this size be secured. The experiment will extend over three years, during which it is hoped that 240 breeding sows will be dealt with.

The factors which influence the production of milk by the cow are also being studied at the Aberdeen Institute, and already certain facts have been discovered which, if confirmed by subsequent experiments, will throw valuable light on the subject of the effect of feeding on milk production. In past work on this subject, attention has been chiefly directed to the fat, "total solids," and salts in milk. At Aberdeen an extensive investigaton has been carried out in which the milk was analysed for fat, sugar, salts, casein, albumin, and globulin and non-protein nitrogen. It has been found that on a fixed diet, as the volume of milk increases the percentage of sugar also increases, but the percentage of protein and salts diminishes. The results suggest that one of the factors that determine the daily volume of milk is the rate of formation of sugar in the mammary gland. The fact that independently of the nature of the diet the percentage composition of milk tends to vary with the volume may explain many apparently contradictory results obtained in investigations carried out to determine the effect of feeding on the quality of milk.

While on the subject of milk, reference may be made to an enquiry which has recently been concluded at Cambridge into the presence of " supernumerary glands," or extra teats, in the udders of dairy cows. A large number of dairy herds were examined in Berkshire, Somersetshire and Devonshire, and it was found that more than half of the animals had these extra teats. It was further found that the glands associated with the teats very often function, secreting milk, but this milk, instead of being drawn off as in the case of the four principal teats, is re-absorbed and the milk sugar is excreted with the urine. Thus there appears to be a waste of milk in the case of animals possessing extra teats.

\section{Growth in Cattle and Sheep.}

We may conclude this chapter by referring to investigations which are in progress at Cambridge into the question of the growth 
of cattle and sheep. The main object of this work is to throw light on the very important question of the most economic age at which these animals should be slaughtered for the production of meat. The work involves the detailed examination of large numbers of animals, and a bare record of the results so far obtained will therefore convey only an inadequate idea of the work involved; but it is clear that before any radical change in the present methods of stock feeders can be recommended it must be justified by conclusive results obtained from experimental observations on a very large scale. In connection with sheep, the Cambridge workers have secured live weight records on the farm for over 400 animals, representing four year's crops of lambs. The condition of management and sex affecting live weight increase have been observed and recorded. Animals are killed at different ages and the amount of live and carcase weight determined; the carcases are then cut up and the weights of bone and meat ascertained. In some cases-the leg in particular - the individual muscles have been weighed. The final batch of animals was killed at Christmas, I92I, and when the data sccured have been worked up the results will be published.

In the case of cattle, the most important problem requiring settlement is the stage at which fattening cattle should be killed. At present stock feeders continue fattening until the animals are "prime fat" and fat begins to accumulate on the flank, in the scrotum, and generally on the outside of the animal. The view apparently held is that it is mainly at this period that fat is laid down in the body generally. The origin of this view is probably due to the fact that the practical man has no criterion of internal fatness except the appearance of what may be called " overflow fat " on the outside of the animal. The experimental evidence so far obtained does not favour this view, but suggests that the deposition of the fat is a gradual process, extending throughout the fattening period. So far as the Cambridge experiments have gone, they indicate that the last month of the fattening period, which the stock feeder now regards as the most important, is in fact the most wasteful. Seven store beasts, uniform with one exception, were bought for fattening at the end of last year. They were killed at intervals of one month, and the percentage of carcase to live weight was found to be as follows:-killed in December, $5 \mathrm{I} \%$; in January, $53 \%$; in February, $55 \%$; in March, $57 \%$; in April, $55 \%$; in May, $59 \%$; in June, (when the animal was prime fat) $60 \%$. Thus with the exception of the April beast, which was unfortunately abnormal in all respects, the series showed a rapid rise for five months, when it remained practically stationary for the last month of fattening, During that month 
the cost of feeding in relation to the actual increase of meat secured made the feeding highly uneconomical.

The proportion of carcase to live weight in these and other animals has been related to certain external measurements made on the live animals. In addition, the carcases were analysed to find where the fat was being deposited, each butcher's joint being analysed separately. From the figures so secured, important data have emerged. . In the first place tentative formulæ have been devised for ascertaining live-weight, dead-weight, and percentage, from measurements of the longitudinal and cross girths of the animal. From these formulæ it may be possible to ascertain, at any stage of fattening, the weight of the animal and the percentage of carcase, without killing or weighing the beast. Thus the condition of the animal for slaughter will be indicated. Further, the figures will show the development of the process of fattening, which of course has an important bearing on the best time to kill. The figures have not yet been secured for a sufficient number of beasts to justify a definite pronouncement, but arrangements have been made with a large firm of butchers in Cambridge under which the required information is being obtained for all animals slaughtered there during the present winter.

Accurate data regarding the rate of growth and fattening are of fundamental importance in estimating the relative economy of various breeds, and of different systems of management and feeding. Rather more than half the food that an animal eats is used up simply in keeping the animal alive-for example, in maintaining the heart-beat, in the periodic expansion and contraction of the lungs in breathing, in mastication and digestion, and in certain other vital functions which do not contribute to the increase of weight which accompanies growth and fattening. This continual requirement of food for maintenance forms a constantly increasing overhead charge on the animal as long as it is alive. The sooner the animal can be made ready for the butcher, the smaller this charge will be. This is the fundamental idea at the root of the Cambridge investigations on growth and fattening. 


\section{CHAPTER VII.}

\section{ANIMAL BREEDING.}

Essentially, the principles underlying the study of heredity apply to both animals and plants; but whereas plants are often self-fertilised, and supply easy material for investigating the phenomena of heredity, animals are bi-sexual, and breeding experiments with animals are more complicated and much more expensive. The scientific breeding of plants has in consequence attained a much higher degree of perfection than in the case of animals. The plant-breeder is now engaged all over the world in improving existing races of plants and introducing new types to meet special needs, and he is already in possession of sufficient information regarding the principles of heredity in plants to enable him to go about his work with some measurc of assurance that he will produce results; he has thus become one of the most powerful influences we possess in connection with the improvement of our food supply. The breeding of animals, on the other hand, cannot be said to have yet got past the stage of investigation of principles, except, perhaps, in the case of small animals such as poultry. The commercial stock-breeder, although he has succeeded in producing cattle and sheep of very high and world famous quality, is still limited to the method of trial and error. The excellent results of his work manifested in the show yard are not gained without continual disappointments and failures, which the show yard does not reveal; there are many pit-falls which he would avoid but cannot, many things which he would like to do if he knew how. Unfortunately, experimental work with large animals such as cattle and sheep is very expensive, and the funds available for research have been too limited to permit of this type of enquiry. An investigation with sheep on a large scale has, however, recently been commenced at the Animal Breeding Research Institute of the University of Edinburgh, and through the courtesy of the Scottish Board of Agriculture we are able to give an account of it later in this chapter. As regards England and Wales, a small annual grant has been provided for some years to enable the Department of Genetics in the Unversity of Cambridge to carry out breeding experiments with poultry and rabbits. These experiments, while they have furnished some results of practical importance to the poultry and rabbit industries, are primarily intended to establish the fundamental principles on which the scientific 
breeding of all animals may be based; for it is possible, by the expenditure of comparatively small sums on rabbits and poultry, to unravel to some extent the complicated skein of animal heredity, and to do a good deal of the difficult " classification" work which is an essential preliminary to scientific stock breeding. This class of work, however, is necessarily of a character which it would be difficult to explain clearly to readers who were not well acquainted with the science of genetics. In fact, the account of two years' investigation in animal breeding-which is the broad purpose of this report in connection with other branches of science-could hardly be made intelligible to the lay reader. We shall therefore content ourselves with a brief summary of the more recent work at Cambridge, laying stress on those aspects of the work which are capable of being applied to an economic use.

It will be desirable to explain the kind of difficulty which the Cambridge Institute is attempting to solve, and this will be made clearer if we refer first to a simple case of inheritance in cattle, which is already well established. The breeder knows, perhaps only too well, that red calves are apt to occur occasionally even in the most highly pedigreed breeds of Aberdeen-Angus or Holstein. They are rarely welcomed, and in most cases the breeder would go to a great deal of trouble to ensure that they never appeared in his herd. He tries to get rid of the taint by vealing the red calves, but still they come from time to time. Now it is a perfectly simple thing to remedy this position if the breeder is able to appreciate the heredity principle involved. The colour of the coat in this case is the outward sign of a definite inheritable character contained in the germ cell. A pure-bred black animal produces germ cells which contain what is known as the factor for black; a pure-bred red animal produces germ cells containing the factor for red. The birth of a new animal arises from the union of two germ cells. In an absolutely pure black herd, every germ cell produced contains the factor for black, so only black animals are possible. On the other hand, if at some period in the history of the herd, a pure black animal has mated with a pure red, the result will be a union of black and red germ cells. In the resulting egg which is to give rise to the new animal, the black factor is dominant to, or conceals, the red, which is recessive; the calf, although black in appearance, will contain the red factor in 50 per cent. of its germ cells. It is known as an "impure dominant" and if that animal is used for breeding, a red calf is bound to appear sooner or later, either in its immediate progeny or their posterity. If the breeder wishes to prevent the appearance of reds in his herd he must 
eliminate the red germ cells, and these may be carried by black animals as well as by red; in other words he must weed out the impure dominants (black, concealing red) as well as the red recessives. Thus a knowledge of the principles of heredity supplies a definite test which can be applied to determine whether a black animal is pure or not, and that test is to mate it with a red animal, that is, with a recessive. So mated, the truebreeding black will produce only blacks, while the impure dominant will produce both blacks and reds. This, of course, is a policy of perfection, and cows in a pedigree herd are too valuable to devote an appreciable proportion of their progeny to testing operations. But since red calves are never born of blacks, unless both parents are impure dominants, it is clear that the use of a bull which has been tested by mating to red cows, and shown to produce only black progeny, would be sufficient to prevent the appearance of red calves in a herd, whatever the proportion of impure dominants among the cows. If the breeder makes use only of tested bulls, this proportion will gradually decrease, and the possibilities of any beast sold being a true black will increase correspondingly. If, however, he uses a new bull without testing it, and it happens to be an impure dominant, a considerable increase must be expected in the number of red calves in later generations, for such a bull introduces as many " red " germ cells as " black," and must necessarily increase the proportion of impure dominants in the herd.

The case of the black-red cattle illustrates a type of problem in which an important external character depends upon a single pair of germ "factors," and in such cases the procedure for ensuring purity is simple. But the characters that breeders are concerned with are rarely so simple and distinct. The cases are usually far more complicated, where a cross seems to result merely in a muddled blend, and at first sight there appears no suggestion of clear cut alternative pairs of factors. The question thus arises as to whether such complicated cases can be resolved in terms of a few definite factors, each of which is transmitted according to the accepted laws of inheritance. It is such problems as these, applied to rabbits and poultry, that have been engaging the attention of the Cambridge workers for some years past, for it was realised that if complex problems in heredity in these small animals could be resolved into simple hereditary units, it was fairly certain that the same thing would apply to the larger animals, and experiments on the latter could then be initiated with every assurance of success. It may here be said that in the case of every problem that has so far been investigated, and which it has been practicable to carry through 
to a conclusion, it has been found possible to explain the inheritance of complicated characters by resolving them into a small number of simple factors.

The experiments with poultry have been mainly directed to studying the inheritance of weight, colour, and hen-feathering in the cock. The original cross in each case was between a Gold-pencilled Hamburgh cock and a Silver Sebright bantam hen. These two breeds differ greatly in size, and the study of weight inheritance may first be dealt with. The Hamburgh is, roughly, twice as heavy as the Silver Sebright. At the time the work was started, practically nothing was known of the inheritance of size, and probably many breeders, if challenged, would have prophesied that the ultimate result would have been the production of a strain of intermediate size-in other words, that "blended inheritance" would result. In point of fact, this was not the case. The first cross birds were of intermediate size, but when a further generation of over 200 birds was raised from them it was found that this consisted of all sorts of sizes, ranging from birds smaller than the Sebright to birds larger than the Hamburgh. Moreover, it was found that the small birds bred true to size at once, and there is evidence that strains of intermediate and of large size could also be established without difficulty. The results support the view that there are definite factors for size which are transmitted in the ordinary Mendelian way-a point of considerable importance to the animal breeder.

A second series of experiments was designed to test the inheritance of " silver" as opposed to "gold." The results have proved beyond question that colour in this case acts as a single inheritable factor, and further that silver behaves as a dominant to gold; in other words, that when a germ cell containing the silver factor combines with a germ cell containing gold, the silver is dominant to, or conceals, the gold, and the resulting egg will hatch out to a "silver" bird. Further, this experiment provides an illustration of an important principle of heredity which is known as sex-linked inheritance. It has been found in certain cases that well-marked characters in animals, other than sexual characters, are linked up with the character for sex; that is, that the factor for "maleness" in the germ cell, for example, may be linked to one or more other factors, which will therefore only appear in the male, and cannot by any possibility appear in the female. Similarly the female may exhibit certain characters which, in the germ cell, are linked to the factor for " femaleness," so that they cannot be reproduced in the male. There is evidence that high fecundity, or egg-laying power, in poultry is linked up with the factor for " maleness," 
so that the highest grade of laying hen, producing eggs some of which will hatch into cockerels and others into pullets, transmits the high-egg-laying capacity only to her sons, and not to her daughters. The high-grade layers must therefore get this factor from their father, and this explains why such high prices are paid to-day for the cockerels from hens with a high eggrecord. In the case of the Hamburgh-Sebright cross, it was found that the silver cock transmits the " silver" factor both to his sons and his daughters; the silver hen, on the other hand, transmits " silver" to her sons, " gold " to her daughters. When a silver hen is mated with a gold cock, all her sons are silver and all her daughters gold. The experiments have further shown that chicks which will feather into silvers can be distinguished in the down from those which will become golds. If, therefore, silver hens are mated with gold cocks, the sexes of the chicks can be told with certainty on hatching. The breeder who uses this type of mating is in a position to kill off all his unwanted cockerels at hatching, and to rear double the number of pullets with the same plant. Thus it is possible, by a careful choice of breeds, to avoid one of the most serious difficulties met with by poultrybreeders who rear large numbers of pullets for egg-production; for with many of the best egg-laying breeds it is not possible to distinguish the sexes with certainty until they are several weeks old, and the rearing of young birds is an expensive process. The sex-linked colour inheritance exhibited by the HamburghSebright cross is not limited to those breeds, but also applies to certain others. For instance, in the Leghorns, the sexes can be separated on hatching if Duckwings and Browns, or Cuckoos and Blacks, are used for the cross ; in the Wyandottes, by using Silvers and Golds; in Plymouth Rocks, by using black and barred birds. There seems to be no good reason why these types should not be improved up to the best egg-laying standard, and if that were done, the question of sex-determination on hatching would no longer be a difficulty.

The third series of experiments in poultry is connected with the peculiarity of hen-feathering in the Sebright cock. This investigation has not yet been concluded. It has already been demonstrated that the factor for hen-feathering in the germ cells acts as a dominant to normal feathering, but intermediate types frequently occur, and the nature of these is now being studied. The case is of general interest in that it is an example of a normally female character becoming associated with the male, in which sex it may give rise to effects not found in the female. The association of a secondary sexual character with the sex in which it is not normally found is not uncommon in animals, and the present case in poultry is a clear cut and 
relatively simple one for the study of an aspect of heredity which may have an important economic application.

Of the experiments with rabbits, the most important have been those dealing with fur pattern, and this investigation is still going on. While the work has an obvious practical application in connection with fur production, this is not regarded as its most important bearing. The main object of the research is to ascertain the principles underlying the inheritance of pattern-a question which is of widespread importance in relation to most of our domesticated animals. It is well-known that in most classes of animals forms occur with white markings. The extent of these markings varies greatly, and a graded series can generally be found with a self-coloured animal at one end of the scale, and an almost white at the other. This is the case in rabbits. A cross between the two extremes produces animals with some white, and when these are bred together in sufficient numbers the whole series of forms-ranging from almost white up to self-colour-is obtained. At the time the experiments were undertaken it was generally regarded as doubtful if the general laws of inheritance applied to such a case. It was thought that the amount of white depended upon a process of selection, and could be increased or decreased at will. As these graded series are commonly found in animals, and moreover apply to many other qualities than pattern, it was important to ascertain whether the generally accepted view of inheritance was justified, or whether the inheritance of pattern is really due to the combination of a few simple inheritable factors. The work at Cambridge during the past twelve years has shown that the second explanation is probably the correct one.

A further series of experiments, dealing with weight in rabbits, has been in progress for the past ten years. These experiments were designed with the idea of making an investigation of mammals on lines parallel to the experiments with poultry already alluded to. A similar procedure was adopted, viz., a cross between a very small breed, the Polish, and one of the largest breeds, the Flemish Giant. As in the poultry, the first crosses proved to be intermediate in size, but when bred together they have so far failed to produce anything approximating to the Flemish, though they have given animals almost as small as the Polish. Why the large size was not produced is a problem at present under investigation. Through the systematic weighing of all animals in this series of experiments, interesting data are being accumulated in connection with fecundity and early maturity, and it is hoped that they will eventually throw light upon inbreeding and crossbreeding-perhaps the most important of all problems connected with stock raising to-day. 
We may now refer to certain work in progress at the Animal Breeding Research Department of the University of Edinburgh. The aim of the Department is to bring to the aid of the practical stock-breeder the methods of investigation employed by the scientifically-trained research worker. An investigation on a large scale has been commenced, in an attempt to improve the fleece of the Scotch Blackface mountain sheep. These sheep are famous for the quality of their mutton, but the fleece is one of the least valuable of all fleeces, and has hitherto been exported principally to America for the manufacture of carpet squares. There is, however, a probability that the import duty on such fleeces will be considerably increased by the American authorities, in which case it may be no longer commercially practicable to send Blackface wool to America, and its disposal in this country would be a matter of some difficulty. It was therefore decided that an effort should be made to see whether it would be possible, without affecting the quality of Blackface mutton, to raise the quality of the wool to such a standard as would enable it to command a market in this country. It is clearly not an experiment which breeders of pedigree stock could be expected to carry out on their own initiative, even under scientific guidance; for there is no guarantee that the quality of the mutton will not be injuriously affected in the process of breeding for wool. The question was therefore taken up by the Board of Agriculture for Scotland in conjunction with the British Research Association for the Woollen and Worsted Industries (Leeds), and at their instigation the Department has secured the co-operation of four well-known breeders of Blackface sheep, who have agreed to undertake experiments on a large scale under the supervision of the Department.

The investigation was commenced in IgI9 and is of a twofold character. In the first place, an attempt will be made, by crossing, to introduce first-rate wool characters into the Blackface breed; secondly, an improvement in wool qualities by selection within the breed will be aimed at. We will consider first the " crossing " experiment. In order to introduce the required wool character, it was decided to use the Southdown breed as the second parent, for this breed produces first-rate mutton, as well as wool of very high quality. It was hoped that by crossbreeding the Blackface with the Southdown, and the production of a large second cross-bred generation, it might be possible to select animals combining the superior mutton qualities of the one with the superior wool qualities of the other, at the same time retaining the well-known hardiness of the Scotch breed. Ten pedigree Southdown rams were therefore purchased by the 
Board of Agriculture for Scotland and distributed amongst the four breeders who are co-operating in the experiment. The first cross generation of some 400 lambs was born in the spring of 1920. As was expected, these showed great variation in their fleece characters, some closely approaching the Southdown, others the Blackface. On the whole, the quality of the fleece was distinctly improved. Most of the ram lambs were sent to the butcher, and his report on the mutton was that it was superior even to pure-bred Blackface mutton; the carcases were heavier, and the appearance of the meat more attractive. All the ewe lambs, and a few selected ram lambs, have been retained for further breeding. They are being wintered in the hills under the same conditions as ordinary Blackface sheep and will receive no special attention of any sort. Thus the cross is being exposed to the test of natural selection, which will eliminate any individual that is unable to withstand the rigours of the Scottish climate. The lambs will be used for breeding in 1922 . Meanwhile the Southdown-Blackface cross is being repeated on the same scale, namely, Io rams to 50 ewes each. On this occasion greater attention is being paid to the selection of the Blackface ewes, since it is possible that the great variation exhibited by the first lot of cross-bred lambs was to some extent due to variation in the Blackface mothers. The co-operation of leading wool-brokers has therefore been secured, and they will assist in the selection of the ewes.

Simultaneously an experiment is in progress to see how far it is possible to improve the Blackface wool by selection within the breed. A close study of the breed shows that it exhibits a wide range of wool characters, varying from wool of quite good quality to hair of the lowest marketable value. Some fleeces are quite free from grey hairs, others contain numerous scattered patches of pigment. There thus seems to be considerable room for selection within the breed. A well-known breeder of Blackface sheep has placed the whole of his flock of about 16,000 sheep at the disposal of the Department for experimental purposes with this end in view. With the assistance of wool experts, a Blackface ram of improved wool quality has been purchased and will be mated with selected ewes. Careful selection will be practised with each generation, and it is hoped that ultimately the wool of the whole flock will be graded up, on lines which can be repeated by other breeders.

The question of the prevalence of black (grey) hairs in the fleece, which limit the choice of dyes, and therefore seriously affect the value of the fleece, is also being studied from another point of view. A careful examination of the fleeces of numerous 
Blackface sheep showed that a completely black face was almost invariably associated with pigmented fibres in the coat, and that a "brokit" face (that is, a face in which the black is in patches) is commonly associated with a completely unpigmented coat. It is possible, therefore, that by the production of a face as nearly white as possible, pigment could be eliminated from the coat. In order to test this, experiments are being carried out with fancy tame rats, in which the problem is very similar. A completely black-headed rat invariably has black patches of hair in its coat. By breeding, the black in the head has been broken up, and at the same time the body cleared from coloured hairs. Breeding is being continued to see whether the production of a completely white rat free from pigment is possible. If so, it is reasonable to suppose that breeding on similar lines amongst Blackface sheep would result in the production of a practically white-faced Blackface and eliminate the undesirable pigmented hairs in the fleece.

Information is also being collected at Edinburgh on the subject of the assumption, by fowls, of secondary sexual characters, owing to disturbance of the internal reproductive organs. These abnormalities usually take the form, in the hen, of the development of "cock" characters-an erect comb, spurs, \&c. The question may prove to be of some importance in its relation to the general tendency to speed up the egg-laying powers of the hen. Some twenty " abnormal " birds have been under investigation during the past year, and the Department would be glad to get into touch with poultry breeders and others who are interested in the subject, particularly those who have abnormal birds in their flocks.

\section{CHAPTER VIII.}

\section{DAIRYING.}

THE Research Institute in Dairying was established at University College, Reading, in Igr2, but up to the present the work has suffered considerably from the fact that the Institute had no dairy farm attached, and no dairy under its control. This difficulty has recently been met by the purchase of Shinfield Manor near Reading, and its adjoining farms of 340 acres. Possession of the farms was obtained in October 1920 , and it is hoped that possession of the Manor House-which will serve as the research laboratory-will be secured in the near future.

The functions of a Dairy Research Institute are wide. Within its province are included all questions relating to the production, 
handling and distributing of milk, and the manufacture of dairy products. These involve the study of the management and feeding of dairy herds, of 'methods of securing and distributing milk, of the constitution of milk and milk products, of the various activities in the dairy, of the technical processes involved in the making of such products as cheese and butter. The chemist, bacteriologist, physiologist, physicist, the specialist in dairy husbandry, and the animal pathologist are intimately concerned in one or other of the technical questions bearing on the subject. Further, the importance of milk from the human standpoint, and its relation to public health, give a value to dairy research quite apart from its agricultural value. It is to be regretted, therefore, that only recently have the means been found for the equipment of an Institute on a scale approximating to the importance of the subject. The account given in this chapter of the work that is now in progress and the results recently obtained will, it is hoped, not only show that valuable work has been done in spite of very considerable difficulties as regards staff and equipment, but will also indicate to some extent the large volume of research which is waiting to be accomplished and which, in the interests both of the producer and the consumer of milk, should be taken in hand as soon as opportunities permit.

The investigations fall into three broad categories; those relating to the management and feeding of dairy herds; those bearing on the question of the cleanliness of the milk that is produced; and those dealing with the technicalities involved in the manufacture or disposal of the various milk products. It will be desirable to refer to the work under these three heads in the order stated, and in the first instance to consider what is being done to solve some of the numerous problems of dairy husbandry.

\section{Dairy Husbandry.}

As the Institute has had no farm or dairy herd under its control it has been necessary to rely mainly on such work as it has been found possible to carry out with the Reading College dairy herd, and to supplement this by information obtained from the Berkshire Milk Recording Society-to whose records the Institute has been allowed free access-and from numerous dairy farmers in the locality who have not hesitated to supply any particulars of value in connection with the investigations of the Institute.

Effect of Age and Period of Calving on Milk Yield.-In a previous chapter reference has been made (on p. Iog) to the results of recent work at the Cambridge Animal Nutrition 
Research Institute on the question of the "heat" periods in cows, and it was shown that one of the main reasons why farmers are often unable to get their cows to the bull at any particular period is that the period of heat is sometimes so short as to be overlooked in practice. It is hoped that the Cambridge workers will before long be able to furnish information to the farmer which will enable him to mate his cows at any period. This work has a close bearing on an enquiry that has recently been made at Reading into the yield of milk from cows calving in different months in the year. The enquiry has involved the examination of over 4,000 milk records of cows of three or more calves. The main source of information has been the records of the Berkshire Milk Recording Society-but particulars have also been obtained from other counties, and the results may be fairly said to cover most of the systems of management adopted in this country. The main facts emerging are that in the case of the cows calving during the winter (October-February), the milk yield per lactation period is from $50-75$ gallons higher than that given by cows calving during the summer. In the case of cows of high milk-yielding capacity, it appears that the highest yield will be obtained if they calve in October or November. Cows of average milk-yielding capacity, however, give the highest yield if they calve in December, January or February. In other words, the date of calving should be timed so that the cow's inherent tendency to produce milk will maintain a high daily output from calving until the advent of early summer grass brings about a second "flush" of milk.

The enquiry has also extended to the milk-yields of cows of different ages. About 3,000 records have been examined in this connection, nearly all of them being from cows of the Dairy Shorthorn type. The average yield from I,I 43 first-calf cows was $5,645 \mathrm{lb}$. The yield increases with each lactation period with marked uniformity; rising gradually to an average of $7,985 \mathrm{lb}$. obtained from 137 sixth-calf cows. This increase, however, is not due solely to advancing age, for the taking of milk records often results in the drafting out of poor milkers. An attempt is now being made to eliminate this factor and thus get an accurate measure of the increase in milk yield due to age, and at the same time to secure information as to the milk yields of the same cows during successive lactation periods.

Breeding.-Are good dairy qualities inherited? To this question, which is of vital importance to the dairy industry, only a very qualified answer can be given, and the answer is chiefly of value in showing the lack of our present knowledge 
in the matter, and the urgent necessity that exists for further information. This is illustrated by the results of an enquiry recently made into the history and milking records of certain non-pedigree Dairy Shorthorns in the Reading College herd. The cow Rose, with a milk-yield of 9,125 lb., had daughters by three different sires, "A," "B," and "C," and in each case the daughters proved heavy milkers during several lactation periods, ranging from an average of $7,098 \mathrm{lb}$. to an average of II,397 lb. "The sire " C" was mated with the best milker amongst the daughters, and the resulting cow gave a milk yield of only $6,058 \mathrm{lb}$. over an average of three lactation periods. Another cow, Fillpail, with a milk-yield of 5,036 lb., when mated with the bull " A " produced a daughter giving a milk-yield of only $\mathrm{I}, 083 \mathrm{lb}$. ; this daughter when mated with the bull " $\mathrm{C}$ " ' produced a cow giving an average yield of $7,792 \mathrm{lb}$. over three lactation periods. Another cow, Bell, with an average milkyield of $8,225 \mathrm{lb}$. mated with the bull " A," produced a daughter giving an average yield of $9,8 \mathrm{gI} \mathrm{lb}$. over six lactation periods; but the progeny of this daughter, when mated with the bulls " $\mathrm{C}$ " and " $\mathrm{D}$," were distinctly disappointing, their average yield being only a little over $3,000 \mathrm{lb}$.

Further, for the purpose of obtaining a progeny record of a bull, it is necessary to have the milk records of the dams as well as those of the daughters, and the breeding value of the bull can be judged by comparing the average milk records of the dams with those of the daughters. This important point is well illustrated by a reference to the progeny records of two bulls used in the College herd. During the period investigated, Bull " A " had 8 daughters by 8 dams; Bull " C" I2 daughters by 9 dams. The results of the examination of the milk records in each case showed that Bull " A " was capable of securing female progeny which gave an average milk-yield of $8,479 \mathrm{lb}$. in an average lactation period of $44^{\circ} 3$ weeks, and which were at least equal to their dams in milk-yielding power. The heifers and cows got by Bull " C" averaged 6,468 lb. in 38.3 weeks, or failed to equal the record of their dams by $\mathrm{I}, 533 \mathrm{lb}$. These figures show conclusively that "A" was much the better bull for breeding purposes. Unfortunately, following the usual custom, he was sold for slaughter before any of his progeny came into milk.

This enquiry has formed the prelude to a more extended study of the inheritance of dairy qualities from sire and dam, the term "dairy qualities" including not only milk-yield, but persistency of milk-yield, quality of milk, capacity for regular breeding, constitution, and the power of transmission of all 
these qualities. Simultaneously an investigation is being made of the external characteristics of cows known by their records to be good or bad milkers, for accurate information on the value of the commonly accepted external indications of milk-yielding powers is necessary as a prelinimary to the study of the breeding of dairy stock. This enquiry is being carried out in co-operation with members of the Berkshire Milk Recording Society and others.

Calf feeding in its effect on the future milk yield.-Another problem which the Institute is attempting to solve relates to the feeding of calves which are intended for the milking herd. It is a common belief among farmers that if young dairy stock are reared under conditions which induce the laying on of fat, they will be less satisfactory as milking cows. In consequence light feeding is adopted; but this entails a certain sacrifice, for heavy feeding would produce stronger and more quickly maturing animals, that is, they would begin to produce milk at an earlier age. The results of research carried out in America with Friesians and Guernseys indicate that heavy feeding has no adverse influence on the potential milking capacity of young stock; but it is not clear how far this applies to cows of the Shorthorn type, which is so popular in this country, and an investigation has therefore been commenced at Reading with a view to solving the problem. To do so, it is necessary to start with calves of, say, a month old, and carry them through for two or three lactation periods. Two lots of five calves have already been purchased, one of which will be fed light and the other heavy. It is hoped to have at least four lots of ten calves each, for definite conclusions can hardly be drawn from results obtained on a smaller scale. The work forms part of a general attempt to ascertain the conditions that affect the growth, health, breeding powers and milk yield of dairy cattle-a subject on which very little information is at present available.

Butter Fat Records.-From the dairy farmer's point of view, the quality of milk is expressed by its butter fat content, and cows yielding milk containing less than a certain percentage of fat may cause the milk of a herd to fall below the standard. In the matter of milk quality we have surprisingly little information on two vital points: first, the external conditions which influence yield and quality: and second, how to ascertain, with the minimum of trouble, the quality of the milk that a particular cow is yielding. In order to solve these problems, the Institute has commenced a detailed investigation of the milk yield of cows. Samples of morning and evening milk are obtained from a number of cows kept under controlled but at the same time strictly 
practical conditions. For each cow information is obtained of the weight of milk yielded, name of milker, hour of milking, feeding ration, temperature of cow, daily weather conditions. The milk, both morning and evening, is analysed for fat, and solids not fat. This is being done right through the lactation period of 42-43 weeks. From a preliminary series of trials that have recently been concluded it is clear that the fat yield of a cow varies enormously from day to day. Now at the present time, statements as to the fat content of the milk of individual cows are based on an average of four to nine samples per year, but we have no means of knowing whether this sampling is sufficiently frequent. That the question is of considerable practical importance may be shown by a simple illustration. A dairy farmer may purchase a bull out of a cow stated to give milk containing an average of, say, $4 \%$ of butter fat. He will expect that bull to get calves which will improve the milking qualities of his herd. Actually, however, the percentage may have been based on an average of only half-a-dozen samples taken during the year, and it may be that the true average, based on sufficiently frequent sampling, is lower. If so, his bull will be a disappointment, and he will have unconsciously made a retrograde step instead of an advance. The only way to find out definitely how frequently samples ought to be taken, in order to get a true indication of the milk quality of a cow, is by the method of morning and evening sampling, throughout the whole lactation period, of a number of cows kept under different conditions; and upon this work-as before indicated-the Institute is now engaged.

\section{Production of Clean Milk.}

There are two incentives to the production of clean milk. One is that the dairy farmer is losing, in the aggregate, great sums by adhering to uncleanly methods. The other is that the presence of the disease organisms that are sometimes found in ordinary whole milk constitutes a danger to public health. The loss to the farmer may be emphasised by a simple statement of fact. The whole milk supply to London alone is estimated at about 90 million gallons per year. Of this quantity, between $\mathrm{I}_{2}^{1} \%$ and $2 \%$ is lost through souring; that is, about $I_{2}^{\frac{1}{2}}$ million gallons have to be thrown away every year through being unfit for human consumption. Assuming a moderate average price of Is. a gallon, this means a loss of about $f 75,000$ on the milk supplied to London. It may be thought that the wholesaler pays this; but actually the farmer pays, for the price he gets for his milk is based on 
the average profits of the distributor. The quantity of whole milk available for consumption in the United Kingdom in Igr8, as estimated by the Committee on the Production and Distribution of Milk, was nearly rooo million gallons, so that the total loss through soured milk is extremely high. These facts ought to be borne in mind by everyone concerned in the production and distribution of milk. Clean milk is not only a source of health; it is a source of profit.

Fortunately for the dairy farmer-who, it must be admitted, is not always far-seeing in this matter-there is a growing public demand for clean milk. But research is necessary to find out what links in the chain which connects the producer to the consumer are weak links from the point of view of cleanliness, and how they may be strengthened. One of the most important lines of research conducted at Reading bears on this question, and some valuable facts have been discovered. The question was first approached at the farmers' end of the chain, and it was found that if milk is properly produced and handled it will keep pure under any conditions of haulage, and in the hottest or most sultry weather, for at least two days, so that if delivered to the consumer within 24 hours, there is no risk of its going sour in the house. This is known as Grade "A " Certified Milk, and it must conform to a definite bacteriological standard; that is, the number of bacteria contained in it must be kept within a specified limit. The production of this type of milk involves special buildings and methods; the cows must be free from tuberculosis, and the milk must be despatched from the farm in sealed bottles. In the neighbourhood of large industrial centres, Grade " A " Certified milk is a commercial proposition, for there is a definite demand for it, and the higher price obtainable justifies the increased expense involved in its production.

But at our present stage of progress the universal production of Grade " A " Certified Milk is an ideal to be aimed at rather than a practical scheme to meet existing conditions. A somewhat lower standard, but yet higher than the average, is required to meet the case of the average dairy farmer, who cannot afford the capital required for new buildings and appliances. The Institute has considered his case, and has found that a verydefinite advance can be made if clean buildings and utensils, a good water supply, and-above all-cleanly methods of milking are employed. A farmer who adopts these methods, and also submits his herd to the tuberculin test-getting rid of animals which are thus found to be tuberculous - is in a position to produce what is known as Grade " A " milk, for which he can obtain a higher price than for ordinary milk. The advantages of producing 
Grade " A" milk is not, however, confined to the higher price obtained; the farmer also finds a much readier sale for his cows. For example, a farmer in the neighbourhood of the Reading Institute, whose dairy herd was until a few years ago " wasting " to the extent of 7 or 8 animals every year, decided to produce Grade " A " milk. He now suffers no " wastage " and is regarded as a source of supply of "tubercle free" beasts to the neighbourhood.

Further, quite apart from the tuberculin test, the introduction of cleanly methods into the cowshed will go far to solve the problem of dirty milk. This is well shown by an interesting experiment conducted on the new farm at Shinfield Manor in Ig2r. A class of students, who were intelligent and interested but had not had experience in methods of clean milk production, were set to work to produce milk from the farm herd during the months of February and March. The milk was taken from cows in a cobwebby, unevenly-cobbled, badly-lit shed, and at first the ordinary methods of the farm worker were followed; the utensils were washed with cold water at the pump and stored outside the shed in the usual way. The milk produced was examined bacteriologically and was found to be very dirty and unsatisfactory. A simple steam steriliser was then brought into the cowshed. The utensils were steamed just before milking, and hot water taken from the steamer was used to assist in the washing up after the milking was finished. In the intervals between milking the vessels were stored in the usual position outside the shed. By this means a great improvement in the cleanliness of the milk was effected, but even so the standard was low. In the third experiment, the same washing and steaming of utensils was adopted, and in addition the cows were washed. In these circumstances, milk of high cleanliness was obtained. It was proved, therefore, that it was possible to produce really clean milk under very disadvantageous sanitary conditions. One fact, however, should be emphasised-namely, that the milker himself must have an intelligent interest in producing clean milk; otherwise, at some stage in the process, dirt is bound to come in, which will upset the whole result. The clean milker requires water, steam and light, and also a certain amount of apparatus, such as brushes, clippers, clothes washing for the cows, clean overall and cap for milking, clean milking stools, soap and soda. The milking pail, strainer, cooler and milk churn must all be washed and steamed before use. Even the milking stool must be kept thoroughly clean, or the hand of the milker may be soiled in picking it up, and the value of his other labours diminished in consequence. 
The production of clean milk at the farm does not, however, complete the story. The milk must be conveyed in churns to the wholesaler and the distributor and thence, usually in small cans, supplied to the consumer. If it is to reach him clean, the cans and the churns must be clean, and one of the most serious defects in our present system of milk distribution is the use of dirty churns. A bacteriologist working at the Institute recently went to the trouble of examining 500 empty milk churns on a railway platform. The churns were on their way back from the wholesaler to the farmers. Each churn was sampled by swilling it with water free from bacteria; the swill was then submitted to bacteriological analysis. It was found that only 80 of the churns-out of 500-were in a usable condition. A further $\mathrm{I}_{40}$ were "passable"; the remaining 280 were teeming with microbes. It was further found that by the simple method of steaming the churns (after washing) for three minutes sufficient bacteria could be destroyed to make the churns absolutely safe for all practical purposes, and that they could then be left for 24 hours without further treatment, provided the lids were left on. This steaming method applies equally to all utensils used in the cowshed or dairy. Steaming for three minutes after washing makes them safe. They must not, however, be again washed with ordinary cold water after steaming; otherwise organisms, such as those that give rise to " ropy milk," may be introduced.

Tuberculosis in Dairy Cows.- Not less than thirty per cent. of the milking herds of this country are affected by tubercle in one form or another. Two years ago an examination was made of the freces of cows on $\mathrm{I} 4$ farms near Reading, and it was found that four of the herds contained apparently healthy cows which were excreting tubercle bacilli, and were thus a source of danger to the whole herd. More recently the Institute has had a cow killed which was presented to it about four years previously. The post-mortem revealed a deep-seated tuberculous lesion in the cow's lung. During the whole of the $4 \frac{1}{2}$ years that it had been at the Institute, although apparently healthy in every way, it had been spreading the microbe of tubercle on the pasture land. The difficulty in dealing with this kind of tubercle is that we do not know how long the microbe lives, or what happens to it when it gets on to the land. An investigation now in progress at the Institute may throw some light on this. As a result of the work, it has already been established that the bacilli can remain alive for at least five months on pasture, for at least twelve months in a dark cowshed, and for at least five months in liquid manure. Whether they have really died at the end of these periods, or whether they have been washed away or undergone a 
change in form, is not known. The life history of the bacillus is therefore an urgent problem requiring solution, and for that reason the Institute has been for some time, and is at present, engaged upon it. One practical fact, however, emerges from what has already been discovered; namely, that a farmer cannot assume that he has got rid of tuberculosis when he has drafted affected cows out of his herd. All the cow buildings should be thoroughly disinfected and finally limewashed.

A Test for Abnormal. Milks.-This account of recent investigations on the subject of clean milk may be concluded by reference to some work on a method suggested by American research workers for distinguishing between normal and abnormal milks. The method consists in adding I drop of a solution of brom-cresol purple to 3 drops of milk in a sterilised tube. With ordinary milk a pale blue colour results. Acid milk gives a yellow colour; alkaline milk gives a violet colour; and the degree of intensity of the colour is some measure of the degree of acidity (or alkalinity) of the milk. If a cow's udder is diseased, or if disease organisms have entered the udder through the teat, the milk from that udder will usually be either acid or alkaline, and a small quantity of it may affect the whole bulk of milk produced from the dairy herd and render it unsaleable. Diseases of the udder are referred to at some length in the chapter on Animal Diseases (see page I38), and as the brom-cresol test is being examined at the Royal Veterinary College, as described in the chapter, it is unnecessary to refer to it here in further detail, beyond saying that the Reading Research Institute has been investigating the possibility of producing from it a simple test which would be more within the range of the farmer. The liquid test requires the use of a sterilised test tube, and this is a practical difficulty on the farm. Brom-cresol papers have therefore been made, consisting of absorbent paper soaked with the liquid and dried, and work is in progress to see whether by the use of these papers a farmer will be able to detect abnormal milk from any cow by the simple process of soaking the paper in the milk and observing the colour produced.

\section{Milk Products.}

Cheese.-Milk which is not consumed whole is usually made into butter or cheese. About butter-making we know a good deal; the standard reached in the farm dairy is often very high. Cheese-making, on the other hand, is a subject on which there is very insufficient information, and a great deal of the cheese on the market to-day is a low-grade product, which, however, finds 
a ready sale because there is a demand for a low-priced cheese, and in the absence of knowledge the demand is satisfied by a cheese of low quality. But it ought to be just as cheap to produce a good cheese as a bad one; the main difficulty is that so little is known of the chemistry of cheese-making, and consequently the methods of manufacture now followed are, from the scientific standpoint, rather crude. In making cheese, the important factor on which almost all stages in the process depend is " acidity."* The first stage in the process, for example, usually consists in adding a "starter " to the milk, the " starter" containing bacteria which control the acidity of the milk. The next stage is the addition of an enzyme, rennet, which coagulates the milk. Subsequent operations, which vary with the type of cheese being produced, are done at various stages in the development of acidity. Finally, the flavour and texture of the cheese depend largely on the degree of acidity. Now at present we have no definite information as to the ranges of acidity which are proper to the various stages in the process of cheese-making. In commercial practice, acidity can only be determined in the earlier stages, during which whey can be separated from the product, and even then the means employed are crude and uncertain. One popular method, for example, is to draw out "threads" from the curd with a hot iron, and the degree of acidity is guessed from thelength of the threads. Even in the most modern cheese factories, the best method employed at present is one of "titration." This method is technically unsound because it only measures the amount of the acidity, which bears no necessary relation to the intensity of the acidity, and it is the latter which is the vital factor. The cheese manufacturer is not to blame, for until more is known regarding the ranges of acidity desired at the various stages, and the methods by which they can be determined, there is no other course for him to follow, and he must remain dependent on chance-as he practically is at present-for the production of cheese of the required quality and flavour, and particularly for the occurrence of the welcomed fungus which gives the blue-veins in Stiltons.

The subject is a wide one and involves much difficult investigation before results are obtainable which can be used in practice. The methods employed are too technical to be described in detail in a publication of this character, but it may be said that the Reading workers have approached the question by investigating the ranges of acidity required for the growth of the organisms responsible for the undesirable discoloration of Stilton cheese.

* We use the term " acidity" because it is the one usually employed, although scientifically it is a loose term and may lead to errors in description. 
This involved, as a preliminary, a study of casein (cheese protein) and the products to which it gives rise, for it was found that some of the organisms lived upon these substances and derived their food from them. The result of this first stage of the research is that the Institute now knows the organisms responsible for the serious fault of discoloration in Stiltons, and the conditions (that is, range of acidity) under which they flourish. The work is now proceeding in order to compare these ranges of acidity with those occurring in the production of good Stiltons, to find out whether it is possible to avoid discoloration by modifying the ranges of acidity. To test for acidity, an electrical apparatus, similar in principle to the one used for soil research work (see page 28) is employed. This is essential for accurate work, for it records the intensity of acidity, which is what we require to know. The method is, of course, much too complicated for use on a commercial scale, but the main thing is to discover the facts, and when that is done they can be put into a form in which the cheese-maker can make use of them, and it will no doubt be possible to suggest to him a method of determining acidity sufficiently accurately for his purpose.

Pig Feeding Experiments.-Under the head of Milk Products we may refer to some experiments conducted at Reading, which were originally started in order to test the value of whey in pigfeeding, but have developed into investigations of considerable importance in their bearing on pig-feeding generally, particularly in its relation to the subject of vitamins (see also page I07). In 1920 the attention of the Institute was directed to the serious loss to the cheese-making industry by the waste of whey. Whey cannot be run into streams or rivers without causing serious pollution, nor can it be satisfactorily dealt with on the land; as a pig food, however, it presented important possibilities, and it was in order to test these, and to ascertain the relative advantages of fresh and sour whey, that the experiments were commenced. It was necessary, however, to consider the value of whey as a winter food from all points of view, as it appeared possible that the beneficial results obtained from feeding whey were not limited to the value of the nutrients which it contained, but were influenced to some extent by the presence of vitamins. A series of experiments was therefore started in the spring of 1920 designed to test these points. In the following account, which gives the results up-to-date, frequent reference is made to vitamin A. It should be explained that this is one of those unknown accessory food substances already referred to, which have never been isolated, but are known to be present in certain foods 
because animals cannot live without them. Vitamin A is present in cod liver oil, but is absent from olive oil.

In the first series of experiments a litter of ro Berkshire pigs, weaned at the age of eight weeks, was divided into five groups. Group I was kept in a sty and fed on a diet consisting of the constituents of whey in which olive oil (free from vitamin A) replaced the fat of the whey. Group 2 was kept under similar conditions and received whey and toppings. Group 3 received the same kind of food as Group 2 but was kept in a portable sty on pasture, since grass contains all the known vitamins. Group 4 was also kept on grass, but had no whey in the ration supplied. Group 5 was kept under farm conditions, being fed on a mixed diet of toppings, whey and swill, and having abundance of green food in addition. At the end of three months on the experimental diet the hogs were slaughtered, the sows being retained for further experiment. The differences in growth and well-being of the hogs were marked, the dressed dead weights being as follows :-Group I-84 lbs.; Group 2-I22 lbs.; Group 3-I20 lbs.; Group 4-I03 lbs.; Group 5-I50 lbs. It was surprising that the animals in Group I should have grown so well on a diet so deficient in vitamins, but on testing the fat of the animals by feeding them to rats whose growth had been brought to a standstill by a deficiency of vitamin $\mathrm{A}$, a striking difference in the nature of the fats was demonstrated. The body fats from pigs in Groups I and 2 were found to be of no value as a source of vitamin $A$, while the grass-fed animals yielded fat containing appreciable amounts of this important growth-promoting substance.

From this experiment it would seem that whey contains insufficient of the vitamin A to allow excess for storage in the fat. If grass or green food is fed at the same time, this deficiency is made up. There would also appear to be a value in whey (as shown by the difference in weight between Groups 3 and 4 ) independent of its vitamin content.

The experiment was continued with the sows of Groups I to 4. In 48 days the weight of the sow in Group I had become almost constant at 132 lbs. Group 2 was making little progress at I 44 lbs Group 3 weighed I8o lbs. and was doing well; Group 4 weighed I52 lbs. At this stage in the experiment a quarter of an ounce of crude cod liver oil, a substance rich in vitamin $A$, was given to the sow of Group I. This small dose, given instead of the olive oil in the diet, caused the immediate resumption of normal growth. The sow in Group 2 also recovered normal growth on being given 2 lbs. of lucerne per day. 
When sufficiently grown the sows were put to the boar and afterwards placed on their original restricted diets, in order to find out the effect produced on the offspring and on the milk. The sow in Group I gave birth to eight pigs, only one of which lived as long as 5 hours. Marked abnormality was shown in the other pigs. This malformation was particularly pronounced in two cases in which the hind limbs were represented by thin, tail-like appendages. This sow was again put on a diet containing vitamin A (in grass) before being put to the boar, with the result that a normal litter was produced. The sows in Groups 2 and 3 produced litters of normal pigs.

The experiments have been continued for a further season and an account will in due course be published. The results have again demonstrated the good effect of cod liver oil (supplying vitamin $\mathrm{A}$ ). The experiments also tested the effect produced by the addition of calcium and phosphates to the diet, and the results show the beneficial effect of these substances, provided a sufficient supply of the essential growth-promoting vitamin is present in the diet.

\section{CHAPTER IX.}

\section{ANIMAL DISEASES.}

Research into animal diseases is carried out mainly at the Royal Veterinary College, London, and at the Veterinary Research Laboratory of the Ministry of Agriculture and Fisheries, New Haw, Weybridge. Worm parasites of animals are investigated at the London School of Tropical Medicine and at the University of Birmingham. This chapter will contain an account of the main lines of research in progress at all four centres, and will also refer to two further investigations which are being carried out by means of special grants.

\section{Research Institute in Animal Pathology, Royal Veterinary College, London.}

The principal diseases which have been under investigation during the past year and which are still being studied are joint-ill in foals, contagious abortion in mares, and contagious mastitis or inflammation of the udder in cows.

Joint-ill in Foals.-This term is applied to cases of acute illness in young foals in which one or more of the large joints of 
the limbs are visibly swollen and inflamed. In many cases the swelling of thejoints is preceded or accompanied by disease of the navel, and the term " navel ill " is therefore almost synonymous with joint-ill. The disease is a common one, and since it has a high mortality it is a source of annual loss and disappointment to breeders, especially to those who possess valuable animals. The disease of the navel is usually of the nature of an abscess, and an examination of the pus which forms there often shows bacteria of the form known as streptococci. Within recent years anti-streptococcus serum - that is, a serum drawn from horses who have been injected with increasingly large doses of streptococci and thereby developed immunity from the disease-has been largely used in the treatment of joint-ill, and its injection into healthy foals has been recommended as a means of prevention. In the belief that previous infection of the mare is responsible for many cases of joint-ill, it has also been held that the disease may be prevented by treating mares with serum or vaccine shortly before foaling. Experiments in connection with joint-ill have been in progress at the Institute since I9I7, and for the first three years an endeavour was made to ascertain whether anti-streptococcus serum was actually effective for prevention or cure. The results of the work indicated that the serum had failed to exert any appreciable influence on the death rate. Further, the histories of nearly 700 cases of joint-ill showed that some of the views hitherto current regarding the disease were erroneous. Except possibly in an insignificant proportion of cases, the disease is not derived from the mare; the foals as a rule are born healthy, and the disease arises from the contamination of the navel with what may be called dirt bacteria. The bacteria known as streptococci are the cause of only about $50 \%$ of the cases, and three or four other species of organisms are accountable for the remainder.

During I920, therefore, the Institute abandoned serum treatment, and resolved to issue vaccine prepared from streptococci. The vaccine is composed of the artificially cultivated organisms killed by heat. Streptococcus vaccine has for several years been widely advertised, and probably to a considerable extent sold, as a remedy of great value against joint-ill, but no statistics of any value have ever been published to show what effect such treatment has either for the prevention or the cure of the disease. During the last foaling season the Institute sent out over 2,000 doses of vaccine prepared from streptococci isolated from actual cases of joint-ill. Some of this vaccine was employed for the treatment of mares before foaling, and the remainder for the treatment of foals immediately after birth or 
for foals that had developed the disease. Altogether about 600 foals were thus treated, but full details of the results have not yet been collected from the veterinary surgeons and owners. It may be said, however, that many of those who have used the vaccine for mares before foaling and for healthy foals at birth have expressed themselves as highly satisfied owing to the small number of cases of joint-ill that subsequently occurred, or to complete freedom from the disease after the vaccination.

Unfortunately, from the outset of the investigation it has been found very difficult to assess the value of any method of treatment, because there has not been discoverable anywhere information to show what is the average incidence of joint-ill among foals in this or in other countries, and until the previous reports of the Institute were published there was also very little information to indicate what is the average mortality among foals attacked with the disease and left untreated or treated by different methods. The figures which the Institute have collected suggest that the mortality among foals affected with the disease is somewhere about $50 \%$, and it is feared that the vaccine treatment practised this year has not lowered that figure. This year an attempt has been made to ascertain both from veterinary surgeons and owners actual figures showing for a number of successive seasons : (I) the number of foals born, (2) the number of those that developed joint trouble, and (3) the number of the latter that died from the disease.

Contagious Abortion in Mares.-This disease has been under investigation at the Institute since I9I6. In the spring of that year, the occurrence of a number of cases of abortion in a stud was reported to the Institute, and an investigation, which was made immediately, led to the isolation of an organism which appeared to be the cause of the trouble, and which was subsequently identified with a bacillus isolated in cases of abortion of mares in Holland and the United States. Later work proved that this bacillus was actually responsible for the disease, and a serum was accordingly prepared for the treatment of pregnant mares known to have been recently exposed to infection. The Institute is now in a position to decide immediately by bacteriological examinaton of the aborted fœtus, or by testing the blood of the mare, whether any case of abortion is caused by this bacillus or not, and by applying the latter test to the other mares it is also possible to ascertain to what extent the disease has spread in the stud. With this knowledge it is often possible to effect an immediate separation between the diseased and the healthy, and thus cut short the outbreak. 
In cases in which it has been found that the bacillus was responsible for the disease, serum has been supplied for the mares that were still carrying their foals, and favourable reports of the treatment have been received. During I920 and I92I the Institute has dealt with a considerable number of cases of actual outbreaks of abortion in mares, and has endeavoured to give the widest publicity to breeders of Thoroughbred, Shire, and other horses that the disease is being investigated. A request that the occurrence of cases should be notified to the Institute has been widely circulated. The object of the continued investigation is not only to assist individual breeders to deal successfully with outbreaks when they occuir, but also to obtain information showing to what extent the disease prevails in this country.

In all cases in which the disease is proved to be of the contagious character an endeavour is made to trace its origin in the particular stud. It has to be admitted that up to the present time this effort has in many cases been unsuccessful, mainly because all the particulars necessary to guide to a conclusion were not forthcoming. The experience of the Institute would indicate that contagious equine abortion is not yet a very common disease in this country, and that it is in fact rare except among thoroughbred horses. There is no doubt, however, that in certain circumstances it might soon assume alarming proportions, and it is greatly to be desired that breeders of all classes of horses should take advantage of the assistance which the Institute offers when an outbreak is notified.

Although what has been learned during recent years marks real progress, much still remains uncertain with regard to a number of important points. The question of the rôle of the stallion in the propagation of the disease is a little uncertain, but the facts in the possession of the Institute indicate that the disease is seldom or never spread in that way. Another point about which further information is required is the duration of the disease in the mare after abortion has occurred, that is to say, the length of time for which such a mare may be capable of spreading the disease. As is now well known, this is often a long period in the case of epizootic abortion in cows, but the facts so far collected by the Institute encourage the belief that the recovery of mares is much more prompt.

Contagious inflammation of the udder, or Mastitis, in cores. -Inflammation of the udder, or what is commonly called " garget," is a very common condition in cows. In almost every herd of moderate size it is possible to find evidence of udder disease 
in one or more of the animals. Even within modern times, inflammation of the udder was very generally ascribed to what were vaguely called " chills," and it was seriously believed that a draught playing on the cow's hind quarters was likely to be followed by an attack of garget.

At the present day, it may safely be asserted that nearly all cases of inflammation of the udder are caused by the multiplication of bacteria either in the so-called milk cistern or in the tissue of the udder itself. It is already a matter of popular knowledge that the tubercle bacillus is responsible for one form of garget, and that form is invested with quite special importance because the milk secreted by the udder may be a cause of infection to human beings. It has also been maintained that certain other forms of garget are important in relation to human health, especially in connection with outbreaks of sore throat. It must be recognised, however, that putting aside all question of danger to human beings, inflammation of the udder has a considerable economic importance because of the temporary or permanent loss of milk from the affected quarter or quarters of the udder. From this point of view even what are called sporadic cases are in the aggregate important. The term "sporadic" as here employed is intended to cover the occasional single cases which occur from time to time in nearly every herd, and is used in opposition to those cases which occur in the form of actual outbreaks involving a considerable or even a large proportion of the whole herd. It must be admitted, however, that the distinction between these two classes of cases is not sharp, for, given the occurrence of a single case, one has no assurance that the disease may not be spread to other cows if all precautions are neglected. With the notable exception of tuberculous inflammation of the udder, the general method of infection in mastitis is by way of the canal of the teat, and the milker's hand is the agent that transfers the baccilli from the diseased to the previously healthy cows.

While the views just expressed now find general acceptance, there is still a great lack of precise information regarding the germs that are responsible for different cases of inflammation of the udder, and the best methods of prevention and treatment. This is reflected in the inadequate account of the condition given in even the most recent editions of the standard text books dealing with diseases of animals.

Although a systematic investigation of inflammation of the udder was only begun during the past year, occasional outbreaks have been dealt with as far as the resources of the Institute allowed in previous years, and the experience thus gained disclosed the 
difficulties which lie in the way of investigation. When assistance in dealing with an outbreak is requested, the first point to be determined is the actual cause of the condition, and with that object the milk has to be examined in order to determine what organisms if any are present in it. At the very outset difficulty arises from the fact that the normal udder generally appears to yield milk containing bacteria, and such bacteria may multiply after the milk has been withdrawn from the udder, and have become numerous before the sample has reached the laboratory. In such circumstances, the difficulty in detecting the particular organism responsible for the mischief is greatly increased. Efforts are being made to discover some substance which when added to the milk at the time of milking might prevent the multiplication of bacteria in transit without actually destroying them. This difficulty of course disappears when the milk can be examined on the spot, but a complete bacteriological examination of milk is scarcely possible except in a fully equipped laboratory.

It may be said, however, that in spite of these difficulties, it is generally possible promptly to come to a conclusion as to what is the particular organism causing the inflammation when the udder is obviously diseased and the milk is altered in appearance. It is only when this point has been determined that one can proceed to consider methods of cure or prevention. Dealing in the first case with prevention, it will be obvious that if the further spread of the disease is to be stopped, steps must be taken to hinder the transference of bacilli from the infected to the healthy cows, especially by the hands of milkers. This applies specially to the visibly diseased cows, but unfortunately in the very contagious form of garget it has been found that precautions of this nature, when confined to the visibly diseased animals, are not effectual in preventing the spread of the disease. The explanation of this failure lies in the fact that in its early stages infection is not manifested by any decided change in the appearance of the milk or by any distinct alteration in the quarter itself. In other words, the difficulty that has to be overcome is that of early diagnosis.

In some outbreaks already dealt with an attempt has been made to reach this object by laborious repeated tests of samples of milk from all the apparently healthy cows in the herd, and in this way fairly satisfactory results have sometimes been obtained. The diagnosis in these cases was reached by what may be called bacteriological methods, but it has recently been suggested that it may be possible to detect infections of the udder at a very early stage because of alterations in the chemical reaction of the 
milk which are induced by the inflammation. For this purpose brom-cresol-purple has been used by investigators in the United States, and in the National Institute for Research in Dairying at Reading. The method is also being employed at the Royal Veterinary College, but it is not yet possible to say whether in practice it will enable one to dispense with the more laborious method of microscopic and cultural examination of milk from all the healthy cows in dealing with an outbreak.

The prevention of the spread of infection in cases of udder diseases acquires special importance from the fact that hitherto very little success has been obtained in the way of cure. The prospects of being able to reach and destroy bacteria either by medicines given to the cow by the mouth or by disinfectants introduced into the udder itself are not at all hopeful. Already, however, vaccines for the treatment of udder disease are being manufactured and sold, but, just as in the case of joint-ill in foals, one can find little or no evidence by which the value of these materials can be judged. In the Institute attempts are being made to test the actual value of vaccine in a large number of cases.

\section{Veterinary Research Laboratory of the Ministry of}

Agriculture and Fisheries, Weybridge, Surrey.

Diagnosis of Disease.-The Ministry's Institute is responsible for the diagnosis of all the "scheduled" diseases, and it also concerns itself with the diagnosis of disease in general. It thus handles a large amount of disease tissue and organs. In connection with this work it has developed, and is developing and extending, those methods applicable to the diagnosis of diseases which can only be properly carried out in a laboratory. The results are particularly apparent in connection with the diagnosis of swine fever, which is often complicated by the simultaneous existence of other diseases with somewhat similar lesions. The most important development, however, has been in connection with rabies, to deal with which a considerable organisation was set up when the disease was found to have re-invaded Great Britain after an absence of 16 years. A new and reliable method of diagnosing this disease has been developed at the Institute, and by the use of this method the time necessary to obtain a definite diagnosis has been reduced from an average of three weeks to about ten hours or less. The advantage of this is obvious, as it enables the authorities to take full action almost immediately the disease is suspected. 
Contagious Abortion in Cows.-The vaccine for giving bovine animals a resistance against this destructive disease was elaborated and worked out at the Institute. It is still being studied with a view to obtaining further improvements. The appreciation of its usefulness may be gathered from the fact that the Laboratory has to prepare 30,000 doses annually to meet the demands of stock owners. Leaflets and reports explaining its use and advantages have been issued for the information of farmers.

Immunisation of Pedigree Stock before export to tropical and sub-tropical countries.- One of the hindrances to our export trade in pedigree stock is the fact that these valuable animals tor the improvement of native breeds so frequently die from the diseases prevalent in the countries to which they are exported. The virus of some of these diseases has been brought to this country, and experiments have been and are being carried out with a view to obtaining a method of immunisation which can be applied before the animals are shipped from Great Britain. Very considerable progress has been made, and it is now a practicable proposition to immunise bovines against tropical red water (Piroplasmosis bigeminum). There is also good reason to believe that it will soon be practicable to immunise against anaptamosis, a disease which takes a heavy toll of animals imported into South Africa, the Argentine and Brazil. Provision has also been made at the Institute for carrying out the actual immunisation of animals before shipment.

Diseases of Sheep.-The investigation of diseases of sheep, which has been much neglected, is receiving attention, and much progress has been made. Some of these diseases-" scrapie," for example-have very long incubation periods, and this necessarily makes experimental investigation a slow process. In "scrapie" the incubation period is about two years.

Helminthology.-The worm parasites of the domesticated animals and the pathology and epizootiology of the diseases caused by them in Great Britain are being studied, and papers on the subject have been published. A specially trained officer to deal with this subject has recently been appointed to the Institute.

Poultry Diseases.-For several years the Institute has been investigating diseases of poultry, but has been greatly retarded by want of proper provision in the way of funds and special staff. That difficulty has now been surmounted. and a poultry pathologist will be appointed to concentrate on this subject. 


\section{WORM PARASITES OF ANIMALS.}

\section{University of Birmingham.}

There is an urgent need for further information regarding animal diseases in this country due to worms. In some cases where the seriousness of the disease is evident, investigations have been carried out and preventive and remedial measures have been devised. There are, however, vast numbers of worms of various sorts which take up their abode in the alimentary tracts of animals, living at the expense of the latter, about which little or nothing is known. In many cases the symptoms of attack are not markedly characteristic, and the only noticeable feature may be loss of condition of the animal, so that the need for further knowledge has not been regarded as urgent. It is clear, however, that the aggregate loss to our flocks and herds, due to worms, must be very great, even though the actual mortality is not high. When the University of Birmingham began work on the subject in I9I3, and investigated a disease of sheep due to round-worm attack, it was found that the infected animals contained a large number of different species of round-worms, many of which had hitherto not been recognised in this country. Before treatment could be suggested for this or any similar disease, therefore, it was necessary to make a systematic survey of the round-worms affecting sheep. This was done, and a complete list of genera and species was completed in I9I4. A detailed study of the life history of one of the worms-Nematodirus filicollis, which causes scouring in sheep-was then made, and the results published in I9I5. About this time there was a serious outbreak of red-worm in horses in the Redditch district. In investigating this outbreak the Department found that the round-worms attacking horses had never been scientifically studied, and that there were nearly 20 totally distinct species present in the diseased animals. A similar study of the red-worms affecting horses was therefore commenced, and a complete list of genera and species published in $19 \mathrm{I} 7$.

Meanwhile another group of worms, the tape-worm, was being investigated. In this case, also, it was soon found that little information existed regarding the various forms of the tape-worm attacking farm animals in this country. The tapeworms attacking fowls were first studied, various species being identified and their life histories investigated. From diseased fowls sent to the Institute it is clear that tape-worms are frequently responsible for emaciation and often cause death. 
None of the life histories of the adult tape-worms affecting grass-eating animals are known. The Institute is now attempting to find out the life history of a tape-worm affecting horses, and at the same time is studying a tape-worm of sheep, known as. the lamb tape-worm, Moniezia expansa. This parasite has recently been causing serious losses amongst lambs and sheep, particularly in North Wales.

A study of the lamb tape-worm common around Aberystwyth is also being made by the University College of Wales, Aberystwyth, with the aid of a special grant.

One of the best known and most dreaded flat worms is, of course, the fluke worm, which causes liver rot in sheep. As is well known, this worm spends a part of its life history in a small water-snail, Limnea truncatula, one of a number of species of somewhat similar snails which are common on wet lands throughout Great Britain. The Advisory Officer in Zoology attached to the University College of North Wales, Bangor, has devoted much time to the study of this worm during the past few years, and in particular has investigated closely the life history of the snail, which had hitherto not been accurately known. He found, amongst other things, that the eggs of the snail can apparently survive very considerable drought, hatching out in the autumn when all adults have perished and the land is apparently free from snails, or only dead snails can be seen. Thus the impression amongst many farmers that land which is apparently free of snails in the autumn will not produce liver rot, may not be correct. Such knowledge is now proving very useful to him in dealing with the outbreak of liver rot in North Wales. The disease lately spread in this district to an alarming extent, and owing to the Advisory Officer's special knowledge of the subject, much of his time has been taken up in dealing with requests for advice from farmers who feared attack. During last summer he carried out a series of spraying experiments with copper sulphate in an attempt to eradicate snails from the pasture land. The results so far are very promising, and are being continued.

\section{Unversity of London (Helminthology Department of the London School of Tropical Medicine).}

An important line of work which has been going on since I9I9: and is still in progress consists in the preparation of a guide to the diagnosis of worms affecting domestic animals by means of the eggs found in their fæces. As a result of the preliminary work the important fact was observed that the eggs of parasites could be grouped according to the classification of the adult worms, 
and that in general the species of a genus of worms possess common egg characters. Thus it will be possible by the examination of eggs found in the fæces, to determine the nature of the worm infection. Already a considerable number of egg photographs have been secured, and the work is approaching completion.

A further " general " line of investigation refers to the method by which animals are infected with worm parasites. It is known that certain round-worms which attack man, such as the hookworm, are able to enter through the skin. The larva throws off its sheath, and penetrates through the skin into the blood stream, whence it finds its way viâ the lungs into the intestines. It is important to know whether this power is possessed by any of the worms affecting farm stock, for if so the latter could contract disease merely through lying on infected pastures. An ingenious method has been devised for ascertaining whether any species of worm has the power of boring through the skin, and this method is being used in an investigation of the worm parasites of horses and sheep.

A series of experiments has also been commenced to find out whether it is possible for damage to be caused to an animal by the larvæ of parasitic worms which are not normally parasitic in it. For example, it is known from recent work in this country and the United States that the eggs of the round-worm of man and the pig, Ascaris lumbricoides, when administered to a number of other animals, mice, rats, guinea pigs, rabbits, and lambs, set free their larvæ on reaching the intestine. These larvæ bore their way through the intestinal wall, and, getting into the blood stream, travel to the liver and lungs, where they produce lesions and finally reach the intestine again by way of the wind-pipe and nesophagus. Such larvæ do not attain maturity in the intestine of the new host, and in most cases are discharged from the body. Near relatives of the round-worm of the pig are known to occur in certain grazing animals, e.g., the horse and the ox, and their eggs on passing out with the droppings, must be widely distributed over pastures where the infected animals feed. These eggs may easily be picked up by other grazing animals put on to the infected pastures. It is therefore of considerable importance to find out whether such eggs can become infective to other animals taking them in during their cropping of the herbage, and whether their larval stage can be set free in the intestine and subsequently cause lesions in the liver and lungs of the new host. It has usually been assumed that such larval stages, belonging to parasites not normal to a given host, would be destroyed by the digestive juices of the animal, but there is reason to suppose that a parasite which is not found in the adult stage in the 
animal, may yet be active in its larval stage and cause injury. This point is regarded as of sufficient importance to justify an extended inquiry.

The study of two round-worm parasites of poultry, namely, Heterakis and Syngamus, has also been carried out during the last two years. Heterakis lives in the intestines of fowls. The complete life history has been worked out. The eggs pass out with the fæces, and hatch in about a fortnight. The larvæ become adult in about three weeks. They do not feed outside the body, so that there is no fear of skin infection, and if the fæces are removed, so will be the sources of infection. Syngamus is the cause of "gapes" in poultry. The eggs (which hatch outside the hen) are infective after about two days for three months. The worm may become adult in the body in I4 days after infection.

Tylenchus (Eelworm) in Clover.-This investigation was carried out at Rothamsted before the worker was transferred from that institution to the London School of Tropical Medicine. Tylenchus is an eelworm which attacks clover plants and is responsible for one form of clover " sickness." The plants are attacked either in the seedling stage or later, the eelworm causing swelling in the stems and a curious twist of the leaves. The disease has been known for many years in this country, and various methods of prevention have been recommended, such as deep ploughing, treatment with potash, salts, \&c., but only as possible remedies. It has been recognised that some clovers are more liable to attack than others, and the object of the investigation was to see if clovers could be classified according to their susceptibility to attack, so that if a farmer knows that eelworm is present in the soil he may avoid sowing a highly-susceptible clover. The classification would also be useful in breeding clovers immune from the disease. One hundred seeds of different varieties of clover were therefore sown in pots of highly infective soil and grown under exactly similar conditions as regards temperature, moisture, \&c. The extent of attack was very carefully estimated. It was found that the red clovers of all nationalities, and kidney vetch were highly susceptible to the disease; the alsike clovers were very much less susceptible; the white clovers were only lightly attacked. A fourth group, comprising lucerne, trefoil and one kind of white clover, was not attacked at all. While these results are very significant, it must be remembered that they represent only one season's work, and require confirmation before they can be regarded as established. 


\section{CHAPTER X.}

\section{FARMING AS A BUSINESS.}

We have considered the various directions in which scientific research is helping the farmer, and have tried to show how a small number of research workers are engaged in studying the soil and the means by which it can be made to produce more abundantly, and in investigating the many problems of animal and plant life. There remains to be considered a subject which is equally important, if its value has not hitherto been so widely recognised. The study of this subject is scientifically described as research into agricultural économics; but in so far as concerns its direct application to problems confronting the farmer, it may be termed the investigation of methods which will enable a farmer to understand his business. For however useful a knowledge of how to increase output may be, the main concern of the farmer is to sell that output at a profit, and to this end he must not only understand the position with regard to the trend of markets and prices, but he must know accurately what the output in question is costing him to produce. It is a curious sidelight on our national attitude of mind that, notwithstanding that agriculture lies at the root of the prosperity of all nations (for we must eat to live), it is often forgotten that farming, after all, is a business, and that if it is to keep pace with industrial competition the farmer must learn to manage his business with the same care and attention to method as does the manager of a factory. Unfortunately the subject of agricultural economics has been seriously neglected in the past, and agricultural teachers have accordingly little enough information to put before the farmer to-day. It is of little use, for example, to tell the occupier of a mixed farm that he should know exactly what it is costing him to produce a gallon of milk, unless at the same time he can be shown how to secure that information, and it is the investigation of problems of this sort which come within the sphere of the research worker. The institution engaged in investigating the subject in this country is the Institute for Research in Agricultural Economics attached to the University of Oxford, and although this was established only a year before the War, considerable progress has already been made, which it is the purpose of this chapter to record. 
The subject which has so far engaged the larger share of attention at the Institute, on account of its prime importance, is cost accounting; in other words, the development of a system of book-keeping which will enable a farmer to ascertain the profit arising from each productive department of his farm, and thus to criticise his own management and to see in what way it could be modified with financial advantage to himself. It is not enough to know approximately what profit is being made on the farm as a whole; this information is, of course, valuable, and many farmers are now having accounts kept on these lines, partly for income tax purposes, and thus have the advantage of knowing how they stand financially at the end of the year. But the result gives no indication as to how any particular branch of farming compares with another branch, and experience of costing shows that the farmer who thinks he can judge of this from experience and from a study of prevailing market prices is often at fault in his conclusions. Certain concrete examples of this, chosen from farms for which accounts were kept by the Oxford Institute, may be quoted. A South-Midland farmer, who was under the impression that he was making money on sheep, found that actually his flocks had involved him in a loss of about $f 600$ during the year. This was for the year ending Lady Day, I92I, and therefore before the present severe slump in prices of sheep, and the loss was directly attributable to the heavy wages bill which was incurred in this department of his farm. The farmer has decided to continue sheep farming for another year, and if it still shows a loss he will consider the question of altering his system of farming. In the case of this farm, also, the accounts revealed a possible wastefulness in the old custom of paying wages partly in cash and partly in kind; for it was shown that the bailiff, whose wages in cash were about $£$ I5o a year, was actually receiving the equivalent of $£ 400$ a year in allowances, thus bringing his total wage to over $f$ II a week. Another case is that of a Sussex farmer, who was firmly convinced that his profits were derived from his store beasts. The first year's accounts showed that he had lost nearly $£ 200$ from these cattle; in the second year, the loss was slightly greater. He therefore decided to alter his policy, and has gone in for dairying, which pays him extremely well. The accounts of this farm also showed that his methods of controlling the feeding of the stock were open to criticism; the rations were admirable, but the stock were actually consuming 30 per cent. more than their prescribed rations. This was rectified in the following year, with the result that the margin of waste due to errors in feeding was reduced to five per cent. 
The above examples illustrate the case for cost accounting. It is realised, of course, that farming is a complicated business, and that the farmer has not the freedom of the manufacturer in the direction of closing down unprofitable articles of production; yet a good deal can be done, within certain limits, to develop the system of farming in the direction of the more profitable lines, given a knowledge of the financial results obtained in each productive department of the farm. The farm records and analysed costs of each important product enable the farmer to judge of the relative financial advantages of various farming processes in a way that neither scientific knowledge nor practical experience can do unaided. He can test the efficiency of various forms of power; he can check the management of horse labour by the record of idle days and their distribution throughout the season; he can check his direction of manual labour by an examination of the percentage cost of labour in any total product-cost when compared with other published results for the same product or with the results of former years on his own farm; he can check the efficiency of feeding and manuring; he can keep control of the issue and use of materials of every kind, feeding stuffs, manures, tools and parts, \&c., and thus prevent their careless use and consequent waste; he is provided automatically every year with a cost valuation of all the live and dead stock, tillages, \&c., on the farm. Briefly, cost accounts furnish the only reliable means by which a man can satisfy himself that losses in certain departments are not being incurred unsuspected because covered by the profit of other departments, and also the means by which to reduce costs by the better organisation of production within departments, so as to turn unprofitable ones into paying enterprises and to make successful ones more successful still. The work published by several Institutions on the cost of milk production is known to most people and may therefore be cited by way of illustration. Examination of the analysed cost in many herds showed a remarkable variation between the best and the worst; in some cases bad results (i.e., high costs) were due to low milk yields, in others to expensive feeding, in others to faulty management of labour; but in every case the cause or causes of the poor results were only ascertained when all the costs of production were available for analysis and comparison.

The great advantages resulting from the adoption of a proper method of cost accounting have been emphasised in the above paragraphs, in order to show that the time that has been and is being spent at the Oxford Institute in devising methods which will be adequate to serve the purpose in view is fully justified. For although at first sight it may appear a compara- 
tively simple matter to construct a system of cost accounts for use on the farm, in practice, owing partly to the inter-dependence of the various departments of the farm, and partly to the relationship of manures, \&c., to rotations of crops, the problem is extremely difficult and complicated. When the Institute was established in I9I3, the subject of cost accounting on the farm was one that had received no attention in this country; there was no literature on the subject, and nothing to guide the Institute in methods and principles of work. Research has, however, resulted in the formulation of a system which, though admittedly not perfect, does show the cost of each operation on the farm, and the profitableness or otherwise of each department. Certain items, such as the distribution of the cost of fallowing amongst subsequent crops, and the influence of manures applied to one crop on succeeding crops, have of necessity to be dealt with on an arbitrary basis, but experience has shown that the probability of error arising from such cases is not of sufficient importance to affect the practical value of the total costs as ascertained by the method.

Records have up to the present been obtained for upwards of 60 farms, and the method adopted may be briefly indicated. The farmer is supplied with weekly labour sheets which are intended to show for each day the class of work done by each man, the time devoted to it, and the number of horses used. These are filled in and returned to the Institute, together with the farmer's cash account. The remainder of the work is done at the Institute. Here the labour sheets are carefully analysed, and the final accounts when made up show the total cost of each department of the farm (wheat, stock, milk, \&c.), the total cost being analysed again into cost due to labour, food, manures, \&c. In particular the accounts show the number of days worked by each horse during the year, and the total cost of its upkeep, so that the economy exercised in the working of the horses can readily be ascertained.

In connection with cost accounting, the Institute is keeping continuously in view the desirability of simplifying the method, wherever this may be possible without affecting its accuracy. The method now used is too complicated for a farmer who has not an accounting clerk, but it may be found possible to modify it in certain directions so that, in most of its stages at all events, it can be done on the farm. In the meantime a simple system o: departmental records has been devised which a farmer can quite easily keep, and which will give him much more information of his business than an ordinary financial statement, although 
it does not give the detailed particulars obtainable from a costing system.

Horse labour plays so large a part in the total cost of production of most farm produce that it is worth while referring to an example of the importance of paying close attention to this item, drawn from data recently compiled by the Institute. The maximum number of working days in a year is 312 , a total obviously unobtainable in practice. Detailed figures regarding the employment and cost of upkeep of the horses on four farms were collected, and it was shown that if the horses had been employed for the maximum number of 3I2 days during the year, they would have cost $2 s .7 d$. to keep for each day worked, whereas owing to the time lost the actual cost was $3 s .7 d$. This clearly points to a waste of horse labour which could be avoided by skilful management, and one of the tests of a farmer's efficiency is provided by an examination of the distribution of horse-labour throughout the year on his farm. His cropping and other work should be so contrived as to provide for the uniform utilisation of horselabour month by month. In the case of the farms above referred to, the percentage of days worked to possible horse-days varied from $38 \%$ in July to $82 \%$ in February. While some variation is, of course, inevitable, it should not be so great as this. The problem may be put in a more concrete form by reference to a further example, taken from the records of a well-managed East Midlands farm. The farmer employs 26 horses, and during each of the six years ending I9I8-I9, the number of days worked per horse was about 244 . Thus the total horse-days required during the year was $244 \times 26=6,344$. If he reduced his horses by two, the remaining 24 must work 265 days each. The problem for the farmer, therefore, is whether he can so arrange his cropping or other system that his horses may be worked for a further 2I days each. If so he can reduce his horses by 2 , which would also mean a saving in labour nearly equal to one man.

\section{Farm Organisation.}

There are questions which arise in the minds of most farmers, to which practical and useful answers can be deduced from a methodical study of the organisation of the various types of farming. For example, a farmer with a certain amount of capital, perhaps mainly represented by live- and dead-farming stock, may ask whether it would pay him better to use this capital on the land he occupies, or to add another fifty acres to his farm. Or he may say: "I have a little more capital than I am now using on my land. Should I use more labour on the land I have, or obtain more land and spread it over that?" He may even say : "My 
farm is not paying well. Should I reduce the acreage, and use all my capital and labour on a smaller farm?" The following example has been furnished by the Oxford Institute to show that a competent investigator, compiling a set of records in a district or for a type of farming, could provide the information on which answers to such questions could be based.

The amount of land and its capital value, the capital of the farmer, with the labour employed, are shown for a group of five farms. The productive result of the combination of the land, capital and labour, is shown in the net output, or the total net sales of the farms.

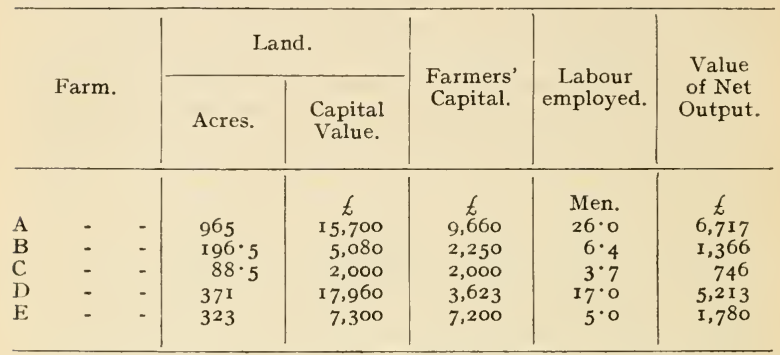

Farmers will appreciate the differences between these farms more quickly if the rents and amounts of farmers' capital are shown per acre, and the amount of labour per Ioo acres.

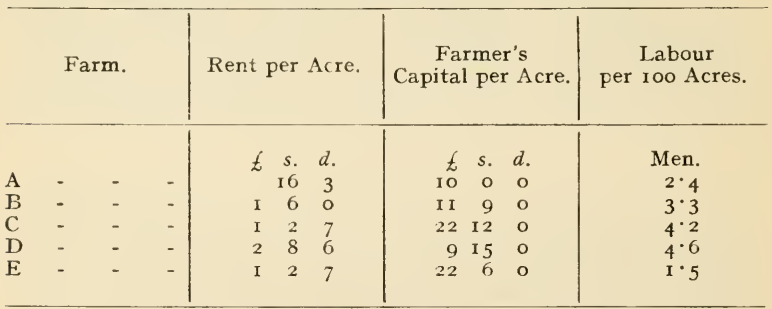

If the rent of the land is an indication of its quality, as most farmers would assume that it is, it will be seen that the application of capital and labour to the land does not vary with its quality. But the result of the varying combinations of the three factorsland, capital and labour-may be judged by finding the amount 
of each which in combination with the others is required to produce a net output of the value of $£$ r,ooo. Here the land is shown in terms of both acreage and capital value.

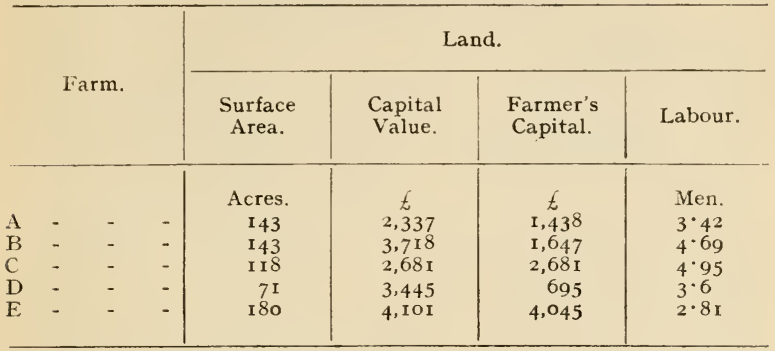

For the purpose of measuring the efficiency of the combination of the three factors it is better to take the capital value of the land rather than the area. On this basis it may be shown that the amount of the combination required to produce $£ \mathrm{I}, 000$ value of net output is represented by the following figures:-

$$
\begin{aligned}
& \text { A } \quad \ldots \quad \ldots 3.00 \\
& \text { B } \quad \ldots \quad \ldots 4^{\circ} 08 \\
& \text { C } \quad \ldots \quad \ldots 4.25 \\
& \text { D } \quad \ldots . \quad \ldots 2.90 \\
& \text { E } \quad . . . \quad \ldots .5 \cdot 38
\end{aligned}
$$

Farm D requires the smallest amount of the three combined factors to produce the amount of net output, but it is almost certain that better results would be obtainable on this farm if the farmer's capital were slightly increased. The capitalisation is too low in proportion to the quality of the land and the amount of labour used. On the whole, Farm A gives the best result. It is a light land farm, of comparatively poor soil and low rent, and the capital and labour appear to be nicely adjusted to requirements. On Farm E more labour is required, and Farm B could probably be better organised if a little more of labour and capital were applied to the land. In the case of farm $\mathrm{C}$ the results would be better if the labour and capital were spread over a little more land.

The above is only a limited record of the work in progress at Oxford, because it is confined to questions which directly and intimately concern the farmer. There are many other matters, whose importance is national rather than local, which come 
within the scope of an Economics Research Institute, but it has not been thought desirable to refer to them in detail in a publication of this character. A few of the more important may, however, be mentioned. Considerable controversy has arisen over the question of the economic possibility of small holdings, and whether the small or the large farm is the most economical from the point of view of the nation. To throw light on this matter an intensive survey has been made of 52 farms of various sizes, totalling 9,390 acres, in a district selected because of the uniformity of the general conditions. The results have been tabulated so as to show the production per unit of land and per unit of labour from holdings of the different sizes included in the area. Similar surveys of the Severn Valley, Pembroke, Malvern district and Montgomery have been carried out, and the results are now being tabulated. Maps have been prepared showing for each county in England and Wales the density of the distribution of each crop and each class of live stock. A comprehensive inquiry into the position of rural industries in England and Wales, such as hurdle-making, basket-making, leather-dressing, \&c., is in progress, and a valuable report on the position in the Oxfordshire area has already been published. The enquiry has been undertaken as a preliminary to considering what steps might be taken to safeguard the existence of these small unorganised local industries, which provide a somewhat precarious means of livelihood for a considerable number of people in the aggregate, and play an important part in the development of the countryside. 


\section{APPENDIX I.-RESEARCH INSTITUTIONS AND ADVISORY CENTRES IN ENGLAND AND WALES.}

\section{RESEARCH INSTITUTIONS.}

Institution.

Rothamsted Experimental Station, Harpenden, HERTS.

(Dr. E. J. Russell, F.R.S.)

$$
\text { Do. }
$$

Plant Breeding Research Institute, University of Cambridge. (Professor R. H. Biffen, F.R.S.)

Animal Nutrition Research Institute, University of Cambridge. (Professor T. B. Wood, F.R.S.)

Department of Genetics, University of Cambridge.

(Professor R. C. Punnett, F.R.S.)

Agricultural and Horticultural Research Station, (University of Bristol) Long Ashton, Bristol. (Professor B. T. P. Barker, M.A.)

East Malling Research Station, East Malling, KENT. (R. G. Hatton, M.A.)

Plant Physiology Research Institute, Imperial College of Science, London.

(Professor V. H. Blackman, F.R.S.)

National Institute for Research in Dairying, Dairying.

Reading.

(Dr. R. Stenhouse Williams.)

Research Institute in Animal Pathology,

Royal Veterinary College, London.

(Sir John McFadyean, M.R.C.V.S.)

Department of Agricultural Zoology, University of Birmingham. (Professor F. W. Gamble, F.R.S.)

Department of Helminthology, London School of Tropical Medicine. (Professor R. T. Leiper.)

Institute for Research in Economics, University of Oxford. (C. S. Orwin, M.A.)

Welsh Plant Breeding Station, University College of Wales, Aberystwyth.

(Professor R. G. Stapledon, M.A.)

Nursery and Market Garden Crops Research Station, Cheshunt.

Agricultural Agricultural Economics.

(Dr. W. F. Bewley.)
Subject.

Plant Nutrition and Soil Problems.

Plant Pathology.

Plant Breeding.

Animal Nutrition.

Breeding of Small Animals.

Fruit Growing and Preserving.

Fruit Growing and Hops.

Plant Physiology.

Animal Pathology.

Agricultural Zoology.

Helminthology.

Plant Breeding.

Nursery and Market Garden Crops. 
Barker, B. T. P., and Spinks, G. T.

Fruit Breeding Investigations. (Journ. Pomology', 1920.)

Annual Reports of the Research Station for 1919 and 1920.

East Malling Research Station, East Malling, Kent.

Hatton, R. G.

Suggestions for the Right Selection of Apple Stocks. (Journ. Roy. Hort. Soc., 1920, XLV, 2 and 3.)

A First Report on Quince Stocks for Pears. (Journ. Roy. Hort. Soc., I $920, X L V, 2$ and 3 .)

Results of Researches on Fruit Tree Stocks at East Malling. (Journ. Pomology, 1920, II, 1.)

Stocks for the Stone Fruits. (Journ. Pomology, 1921, II, 4.)

Black Currants Varieties: A Method of Classification. (Journ. Pomo$\log y, 1920, I, 2$ and 3.)

The Importance of Suitable Stocks in Planting Young Fruit Trees. (Journ. Kent Farmers' Union, 1921, $X, 3$.)

Variety Trials with Potatoes. (Journ. Kent Farmers' Union, 1921, $I X$, I.)

Potato Spraying. Three Years' Results at East Malling Research Station. (Journ. Kent Farmers' Union, 1921, X, 1.)

Variety Trials with Oats and Barley. (Journ. Kent Farmers' Union, 1920, VIII, 6.)

Control of Apple Blossom Weevil. (Journ. Kent Farmers' Union, I $921, I X, 6$.)

Grubb, N. H.

Tests of Fungicides on Apple Trees. (Journ. Pomology, 1921, II, 2.)

Results of Apple Pruning Experiments. (Journ. Kent Farmers' Unior, 1921, $X, 4$.)

Experiences with Fungicidal Sprays. (Journ. Kent Farmers' Union, $192 \mathrm{I}, I X, 5$.)

Wellington, R., Hatton, R. G., and Amos, J.

The "Running off" of Black Currants. (Journ Pomology, 192r, II, 3.) Amos, J.

Wheat Trials at East Malling Research Station. (Journ. Kent Farmers' Union, $1921, X, 3$.

Meteorological Observations. (Monthly contributions to Journ. Kent Farmers' Union.)

Annual Report of Research Station, December, 1920.

\section{Experimental and Research Station, Cheshunt, Herts.}

Lloyd, Ll.

The habits of the Glasshouse Tomato Moth, Hadena (Polia) oleracea, and its Control. (Ann. Appl. Biol., r920, VII, r.)

Bewley, W. F

"Damping off" and "Foot Rot" of Tomato Seedlings (Ann. Appl. Biol.. 1920, VII, 2 and 3.)

Bewley, W. F., and Buddin, W

On the Fungus Flora of Glasshouse Water Supplies in relation to Plant Disease (Ann. Appl. Biol., r921, VIII, 1.)

\section{Animal Nutrition Institute, University of Cambridge.}

wood, T.B

Rations for Live Stock. (Misc. Pubn. Min. Agric., No. 32.) 
Wolf, C. G. L.

The Survival of Motility in Mammalian Spermatozoa. (Journ. Agric. Sci., XI.)

Wood, W. A.

The Limit of the Breeding Age of Thoroughbred Mares. (Vet. Journ., I92 I, LXXVII, 12.)

Hammond, J.

Recent Research in Egg Production. (Journ. Min. Agric., XXVII, I I.)

Relative Growth and Development of different breeds and crosses of Sheep. (Journ. Agric. Sci., XI, 4.)

Further Observations on the factors controlling fertility in Domestic Animals. (Journ. Agric. Sci., XI, 4.)

Woodman, H. E.

A comparative investigation of the corresponding proteins of cow and ox serum, cow's colostrum and cow's milk by the method of Protein Racemisation. (Biochem. Journ., $X V, 2$.

Wood, T. B., and Woodman, H. E.

The Digestibility of Oat and Tare Silage. (Journ. Agric. Sci., XI, 3.)

Foreman, F. W.

Rapid Volumetric Method for the Estimation of Amino-acids, Organic Acids and Organic Bases. (Biochem. Journ., Vol. XIV.)

\section{Rowett Research Institute, University of Aberdeen.}

Orr, J. B.

Note on the Influence on Increased Water Ingestion on Blood Pressure. (Proc. Physiol. Soc., June, 1920, and Journ. Physiol., Vol. 54, p. I I.)

On the Physiological Cost of Muscular Work. The Significance of the Respiratory Quotient in Indirect Calorimetry. (Brit. Med. Journ., Julv, 1921.)

The Ápplication of the Indirect Method of Calorimetry to Ruminants. (Paper read at Agricultural Section, British Association, Sept., 1921.)

On Research in Agriculture. (Aberdeen Univ. Review, April, 1921.)

Orr, J. B., and Kinloch, J. P.

On the Influence of Diet on the Energy Expenditure in Work. (R.A.M.C. Journ., Feb., r92r.)

Paton, D. Noel, University of Glasgow, and Orr, J. B.

Essentials of Veterinary Physiology. (I920.)

Plimmer, R. H. A.

Note of Scurvy in Pigs. (Biochem. Journ., Vol. XIV, p. 57o.)

Analyses and Energy Value of Foods. (H.M. Stationery Office, r920.)

Plimmer, R. H. A., Rosedale, J. L., with the assistance of Crichton, A., and Topping, R. B.

The Rearing of Chickens in Confinement: Part I. The vitamine requirements; Part II. The effect of "good" protein. (Paper at Biochem. Society, Sept., I921.)

Elliot, W. E., M.P., and Crichton, A.

The Etiology of Rickets in Pigs. (Paper read at Agricultural Section of British Association, September, 1921, appearing in British Journ. of Experimental Pathology, Feb., 1922.)

Taylor, W., and Husband, A. D.

On the Influence of Rate of Secretion of Milk on its Percentage Composition. (Paper read at Agricultural Section of British Association, Sept., I92I.) 


\section{Department of Genetics, University of Cambridge.}

Punnett, R. C.

The Genetics of the Dutch Rabbit.-A Criticism. (Journ. Gonetics, IX, March, 1920.)

Punnett, R. C., and the late Bailey, P. G.

Genetic Studies in Poultry. II. Inheritance of Egg-Colour and Broodiness. (Journ. Genetics, $X$, Dec., 1920.)

Genetic Studies in Poultry. III. Hen-Feathered Cocks. (Journ. Genetics, XI, Apr., 1921.)

Punnett, R. C., and Pease, M. S.

Genetic Studies in Poultry. IV. On the barred Plumage of certain breeds. (Journ. Genetics, XI, Dec., 1921.)

Punnett, R. C.

Mendelism, the Industry and the Fancy. (Transactions of the First World's Poultry Congress at The Hague, Scheveningen, 1921.)

Research in Animal Breeding, I-IV. (Journ. Min. Agric., April-July', 1921.)

Animal Breeding Research Department, University of Edinburgh.

Crew, F. A. E.

The Assumption of the Male Characters by the Domestic Hen. (Utility Poultry Journal, Sept., 1921.)

On the Fleeces of Certain Primitive Breeds of Sheep. (Ann. Appl. Biol., VIII, 3-4, I92I.)

National Institute for Research in Dairying, Reading.

Stenhouse Williams, R., Hoy, W. A., and Sargeant, M.

Can the Ordinary Farmer produce Pure Milk? (Modern Falming, Oct., 1921.)

Stenhouse Williams, R.

Methods of Production and Distribution of Milk. (Report on the Bristol Show of the Bath and West and Southern Counties Society, June, 1921.)

Stenhouse Williams, R., and Mackintosh, J.

Milk in its Economic Aspect. (The Milk Industry, II, 2, Aug., 1921. The Dairyman, XLIV, No. 2, Oct., 1921.)

Venn, E. C. V.

The Influence of Reaction on Colour Changes in Tyrosine Solutions. (Biochem. Journal, $X I V, 2$, 1920.)

Mattick, E. C. V., and Stenhouse Williams, R.

The Influence of Reaction on Colour Changes in Tryptophan Solutions. (Biochem. Journ., XV, No. 2, 1921.)

Golding, J.

The Value of Whey in Feeding Pigs. (Agric. Educ. Assoc., June, 1921.)

Golding, J., and Mattick, E. C. V.

The Further Development of the Brom-Cresol Purple Test. (Agric. Educ. Assoc., June, 1921.)

Mackintosh, J.

The Feeding of Dairy Cows. (Published by the Institute, Oct., I92 I.)

Mattick, A. T. R.

The Sterilization of empty Milk Churns under Pressure. (Journ. Hygiene, $X X, 2$, Oct., 1921.)

Knight, E. G., Freear, K., and Stenhouse Williams, R.

A Study of Factors concerned in the Production of Clean Milk, Part I. (Camb. Univ. Press, pub. P. S. King and Sons, Ltd., June, 1920.)

Frcear, K., and Venn, E. C. V.

The Acidity of Ropy Milk. (Biochem. Journ., XIV, Nos. 3 and 4, 1920.) 
Freear, K., Mattick, A. T. E., and Stenhouse Williams, R.

A Study of the Bacteriological Examination of Crade " A " (cert.) Milk.

(Journ. Hygiene, $\mathrm{YX}, 2$, Oct., r921.)

Cumming, A. F., and Mattick, A. T. R.

An Enquiry concerning the State of Cleanliness of empty Milk Churns. (Journ. Hygiene, $X I X, N o .1$, 1920.)

Drummond, J. C., Golding, J., Zilva, S. S., and Coward, K. H.

The Nutritive Value of Lard. (Biochem. Journ., XIV, 6, 1920.)

Hoy, W. A., and Stenhouse Williams, R.

Report on a Simple Steam Sterilizer. (The Dairy Supply Co., Museum St., London, June, 1921.)

Zilva, S. S., Golding, J., Drummond, J. C., and Coward, K. H.

"The Relation of the Fat-soluble factor to Rickets and Growth in pigs." (Biochem. Journ., $X V$, No. 3, 1921.)

Harries, F. H. R., and Stenhouse Williams, R.

Bovine Tuberculosis-The Etiological Support of Family History. (Journ. of Hygiene, $X X, 2$, Oct., 1921.)

\section{Royal Veterinary College, London.}

Transformation of the Aveolar Epithelium in Verminous Pneumonia in the Sheep. (Journ. Comp. Path. Therap., Dec., 1920.)

Researches Regarding Epizootic Abortion of Cattle. (Journ. Comp. Path. Therap., March, June and Sept., I921.)

Meggitt, F. J.

\section{University of Birmingham.}

A contribution to our knowledge of the tapeworms of Poultry. (Parasitology, $X I I I, 1920$.

A new species of Cestode (Oochoristica erinacei) from the hedgehog. (Parasitology, XII, I920.)

On two new tapeworms from the Ostrich, with a key to the species of the genus Davainea. (Parasitology, XIII, I921.)

On a new Cestode from the pouched rat, Cricetomys gambianum. (Parasitology, XIII, 1921.)

Jackson, H. G.

A revision of the Liver Fluke genus Fasciola. (Parasitology, XIII, I921.)

Boulenger, C. L.

Sclerostomes of the Donkey. (Parasitology, XII, I920.)

Some Nematode parasites of the Zebra. (Parasitology, XII, 1920.)

\section{Research Institute in Agricultural Economics, University of Oxford.}

Orwin, C. S.

The Present Position of Agriculture. (Oxford Tracts on Economic Subjects, No. 7, Oxford Univ. Press.)

The Control of Farm Management and Some Fundamental Principles in Agricultural Costing. (Journ. Min. Agric., Vol. XXVIII, 3.)

The Study of Agricultural Economics. (Report of the Brit. Assoc. for Adv. Sci., 1921, Edinburgh.)

Farming Costs. (Oxford Univ. Press, 1921.)

Ashby, A. W.

The Training of the Clergy and Social Leadership. (Appendices 2 and 3 in the Report of the Archbishops'Committee on the Church and Rural Life.)

Prices of Farm Produce and Wages of Farm Workers. (Journ. Roy. Soc., Vol. 8o.)

The Work of the Agricultural Wages Board. (Journ. Roy. Soc., Vol. 8o.) 
Co-operation in Agriculture, ( 1 ) Theoretical. (Oxford Tracts on Economic Subjects, No. 14, Oxford Univ. Press.)

Co-operation in Agriculture, (2) Historical and Descriptive. (Oxford Tracts on Economic Subjects, No. 16, Oxford Univ. Press.)

The Economics of Large and Small Farms. (Oxford Tracts on Economic Subjects, No. 24, Oxford Univ. Press.)

The Value of Economic Study in Agricultural Education and Farm Management. (Journ. of the Univ. College of Wales, $X, 1921$.

Standards of Production in Agriculture. (Paper read at the Brit. Assoc. Adv. of Sci., Edinburgh, Sept., 1921, to be published in the Edinburgh Review, Jan. 1922.)

Woods, K. S.

The Rural Industries Round Oxford. (Oxford Univ. Press, 1921.) Fitz-Randolph, Helen.

Besom-Making in Derbyshire and Nottinghamshire. (Journ. Min. Agric., Vol. XXVIII, 5.)

\section{ADVISORY CENTRES. Armstrong College, Newcastle-on-Tyne.}

Collins, S. H., and Spiller, Arnold.

Sugar in Oat Straw and Cattle Foods. (Journ. Soc. Chem. Ind., 1920, pp. $66 T$ and $82 T$.)

\section{University College of North Wales, Bangor.}

Robinson, G. W.

The Physical Properties of the Soil in Relation to Survey Work. (Chem. News, July Ist, 1921.)

\section{School of Agriculture, Cambridge.}

Petherbridge, F. R.

Potato Spraying Trials in the Cambridgeshire Fens, 1919. (Journ. Min. Agric., Vol. XXVII, No. 3, June, 1920.)

The Life-History of the Strawberry Tortrix Oxygrapha Comariana (Zeller). (Ann. App. Biol., Vol. VII, No. 1, Sept., 1920.)

Observations on the Life History of the Wheat-bulb Fly (Leptohylemyia coarctata, Fall). (Journ. Agric. Sci., Vol. XI, Part I, Jan., I921.)

Frit Fly (oscinis frit) in Winter Wheat. (Ann. App. Biol., Vol. VII, No. 4, Feb., 1921.)

Brooks, F. T.

\section{School of Botany, Cambridge.}

Plant Sanitation in fruit plantations. (Trans. Brit. Myc. Soc., 1920.) Investigations on some Tomato Diseases. (Trans. Brit. Myc.Soc., 1921.)

Hanley, J. A.

\section{University of Leeds.}

The Need for Lime on Ploughed-out Grass Land. (Bull. I15, Univ. of Leeds and York Cncil. for Agric. Educ.)

Comber, N. M.

A Qualitative Test for Sour Soil. (Journ. Agric. Sci., 1920, $X, 420$.) The Flocculation of Soils. (Journ. Agric. Sci., 1920, X, 425.)

The Flocculation of Soils, II. (Journ. Agric. Sci., I921, XI, 450.)

The Mechanism of Flocculation in Soils. (Trans. Faraday Soc., 1921, $X V I I$.) 
Godden, W.

The Digestibility of Straw after Treatment with Soda. (Journ. Agric. Sci., 1920, $X, 437$.)

Digestibility of Peat Moss after Treatment with Acid. (Journ. Agric. Sci., 1920, $X, 457$.)

Millard, W. A.

Common Scab of Potatoes. (Report No. 118, Univ. of Leeds and York Cncil. for Agric. Educ., Dec., 1920.)

Common Scab of Potatoes. (Journ. Min. of Agric., April, 1921.)

Millard, W. A., and Burr, S.

Dry Spraying for the Destruction of Charlock. (Journ. Min. of Agric., May, 1921.)

Taylor, T. H.

The Frit-fly on Oats. (Bull. No. 108 of Univ. of Leeds and York Cncil. for Agric. Educ., r9r8.)

Observations on the Habits of the Turnip Flea-beetle. (Entomologist, Vol. II, April, 1918.)

Smith, K. M.

\section{University of Manchester.}

Investigations of the Nature and Cause of the Damage to Plant Tissue resulting from the feeding of Capsid bugs. (Ann. of Appl. Biology, Vol. VII, No. I, Sept., I920.)

Some Preliminary Attempts at Control of the Carrot and Onion Flies. (Fruit Grower, Vol. L, 1, March 31 st and April 7 th, 1921.)

Further Trials in Control of the Onion Fly. (Fruit Grower, Vol. L, Ir, Dec. Ist, I92 r.)

Salmon, E. S.

\section{South-Eastern Agricultural College, Wye.}

On Forms of the Hop Resistant to Mildew, IV. (Ann. Appl. Biol., $V I, 293-310$, 1920.)

Third Report on the Trial of New Varieties of Hops. (Ashford, April, r920, I-I9.)

Notes on some Fungous Diseases. (Fruitgrower, April, 1920, 701-702.

Hop-mould and its Control. (Journ. Min. Agric., XXVIII, 150-157, 260-263, r92 I.)

Fourth Report on the Trial of New Varieties of Hops. (Ashford, July, 1921, 1-20.)

On Forms of the Hop Resistant to Mildew, V. (Ann. Appl. Biol., $V I I I, 146-163, \mathrm{r} 92 \mathrm{r}$.)

Salmon, E. S., and Wormald, $\mathrm{H}$.

Prevention of "Bunt" in Wheat. (Journ. Min. Agric., XXVII, IOI3-IO2 I, I92 I.)

The Potato "Blight" Fungus on Tomatoes under Glass in April. (Gard. Chron., June 25th, 1921, p. 3 Ir.)

Varietal Resistance to American Gooseberry Mildew in Red Currants. (I.c., July 23rd, 1921, p. 47.)

Wormald, $\mathrm{H}$.

The "Brown Rot" Disease of Fruit Trees, with Special Reference to two Biologic Forms of Monilia cinevea Bon, Part II. (Ann. of Bot., Vol. XXXIV, pp. 143-171, April, 1920.)

On the occurrence in Britain of the Conidial Stage of Sclerotinia Mespili Schell. (Ann. of Appl. Biol., Vol. VII, pp. 173-177, Dec. 1920.)

On the Occurrence in Britain of the Aseigerous Stage of a "Brown Rot" Fungus. (Ann. of Bot., Vol. XXXV, pp. 125-135, Jan., I92 r). 


\section{INDEX TO MAIN SUBJECTS OF RESEACH.}

The SoIl and Plant GRowTH.

Rothamsted Experimental Station:-

Soil bacteria and protozoa Soil nitrates and bacteria -

Farmyard manure and clover

Artificial farmyard manure

Green manuring

Effect of liming on composition of herbage

"White roots" of barley and wheat - - -

Plant poisons as stimulants

Farm weeds - - -

Crop statistics - - -

Physical properties of the soil

Dynamometer tests -

Soil acidity (also at School of Agriculture, Cambridge, University of Leeds, and University College of North Wales, Bangor) -

University of Leeds:-

"Flocculation" in soils

Midland Agricultural and Dairy College :-

Willows : cultivation and subsequent treatment -

Plant Breeding.

Plant Breeding Institute, Cambridge :-

Wheat breeding - - 30

Oat breeding - $\quad$ - 32

Barley breeding - $\quad$ - 32

Potato breeding - - 33

Factors contributing to yield - - - - 38

Influence of root system - 39

Plant Breeding Institute, Aberystwyth:-

Breeding of herbage plants

Oat breeding - - -

Influence of root system - $\quad 39$
Plant Physiology.

PAGE

Imperial College of Science :Factors influencing crop yield - - - - 42

Resistance to disease- $\quad-\quad 45$

Electrical treatment of crops - . - .

Fruit-Growing AND

Preserving.

Agricultural and Horticultural Research Station, Long Ashton:-

Root-stocks, classification of Root investigations - -

Treatment of the tree. $5 \mathrm{I}$

(Ringing, Pruning, Use of intermediate stocks) -

Manuring - - - - 62

Fruit breeding - - - 63

Cider and perry investiga. tions

Fruit and vegetable preservation and storage (and at Campden Experimental Factory)

66

\section{East Malling Research}

Station :-

Root-stocks, classification of 5 I

Pruning - - - - 60

Manuring - - - - 63

Plant Diseases.

Rothamsted Experimental

Station :-

Fungi and algæ in soil - $\quad$ o

Possibility of change in fungi and bacteria - 71

Basis of spraying - - $7 \mathrm{I}$

Wart disease of potatoes - 72

Insects and allied organisms in soil - - - - 84

Plant lice, or green fly - 85

Chemotropism - - - 86

Insecticides and fungicides 97 
INDEX.

University College of North Wales, Bangor:-

Finger-and-Toe in swedes -

Bacterial rots of swedes and turnips

Rust diseases of oats

Agricultural and Horticultural Research Station, Long Ashton, Bristol :-

Sulphur as a fungicide -

Canker of apple trees -

Bark canker of apple trees -

"Die Back" of plum trees

"Bud Rot" of apple trees

"Shot Hole" of peach trees, \&c.

Wilt of Michaelmas daisies - - - -

"Big Bud" and "Reversion" of black currants -

Apple-blossom weevil -

Insecticidal washes -

School of Agriculture, Cambridge :-

Wheat bulb fly

Frit fly in winter wheat

90

9 I

School of Botany, Cambridge :-

"Silver-leaf" "disease 76

East Anglian Institute of Agriculture, Chelmsford :-

Eelworm in tomatoes

96

Cheshunt Experimental and Research Station :-

"Damping-off" and "Footrot" of tomato plants -

"Sleepy disease" of tomato Arum "soft rot" - Glasshouse tomato moth White fly in greenhouses - 96

University of Leeds :-

Dry spraying for charlock - $\quad 78$

Common scab in potatoes - 78

Bacterial disease of rhubarb 79

Garden chafer - $\quad$ - $\quad$ - $9 \mathrm{I}$

Wireworm experiments - $9 \mathrm{r}$

East Malling Research Station, Kent :-

Fungicides on apple trees -
University of Manchester :"Mosaic" and "Leaf Curl " or "Leaf Roll" of potato 80 Carrot fly - - $\quad$ - $\quad 92$ Onion fly - $\quad$ - $\quad$ - 92

Armstrong College, Newcastleon-Tyne:-

Wireworm experiments - 93

Black fly on beans - $\quad$ - 93

South-Eastern Agricultural College, Wye:-

Lime-sulphur wash - - 8 I

Bunt in wheat - - $\quad$ - $8 \mathrm{I}$

Hop diseases - - $\quad 8_{2}$

"Brown Rot " of fruit trees 82

Woolly aphis - $\quad$ - $\quad$ - 93

Insecticidal washes - $\quad$ - 94

Cure for ground pests $\quad 94$

Red spider - $\quad$ - $\quad$ - 95

Animal Husbandry.

Animal Nutrition Research Institute, Cambridger-

Protein investigations -

Estimation of organic constituents of plant and animal juices - _ - IOI

Digestibility of feeding stuffs $\mathrm{IO}_{2}$

The Calorimeter- - $\quad$ - 105

Vitamins: Use of rye meal in pig feeding- - $\quad$ - 107

Physiology of reproduction 109

Effect of feeding on size of

litter in pigs - - $\quad$ - IIO

Extra teats in udders of dairy cows - - - III Growth in cattle and sheep I I

Rowett Research Institute in Animal Nutrition, Aberdeen:-

Protein investigations - $\quad 99$

The Calorimeter- - - 106

Vitamins : " Rickets " in pigs - - $\quad-\quad-107$

Factors influencing milk production by the cow - II I

Armstrong College, Newcastleon-Tyne:-

Feeding value of oat straw ro 3

University of Leeds:-

Feeding experiments .

\section{9}


Animal Breeding.

Department of Genetics, Cambridge:-

Inheritance of weight in poultry - - - -

Inheritance of colour in poultry - - - -

Inheritance of hen-feathering in cockerels - -

Inheritance of fur pattern in rabbits

Inheritance of weight in rabbits - - -

University of Edinburgh:-

Improvement of fleece of Scottish Blackface sheep Secondary sexual characters in fowls -

\section{DAIRYING.}

National Institute for Research in Dairying, Reading :Effect of age and period of calving on milk yield

Breeding investigations

Effect of calf feeding on future milk yield - - I26

Butter fat records - $\quad$ - 126

Production of clean milk - 127

Tuberculosis in dairy cows 130

Test for abnormal milks - I3I

Ranges of acidity in cheese making - - - - I3I

Pig feeding experiments : Vitamins

I 8

PAGE

University College of North Wales, Bangor:-

Liver rot of sheep - - It4

\section{Agricultural Economics.}

Research Institute in Agricultural Economics, Oxford:Cost accounting Farm organization 



\section{NON-CIRCULATING BOOK}

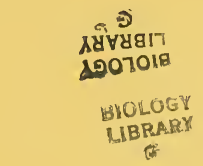

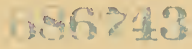

$\sqrt{3} 41$

BIOLOGY
LIBRARY
E

UNIVERSITY OF CALIFORNIA LIBRARY 
